\author{
Universidade de São Paulo \\ Instituto de Física
}

\title{
Desenvolvimento do canhão de nanopartículas magnéticas baseado em magnetron sputtering do tipo hollow cathode
}

\section{Rodrigo Dias Garcia}

Orientador: Prof. Dr. Antonio Domingues dos Santos

Dissertação de mestrado apresentada ao Instituto de Física da Universidade de São Paulo, como requisito parcial para a obtenção do título de Mestre em Ciências.

Banca Examinadora:

Prof. Dr. Antonio Domingues dos Santos - Orientador (IFUSP)

Prof. Dr. Koiti Araki (IQ-USP)

Prof. Dr. Varlei Rodrigues (IFGW - UNICAMP)
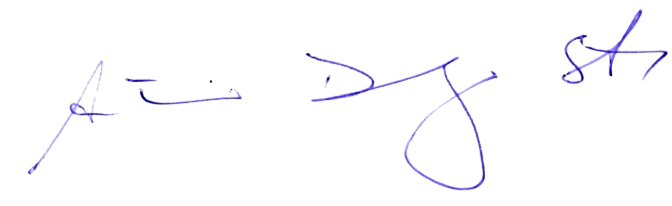
FICHA CATALOGRÁFICA

Preparada pelo Serviço de Biblioteca e Informação do Instituto de Física da Universidade de São Paulo

Garcia, Rodrigo Dias

Desenvolvimento do canhão de nanopartículas magnéticas baseado em magnetron sputtering do tipo hollow cathode. São Paulo, 2021.

Dissertação (Mestrado) - Universidade de São Paulo. Instituto de Física. Depto. de Física dos Materiais e Mecânica.

Orientador: Prof. Dr. Antonio Domingues dos Santos Área de Concentração: Física da matéria condensada

Unitermos: 1. Nanopartículas; 2. Instrumentação (Física); 3. Substância magnética. 


\author{
University of São Paulo \\ Physics Institute
}

\title{
Development of the magnetic nanoparticle deposition gun based on hollow cathode magnetron sputtering
}

\section{Rodrigo Dias Garcia}

Supervisor: Prof. Dr. Antonio Domingues dos Santos

Dissertation submitted to the Physics Institute of the University of São Paulo in partial fulfillment of the requirements for the degree of Master of Science.

Examining Committee:

Prof. Dr. Antonio Domingues dos Santos - Supervisor (IFUSP)

Prof. Dr. Koiti Araki (IQ-USP)

Prof. Dr. Varlei Rodrigues (IFGW - UNICAMP) 

À Kalina. 



\section{Agradecimentos}

Ao meu orientador, Prof. Dr. Antonio Domingues dos Santos, pelos ensinamentos, pela humildade e pela amizade. Obrigado, Toninho.

À minha mãe, por ser tudo que pôde ser para mim. Obrigado, "minha mãe".

À minha família, por toda confiança e apoio incondicional. Em especial, à Lu. Queria que você pudesse ter visto.

Ao pessoal do laboratório. Sérgio, Marcelo, Paulo e Marco, obrigado por me socorrerem em cada problema que tive. Fernanda e Douglas, obrigado pela paciência.

Aos professores que tanto me ensinaram durante a graduação e esse mestrado.

Aos amigos que fiz ao chegar em São Paulo, Alvaro, André, Caíke, Cesão, Chacon, Geovane, Hélio, Leo, Popoto, Ramon, Thiago e Wilson, por tornarem a graduação mais leve.

Aos amigos de Salvador, Ciuza, Grassi, lan, Raniere e Júlia, que me fazem sempre voltar à minha cidade.

À Gabriela e à Elis, por me incluírem no seu mundinho.

Àqueles que tenho pouco ou deixei de ter contato. Os percalços da vida fazem parte de nós.

A todos que me acompanharam ao tomar um café. Muitos colegas e muitos cafés.

A todos os funcionários da USP, por permitirem que possamos fazer ciência.

O presente trabalho foi realizado com apoio da Coordenação de Aperfeiçoamento de Pessoal de Nível Superior - Brasil (CAPES) - Código de Financiamento 001. 

"A vida não é fácil para ninguém. Mas... O que importa? É necessário preservar e, acima de tudo, confiar em nós próprios. Temos de sentir que somos dotados para realizar uma determinada coisa e que temos de a alcançá-la, custe o que custar!" 



\section{Resumo}

O desenvolvimento de novos métodos de produção de partículas nanométricas tem sido um dos pontos focais nos últimos anos na pesquisa em ciência de materiais. As nanopartículas (NPs) são utilizadas em eletrônica, biotecnologia, química e na indústria em geral devido às suas propriedades catalíticas, elétricas, ópticas ou magnéticas. Este trabalho consiste no desenvolvimento de um método físico para a produção de nanopartículas magnéticas utilizando um canhão magnetron sputtering radial desenvolvido por nós, baseado no método de agregação gasosa. Na montagem, as amostras foram preparadas no canhão de NP, instalado como um novo canhão em um sistema de magnetron sputtering comercial. Normalmente, o sistema de sputtering opera a uma pressão de 5 mTorr na câmara principal. No entanto, no canhão de NP, existe uma pressão interna de $780 \mathrm{mTorr}$, sob o fluxo de $A r$ de $80 \mathrm{sccm}$. Os átomos removidos do alvo são termalizados pelo fluxo de Ar e condensados para formar NPs, que são extraídos do canhão de NP aerodinamicamente, indo em direção ao substrato. $O$ dispositivo é capaz de produzir filmes de NPs de diferentes metais, incluindo metais ferromagnéticos, e também co-depositar as NPs simultaneamente com outro filme de sputter. Foram produzidas NPs de Cu e Co. As NPs de Cu foram produzidas com diâmetro médio de 5,79(8) nm e desvio padrão de 2,97(5) nm, com cristalinidade compatível com a estrutura FCC. As NPs de Co apresentaram diâmetro médio de 3,88(3) nm e desvio padrão de $1,74(2) \mathrm{nm}$, com cristalinidade compatível com as estruturas FCC e HCP. As NPs de Co apresentaram comportamento ferromagnético quando produzidas sozinhas, dada a aglomeração de NPs no substrato. Porém, quando co-depositados com filmes de $\mathrm{Si}_{3} \mathrm{~N}_{4}$, a aglomeração de NPs no substrato foi minimizada e as amostras apresentaram comportamento superparamagnético. Este comportamento foi descrito combinando a função de Langevin e uma distribuição de diâmetros. NPs de Co intercaladas com $\mathrm{Si}_{3} \mathrm{~N}_{4}$ apresentaram diâmetro médio de 3,1(1) nm e desvio padrão de 1,2(1) nm. NPs de Co cobertas com $\mathrm{Si}_{3} \mathrm{~N}_{4}$ apresentaram diâmetro médio de 3,8(2) $\mathrm{nm}$ e desvio padrão de 2,2(2) nm. Ambas as amostras apresentaram envelhecimento, com uma perda de $66 \%$ das NPs de Co, após uma semana.

Palavras-chave: nanopartículas; magnetron sputtering; nanomagnetismo; agregação gasosa; hollow cathode 



\section{Abstract}

The development of new production methods of nanometric particles has been one of the focal points in the recent years on material science research. Nanoparticles (NPs) are used in electronics, biotechnology, chemistry and in the industry in general as a result of its catalytic, electric, optical or magnetic properties. This work consists of the development of a physical method for the production of magnetic nanoparticles using a homemade radial magnetron sputtering, and the gas aggregation method. In the setup, the samples were prepared in a NP gun, installed as a new gun on a commercial magnetron sputtering system. Typically, the sputtering system operates at a pressure of $5 \mathrm{mTorr}$ in the main chamber. However, in the NP gun there is inside a pressure of $780 \mathrm{mTorr}$, under the argon flux of $80 \mathrm{sccm}$. The atoms removed from the target are thermalized by the argon flux and condensed to form NPs, which are extracted from the NP gun aerodynamically, flowing in direction to the substrate. The device is capable of producing films of NPs of different metals, including ferromagnetic metals, and also co-deposit the NPs simultaneously with other sputtered film. Cu and Co NPs were produced. For Cu NPs the averaged diameter was 5.79(8) nm and standard deviation of 2.97(5) nm, with crystallinity compatible with the FCC structure. The Co NPs presented an average diameter of 3.88(3) $\mathrm{nm}$ and standard deviation of 1.74(2) nm, with crystallinity compatible with the FCC and HCP structures. The Co NPs showed ferromagnetic behavior due to the agglomeration of NPs in the substrate. But, when co-deposited with $\mathrm{Si}_{3} \mathrm{~N}_{4}$ film, the agglomeration of NPs on substrate was minimized and samples showed superparamagnetic behavior. This behavior was described by a combination of Langevin function and a distribution of diameters. Co NPs film dispersed with capping and buffer layer of $\mathrm{Si}_{3} \mathrm{~N}_{4}$ showed average diameter of 3.1(1) nm and standard deviation of 1.2(1) nm. Co NPs film covered with $\mathrm{Si}_{3} \mathrm{~N}_{4}$ showed average diameter of 3.8(2) nm and standard deviation of $2.2(2) \mathrm{nm}$. Both samples showed aging, with a loss of $66 \%$ of Co NPs, after one week.

Keywords: nanoparticles; magnetron sputtering; nanomagnetism; gas aggregation; hollow cathode 



\section{Lista de Figuras}

2.1 Curva esquemática de coercividade versus tamanho da partícula maghética . . . . . . . . . . . . . . . . . . . . 4

3.1 Esquema do canhão de um sistema de sputtering do tipo magentron para producão de filmes em substrato. . . . . . . . . . . . . . . . . 9

3.2 Imagem do equipamento com os principais componentes destacados. . 10

3.3 Visão interna da câmara principal do equipamento de sputtering. $\quad$ Cahhão de NPs indicado e demais canhões de sputtering. . . . . . . . . . 11

3.4 Diagrama esquemático do canhão de NPs planar. . . . . . . . . . . . 13

4.1 Diagrama esquemático do canhão de MSR inicial. . . . . . . . . . 16

4.2 Simulação do fluxo magnético do sistema radial. . . . . . . . . . . . 17

4.3 Diagrama esquemático do canhão de MSR com a peça polar inferior sem encostar no alvo . . . . . . . . . . . . . . . . . . . . . . 17

4.4 Simulação do fluxo magnético com apenas 1 peça polar tocando o alvo. 18

4.5 Simulação do fluxo magnético do sistema radial com ambas peças polares tocando o alvo . . . . . . . . . . . . . . . . . . . . . 18

4.6 Diagrama esquemático do canhão de MSR em versão final. . . . . . . . 19

4.7 Desenho esquemático do gerador de NPs radial. . . . . . . . . . . . . 19

4.8 Relação entre pressão e fluxo dentro do gerador de NPs. . . . . . . . . 20

4.9 Exemplo de malha gerada no Gmsh . . . . . . . . . . . . . . . . . . 21

4.10 Comparação entre as simulações do fluxo de gás do GNP com canhão planar (a) e com canhão radial (b). . . . . . . . . . . . . . . . . . . . 22

4.11 Comparação entre as simulações do fluxo de gás no GNPR sem parede angulada (a) e com parede angulada (b) sobre o canhão de MSR. . . . 23

4.12 Diagrama esquemático do GNPR em sua versão final. . . . . . . . . . . 24

4.13 Diagrama esquemático do canhão de MSR desenvolvido para revestimento de NPs em voo . . . . . . . . . . . . . . . . . . . 26

5.1 Imagens em folha de papel de NPs de cobalto depositado usando bico de saída circular de diâmetro (a) 2,5 $\mathrm{mm}$ e (b) $3,0 \mathrm{~mm}$. . . . . . . 28 
5.2 Intensidade das manchas de NPs de cobalto em diferentes fluxos na

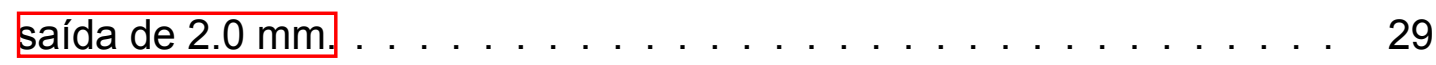

5.3 Gráfico do ajuste gaussiano à uma mancha de NPs de cobalto, corres-

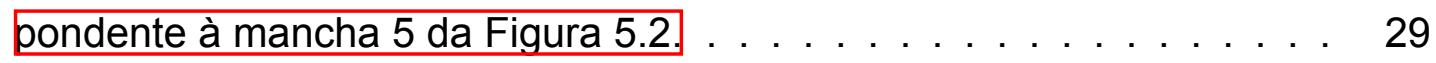

5.4 Imagem obtida por MET das NPs de cobre. . . . . . . . . . . . 30

5.5 Método de subtração de fundo em imagem obtida por MET das NPs de cobre (a). Subtrai-se a média (b) resultando na imagem de microscopia com aumento de contraste (c) . . . . . . . . . . . . . . . . . . 31

5.6 Média gaussiana aplicada à imagem obtida por MET com contraste mehorado (a) e limitação da escala de cinza aplicada às imagens com média gaussiana $(\mathrm{b}) . \ldots \ldots \ldots \ldots \ldots$. . . . . . . . . . . 32

5.7 Exemplos de NPs de cobre selecionadas através do tratamento da imagem obtida por MET (a) e circunscrição das NPs de cobre selecionadas ha imagem obtida por MET (b). . . . . . . . . . . . . . . . . . . . 32

5.8 Distribuição de diâmetros de aglomerados e NPs de $\mathrm{Cu}(\mathrm{a})$ e distribuição

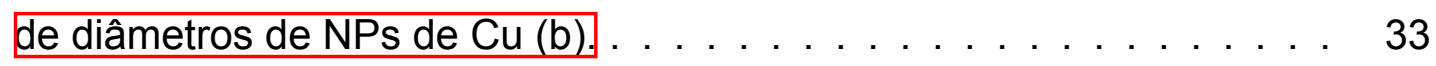

5.9 Comparação entre as PDFs de diâmetros para NPs de Cu aglomeradas esegmentadas. . . . . . . . . . . . . . . . 33

5.10 Imagem obtida por MET mostrando a presença de planos cristalinos nas NPs de cobre. . . . . . . . . . . . . . . . . . . . . 34

5.11 Imagem obtida por MET das NPs de cobalto. . . . . . . . . . . . . . 35

5.12 Distribuição de diâmetros de aglomerados de NPs de Co (a) e distribuição de diâmetros de NPs de Co (b). . . . . . . . . . . . . . . . . 36

5.13 Comparação entre as PDFs de diâmetros para NPs de Co aglomeradas esegmentadas. . . . . . . . . . . . . . . . 36

5.14 Comparação entre as PDFs de diâmetros para NPs de Cu e NPs de Co. 37

5.15 Imagem obtida por MET mostrando a presença de planos cristalinos nas

NPs de cobalto . . . . . . . . . . . . . . . . . . . . . . . 38

5.16 Imagem obtida por MET mostrando a presença do padrão haxagonal da estrutura cristalina das NPs de cobalto. . . . . . . . . . . . 38

5.17 Curva de histerese de uma amostra de NPs de Co depositadas por 5 minutos e 30 segundos em substrato de Kapton. . . . . . . . . . . . . 39

5.18 Diagramas esquemáticos das amostras produzidas através da co-deposição de $\mathrm{Si}_{3} \mathrm{~N}_{4}$ e NPs de Co . . . . . . . . . . . . . . . . . 41

5.19 Curvas de histerese para NPs de Co co-depositadas com $\mathrm{Si}_{3} \mathrm{~N}_{4} \ldots \ldots 41$

5.20 Curvas de magnetização ajustadas para NPs de Co co-depositadas com $\mathrm{Si}_{3} \mathrm{~N}_{4}$.

5.21 Comparação entre as PDFs de diâmetros para amostras analisadas por MET e por curva de histerese. 
5.22 Curvas de magnetização ajustadas para NPs de Co co-depositadas com $\mathrm{Si}_{3} \mathrm{~N}_{4}$, após 1 semana da produção. . . . . . . . . . . . . . . . 44

5.23 Comparação entre as PDFs de diâmetros no dia da produção e após 1 semana para as amostras (a) NP-intercalado e (b) NP-revestido. . . . . 45 


\title{
Lista de abreviações e siglas
}

\author{
Ag Prata \\ B Boro \\ Co Cobalto \\ $\mathrm{Cu} \quad$ Cobre \\ FCC Cúbico de face centrado \\ FFT Transformada rápida de Fourier \\ GNPR Gerador de nanopartículas radial \\ HCP Hexagonal compacto \\ He Hélio \\ MET Microscopia eletrônica de transmissão \\ MSR Magnetron Sputtering Radial \\ N Nitrogênio \\ N\&N Nanociência e Nanotecnologia \\ Ni Níquel \\ NP Nanopartícula \\ PDF Função densidade de probabilidade \\ VSM Vibrating-sample magnetometer \\ Xe Xenônio
}





\section{Sumário}

1 Introdução 1

2 O interesse nas nanopartículas 3

2.1 Magnetismo em nanopartículas . . . . . . . . . . . . . . . . . 3

2.2 Métodos de produção $\ldots \ldots \ldots \ldots \ldots \ldots$

3 Metodologia experimental $\quad 7$

3.1 Técnicas de caracterização . . . . . . . . . . . . . . . . . . . . 7

3.1.1 Microscopia eletrônica de transmissão . . . . . . . . . . . . 7

3.1.2 Magnetômetro de amostra vibrante . . . . . . . . . . . . 8

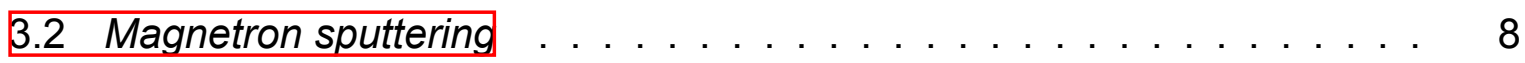

3.3 Condensação de vapores e crescimento de NPS . . . . . . . . . . . . 11

3.4 Gerador de nanopartículas planar . . . . . . . . . . . . . . . . . 12

4 O novo gerador de nanopartículas 15

4.1 Desenvolvimento do canhão de sputtering do tipo hollow cathode . . . 16

4.2 Fluxo de gás do gerador de NPS . . . . . . . . . . . . . . . . 20

4.3 Outras possibilidades de uso do canhão radial . . . . . . . . . . 25

5 Resultados experimentais $\quad 27$

5.1 Parâmetros e aspectos visuais da deposição . . . . . . . . . . . . 27

5.2 Microscopia eletrônica de transmissão $\ldots \ldots \ldots \ldots \ldots \ldots$

5.2 .1 Nanopartículas de Cobre . . . . . . . . . . . . . . . . . 30

5.2 .2 Nanopartículas de Cobalto . . . . . . . . . . . . . . . . . 35

5.3 Magnetômetro de amostra vibrante . . . . . . . . . . . . . . . . . . . . 39

5.3.1 Nanopartículas de cobalto co-depositadas com material dielétrico 40

5.3.2 Processo de envelhecimento (aging) das nanopartículas de cobalto 44

\begin{tabular}{lll}
\hline 6 Conclusões & 47
\end{tabular}

\begin{tabular}{ll}
\hline Bibliografia & 51
\end{tabular} 



\section{Capítulo 1}

\section{Introdução}

Nanociência e Nanotecnologia ( $N \& N$ ) envolve o uso de materiais com pequenas estruturas ou pequena dimensão, denominados nanomateriais. É possível generalizar N\&N como a área de estudo associada ao desenvolvimento, fabricação e aplicação de nanoestruturas e nanomateriais, além do entendimento de propriedades e fenômenos físicos inerentes a esta escala.

Nanomateriais possuem, como principal característica, uma ou mais dimensões na escala nanométrica, abaixo dos 100 nanômetros. O tamanho reduzido desses materiais Ihes permitem apresentar propriedades diferentes das estruturas macroscópicas (bulk ${ }^{\text {W }}$ ), ao mesmo tempo que não possuem o comportamento de um átomo isolado. As diferenças podem estar presentes na temperatura de fusão da estrutura cristalina ou mesmo nas propriedades ópticas, catalíticas ou magnéticas do material.

Dentre os objetos nanométricos, as nanopartículas (NPs) são de grande interesse. Estas possuem forma bem definida (esferas, cubos etc.), uma distribuição de tamanhos conhecida e são caracterizadas, em geral, por serem objetos zero dimensionais, tendo todas as suas dimensões em escala nanométrica.

Mesmo nos restringindo às NPs, o campo de estudo se mostra vasto. Isso se dá por conta da grande quantidade de materiais que podem ser utilizados na produção de NPs, como: polímeros, metais, óxidos metálicos, semicondutores, biomateriais etc. [1, 2].

Outro aspecto é a variedade de técnicas que podem ser empregadas na produção de NPs. Podemos classificá-las essencialmente dentro de três categorias: (i) condensação de vapor atômico, (ii) síntese química, e (iii) processos de estado sólido, tais como a moagem. Com o intuito de explorar novos fenômenos e propriedades físicas e aplicar NPs de forma coerente, o primeiro passo é o domínio da fabricação e do processamento dos nanomateriais de interesse.

Em geral, os métodos utilizados para a produção de NPs são majoritariamente

\footnotetext{
${ }^{1}$ Do inglês: massivo, volumoso.
} 
químicos. No âmbito magnético, isto leva a uma grande facilidade de produção de NPs, porém, em geral, ficam fortemente circunscritos aos óxidos de $\mathrm{Fe}$, Co e $\mathrm{Ni}$, conhecidos como ferritas. Como muitas das possíveis aplicações de materiais magnéticos exigem o uso de nanomateriais com maior magnetização, o uso de óxidos estabelece uma limitação prática. Por conta disso, este trabalho se dedica ao desenvolvimento de uma metodologia física para a produção de NPs, com o intuito de produzir NPs puramente metálicas.

A técnica de produção de NPs por agregação gasosa consiste da produção de aglomerados a partir de um vapor atômico do material de interesse [3] . Esse método é simples e permite a produção em atmosfera controlada, evitando possíveis oxidações. No Laboratório de Materiais Magnéticos (LMM) do Instituto de Física da Universidade de São Paulo (IFUSP) a técnica de produção de NPs pelo método de agregação gasosa tem sido aprimorada ao longo da última década.

O sistema utilizado no LMM até o início desse projeto havia sido desenvolvido como uma adaptação de um dos canhões planares do sistema de magnetron sputtering [4, 5], no qual uma câmara intermediária foi acoplada, produzindo uma atmosfera do gás de trabalho em alta pressão relativa (entre 0,1 e 2 Torr). O gás escoa pela câmara, saindo por uma abertura na extremidade oposta ao canhão de sputtering. $\mathrm{O}$ vapor atômico gerado pelo processo de sputtering é, então, resfriado termodinamicamente pelo gás de trabalho, formando aglomerados por condensação, removidos do tubo cilíndrico pelo escoamento do gás. As NPs formadas são arrastadas até o bico de saída pelo mesmo fluxo de gás e, após isto, mantém, por inércia, suas trajetórias até o substrato. Com o objetivo de produzirmos NPs do tipo core@shell foi também desenvolvido um magnetron sputtering radial para que fosse possível o revestimento das NPs extraídas do tubo cilíndrico.

Contudo, ao início desse projeto, o "canhão antigo de nanopartículas" apresentava instabilidades na sua operação. Quedas da taxa de produção ocorriam no decorrer do tempo as quais somente eram recuperadas após a quebra e restauração do vácuo do equipamento, tornando o seu uso pouco prático. Assim, esse projeto teve por objetivos a reestruturação do gerador de nanopartículas numa estrutura de magnetron sputtering radial e, através de seu uso, determinar os parâmetros experimentais para a produção de nanopartículas de Cu e de Co e para a produção da casca de Ag no sistema desenvolvido.

O sistema foi reestruturado de modo a utilizar um flange livre do equipamento de magnetron sputtering, o que acrescentou um quinto canhão ao equipamento. Cabe ressaltar que o uso do canhão de NPs não altera a pressão na câmara principal do sistema de sputtering, o que permite a deposição simultânea de NPs e filmes finos. 


\section{Capítulo 2}

\section{O interesse nas nanopartículas}

Ao longo das últimas décadas, um progresso extraordinário foi feito em materiais nanoestruturados e um aumento dramático nas atividades de pesquisa em muitos campos diferentes criou a necessidade de trabalhos fundamentais sobre o assunto. Logo, é natural o interesse do LMM no estudo da produção e caracterização das nanopartículas de caráter magnético.

As nanopartículas magnéticas têm sido o foco de muitas pesquisas recentemente porque possuem propriedades atraentes que podem ver o uso potencial em catálise, incluindo catalisadores baseados em nanomateriais [6], biomedicina [7], microfluídica [8], imagem por ressonância magnética [9], armazenamento de dados [10], nanofluidos [11] e filtros ópticos [12]. Comumente, essas partículas são compostas de materiais magnéticos a base de ferro, níquel e cobalto.

Nesse capítulo, veremos de forma sucinta propriedades magnéticas e métodos de produção de NPs.

\subsection{Magnetismo em nanopartículas}

Nanopartículas magnéticas constituem uma classe de NPs que podem ser manipuladas usando campos magnéticos. O comportamento magnético de um sistema composto de nanopartículas é dependente das propriedades físicas individuais de cada partícula e do ambiente em que está inserida. Dentre as mais importantes características físicas, temos composição química, distribuição de tamanho e morfologia das partículas, parâmetros intrínsecos dos materiais (anisotropia magneto-cristalina e magnetização de saturação, entre outras) e interação superfície/interface. Em geral, esses parâmetros possuem processos bem definidos para serem obtidos para materiais massivos, porém para sistemas compostos por nanopartículas ainda não estão estabelecidos. 
Efeitos de superfície devido à quebra de simetria da rede cristalina são comuns nessa escala, já que uma porcentagem não desprezível dos momentos magnéticos está na camada superficial. Esses momentos possuem um número de coordenação menor do que o dos momentos internos, e essa falta de ligações cria uma desordem magnética maior na superfície. Em sistemas ferromagnéticos, o acoplamento magnético na região de superfície pode ficar altamente frustrado, levando à redução do ferromagnetismo [13]. Essa camada superficial é conhecida por "camada morta" (dead layer) e esse efeito é atribuído à diminuição da magnetização de saturação observada experimentalmente em nanopartículas [14, 15, 16].

A importância do tamanho de uma partícula para o seu comportamento magnético pode ser ilustrado pelo campo coercivo $H_{c}$, uma propriedade magnética importante para caracterizar diferentes regimes [17]. Na Figura 2.1] é mostrado esquematicamente a relação entre o campo coercivo e o diâmetro $D$ de uma nanopartícula dada uma temperatura finita.

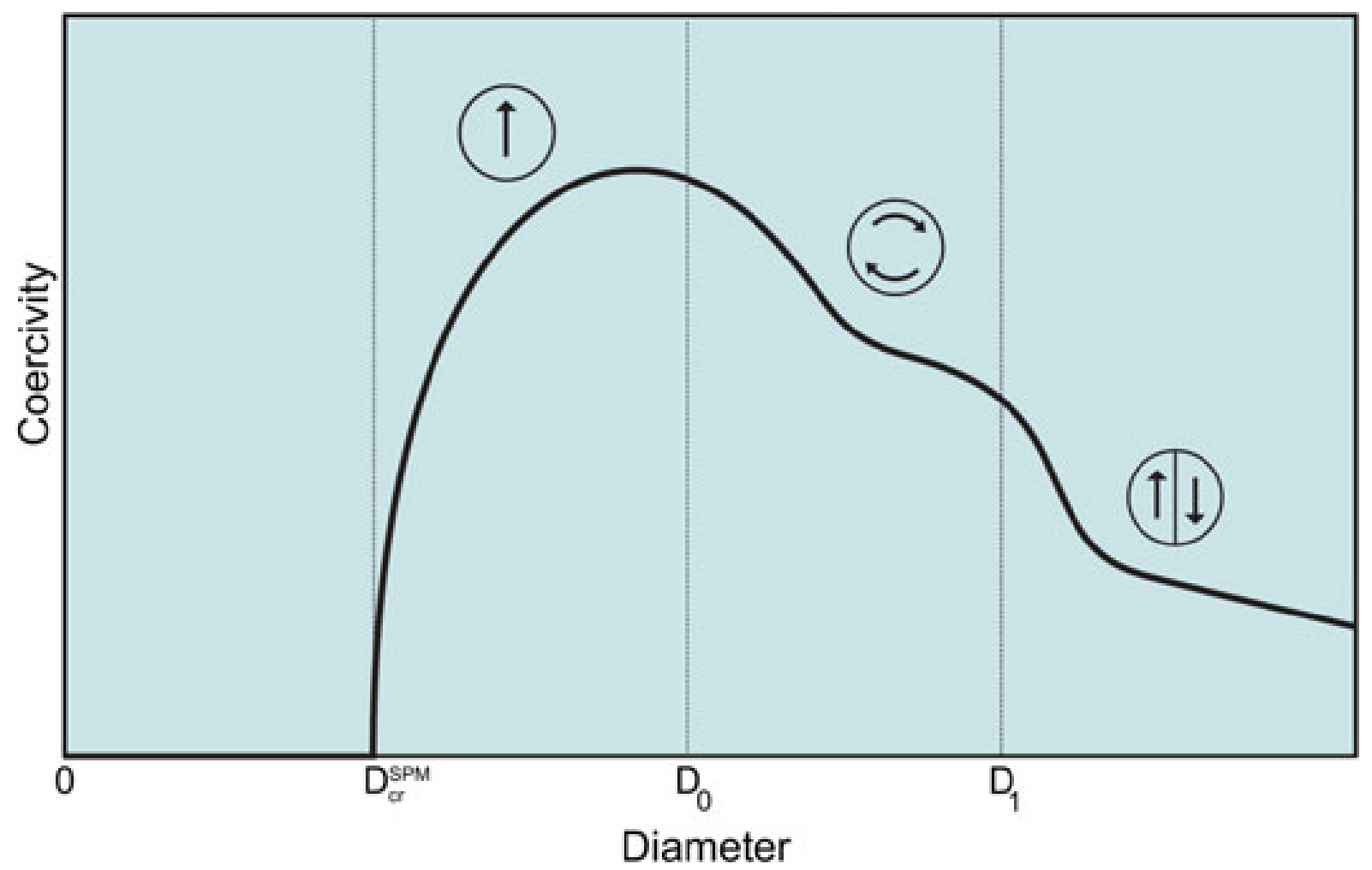

Figura 2.1: Curva esquemática de coercividade versus tamanho da partícula magnética. Extraído de [17].

O tamanho da nanopartícula define o arranjo magnético. Seguindo a referência [17], temos regimes multidomínios, vórtice, monodomínio e superparamagnético. Podemos ver que $H_{c}=0$ para $0<D<D_{c r}^{s p m}$ (tipicamente alguns nanômetros) devido à instabilidade do momento magnético, sendo um comportamento superparamagnético. Diâmetros intermediários $D_{c r}^{s p m}<D<D_{0}$ apresentam momento estável, no qual a 
partícula é um domínio isolado e a coercividade cresce com $D$, num comportamento ferromagnético. Em partículas moles magneticamente, a partícula pode apresentar um queda da coercividade devido à ordem de vórtice magnética em $D_{0}<D<D_{1}$. Por fim, em diâmetros $D>D_{1}=D_{c r}$ tipicamente com algumas centenas de $\mathrm{nm}$, se estabelece o regime de multidomínio e a coercividade cai com o aumento de $D$. Para uma NP esférica de cobalto, um dos materiais de estudo desse trabalho, é esperado $D_{c r}^{s p m} \approx 8$ nm na temperatura ambiente ao utilizarmos a equação

$$
D_{c r}^{s p m} \approx\left(\frac{6}{\pi} \frac{25 k_{B} T}{K}\right)^{1 / 3},
$$

nos quais $k_{B}$ é constante de Boltzmann, $T$ é a temperatura e $K$ é a constante de anisotropia do material. Porém, se consideramos a dead layer, o tamanho físico pode ser maior.

É possível analisar o tamanho de uma NP magnética de diferentes modos. Ao realizarmos uma análise de tamanhos por microscopia, obtemos um tamanho relativo a estrutura completa da NP, o tamanho físico. Por outro lado, uma medida magnética nos daria o tamanho relativo somente a parte magnética da NP, desconsiderando a dead layer e eventuais óxidos formados na superfície. Isso nos forneceria um tamanho magnético, que seria menor do que o tamanho da estrutura completa da NP.

\subsection{Métodos de produção}

Os métodos mais comuns na produção de nanopartículas são os químicos e os físicos, os quais podem ser divididos em dois grandes grupos. No métodos top-down, um material macroscópico é dividido em pequenas partes, em geral por metodologia física. O processo a ser utilizado depende da composição química e das características desejadas [3, 18]. Dentre os métodos físicos, podemos citar a moagem e melt mixing [19].

Nos métodos bottom-up (físicos ou químicos), o ponto de partida são átomos ou moléculas que dão origem ao nanomaterial de interesse através de interações químicas. Uma série de abordagens bottom-up foram desenvolvidas para a produção de nanopartículas, desde a condensação de vapores atômicos em voo ou em superfícies até a coalescência de átomos em líquidos. Por exemplo, técnicas de fase líquida foram desenvolvidas para produzir nanopartículas de materiais semicondutores ou magnéticos, se baseando em micelas invertidas [20, 21].

Em geral, os métodos bottom-up utilizados para a produção de NPs são mais frequentemente químicos. Isto leva a uma grande facilidade de produção de NPs magnéticas. Grandes quantidades de material podem ser produzidas e têm-se alto controle no tamanho e forma das nanopartículas. Em contrapartida, a síntese química dos na- 
nomateriais pode não fornecer a composição correta, estando mais sujeita a presença de impurezas. Isto requer um tratamento térmico com redução química repetida da superfície das partículas.

Outro problema é a aglomeração indesejável em qualquer fase do processo de síntese que pode alterar as propriedades das nanopartículas. Além disso, NPs magnéticas ficam, em geral, fortemente circunscritas aos óxidos de $\mathrm{Fe}$, Co e Ni, conhecidos como ferritas. Como muitas das possíveis aplicações de materiais magnéticos exigem o uso de nanomateriais com maior magnetização, o uso de óxidos estabelece uma limitação prática.

Métodos físicos, por outro lado, estão comumente relacionados com a formação de aglomerados por processos energéticos. Partindo de métodos de evaporação atômica usados na produção de filmes finos, é possível produzir nanopartículas condensando o vapor atômico em tempo de voo em sistemas de vácuo, metodologia conhecida como método de agregação gasosa [22, 23, 24, 25, 26]. O vapor atômico pode ser gerado por diversos métodos, dentre eles os métodos de evaporação por laser [27], por feixe de elétrons [28] ou íons [29], térmica [30] e sputtering [4, 19].

O sistema desenvolvido neste trabalho está relacionado com estas técnicas de aglomeração de vapor atômico e consiste em uma adaptação da técnica de magnetron sputtering utilizada na produção de filmes finos [31]. As técnicas de condensação de vapor atômico têm suas origens na década de 70 [32]. Em sistemas parecidos com o nosso, o uso de diferentes gases ( $\mathrm{He}, \mathrm{Ar}, \mathrm{Xe}$ ) como elemento condensador é uma ferramenta muito comum de ser utilizada para modificar o tamanho das nanopartículas [33]. Devido as suas diferentes massas atômicas, a eficácia destes gases inertes em condensar as NPs varia fortemente. Neste trabalho, no entanto, utilizou-se apenas o Ar como elemento condensador. Tal decisão teve a vantagem de simplificar o sistema e a desvantagem de diminuir o nosso leque de ferramentas para modificar o tamanho das NPs.

A extração do material pode ser feita de diversas maneiras como, por exemplo, através de lentes aerodinâmicas ou eletrostáticas. No sistema desenvolvido, a própria aerodinâmica do equipamento é capaz de colimar este material e removê-lo em direção ao substrato. A operação em vácuo permite que não haja oxidação das NPs durante a produção e traz a possibilidade de novas aplicações. Por exemplo, métodos de produção químicos dificultam aplicações em microeletrônica, pois as NPs são, principalmente, produzidas em meio aquoso. O nosso sistema, por operar em vácuo, permitiria aplicações em microeletrônica. 


\section{Capítulo 3}

\section{Metodologia experimental}

Em relação às técnicas experimentais, alguns tópicos precisam ser discutidos. Em primeiro lugar, é necessário definir os métodos de caracterização do material a ser gerado. Em seguida, é preciso entender por quais mecanismos ocorre a agregação do vapor atômico. $\mathrm{O}$ equipamento de magnetron sputtering usado e seu funcionamento é explorado logo após. No final deste capítulo, apresentaremos também o gerador de NPs desenvolvido anteriormente a esse trabalho. O desenvolvimento do novo gerador de NPs terá o Capítulo $₫$ dedicado a essa discussão.

\subsection{Técnicas de caracterização}

Nessa sessão, citamos as técnicas de caracterização das amostras produzidas ao longo deste trabalho, discutindo a escolha de cada uma, bem como os substratos utilizados.

\subsubsection{Microscopia eletrônica de transmissão}

As amostras produzidas foram, inicialmente, submetidas a medidas de microscopia eletrônica de transmissão (MET) com o intuito de se fazer uma caracterização morfológica inicial. As medidas de MET foram realizadas no Centro Analítico de Instrumentação do Instituto de Química da Universidade de São Paulo (Central Analítica) em um microscópio eletrônico JEOL JEM 2100, operado pelo Sr. Alfredo Duarte, técnico da Central Analítica. As amostras utilizadas foram preparadas em um substrato composto de grades de $\mathrm{Cu} / \mathrm{C}$ próprias para o equipamento, modelo PELCO ${ }^{\circledR} 01824$. O substrato possui um filme contínuo de carbono com menos de $3 \mathrm{~nm}$ de espessura sobreposto a uma renda de carbono. O filme rendado é sustentado por uma grade de cobre, com mesh 400. O tamanho dos orifícios no filme rendado estão, geralmente, na faixa de $1 / 4 \mu \mathrm{m}$ a $5 \mu \mathrm{m}$. A tensão aceleradora utilizada foi de $200 \mathrm{kV}$. 


\subsubsection{Magnetômetro de amostra vibrante}

Um magnetômetro de amostra vibrante (VSM) tem como princípio de operação a lei de indução de Faraday. A amostra magnética de interesse é colocada em uma região com campo magnético ajustável que faz com que ela se magnetize. A peça onde a amostra é fixada é vibrada em uma frequência bem definida $(\sim 80 \mathrm{~Hz})$, fazendo com que o fluxo magnético em bobinas sensoras varie em função do tempo. A variação do fluxo magnético gera uma diferença de potencial induzindo um sinal proporcional ao momento magnético total da amostra magnética. Assim, variando o campo magnético, é possível medir as curvas de histerese. Além disso, é possível variar a orientação da amostra a fim de verificar a existência de eixos preferenciais de magnetização.

Os VSMs utilizados pertencem ao Laboratório de Materiais Magnéticos (LMM) do IFUSP. O campo máximo utilizado foi de $5 \mathrm{kOe}$. Folhas de Kapton foram utilizadas como substrato para minimizar contribuições nas medidas magnéticas.

\subsection{Magnetron sputtering}

A técnica de magnetron sputtering é baseada na ejeção de átomos de uma superfície alvo a partir do bombardeamento por íons energéticos. No seu uso para produção de filmes finos ou nanopartículas, a técnica é considerado um método físico do tipo bottom-up. Essa técnica permite a deposição de átomos em um substrato, portanto sendo utilizada no crescimento de filmes semicondutores e metálicos. Um esquema simplificado do canhão de sputtering para deposição em um substrato é mostrado na Figura 3.1. Utilizando um alvo do material de interesse, aplica-se um potencial elétrico gerando íons do gás de trabalho. Essa configuração forma um plasma estável, mantido pelo potencial aplicado. Ímãs são posicionados junto ao alvo para melhor direcionamento e confinamento do plasma. Assim diminui-se o potencial elétrico e pressões de gás inerte necessários, consequentemente aumentando a eficiência do processo de sputtering. A posição dos ímãs é dependente da geometria do alvo, como veremos a frente. A colisão dos íons do plasma com a superfície do alvo, transmite energia aos seus átomos, podendo removê-los e gerar uma nuvem atômica. $O$ vapor atômico gerado pelo processo é espalhado em todas as direções, se dirigindo ao substrato desejado e lá se condensando. O porta-substrato é rosqueado a um cabeçote ligado a um pequeno motor, possibilitando a rotação das amostras sobre seu eixo. Essa rotação permite um melhor controle sobre a homogeneidade da distribuição de material depositado.

O equipamento de sputtering utilizado nesse trabalho foi um modelo comercial ATC 2000, fabricado pela empresa AJA International e localizado no Laboratório de Materiais Magnéticos do Instituto de Física da USP. A Figura 3.2 apresenta uma vi- 
são geral do sistema de sputtering. O equipamento consiste numa câmara principal de aproximadamente $120 \mathrm{~L}$, na qual ocorrem todas as deposições, e uma câmara secundária, que possibilita a troca de substratos enquanto é mantido o vácuo da câmara principal. Para a produção do vácuo, o sistema conta com duas bombas turbo moleculares, sendo uma para cada câmara. Cada bomba turbo molecular é associada a uma bomba de vácuo mecânica. Com isso, o sistema alcança pressões da ordem de $10^{-7}$ Torr.

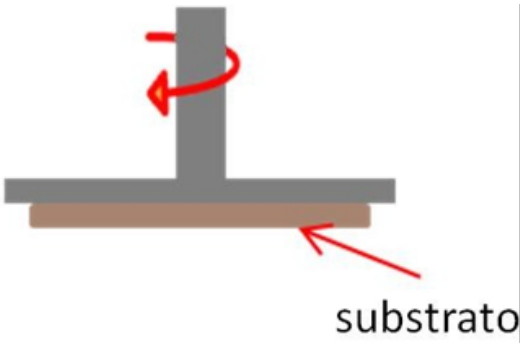

plasma

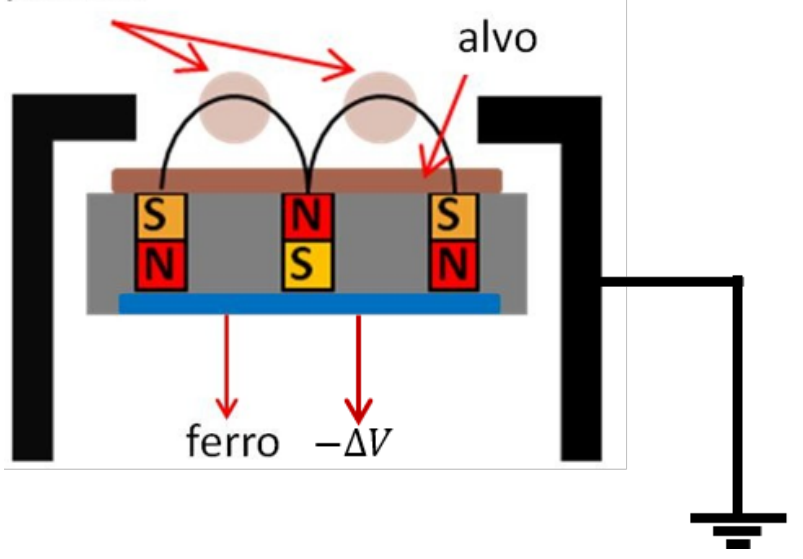

Figura 3.1: Esquema do canhão de um sistema de sputtering do tipo magentron para produção de filmes em substrato. Adaptado de [34].

O monitoramento de pressão é realizado na câmara principal com um sensor termorresistivo para pressões de $10^{3}$ a $10^{-4}$ Torr, um medidor ion-gauge para medidas de $10^{-4}$ a $10^{-8}$ Torr e um medidor capacitivo Baratron de alta precisão durante os processos de deposição. A câmara secundária também possui um sensor termorresistivo e um medidor ion-gauge para monitoramento de pressão. O sistema necessita de aproximadamente 12 horas para alcançar a pressão de $10^{-7}$ Torr na câmara principal e aproximadamente $30 \mathrm{~min}$ para a câmara secundária.

O sistema possui originalmente 4 canhões de sputtering e foi acrescentado o gerador de NPs desenvolvido durante esse projeto como quinto canhão. Os canhões de sputtering podem ser alimentados por dois tipos de fontes: fontes de corrente contínua DC e fontes de rádio frequência RF. As fontes DC são utilizadas para alvos de materiais condutores, enquanto as fontes RF são utilizadas para alvos de material dielétrico a fim de evitar o acúmulo de cargas superficiais. Ambos tipos de fontes possuem 
potência máxima de $500 \mathrm{~W}$. Todos os canhões possuem entrada de gás própria e os 4 canhões de fábrica possuem um obturador (shutter) para bloqueio do fluxo de material removido dos alvos. Uma visão geral interna do sistema de sputtering pode ser vista na Figura 3.3.

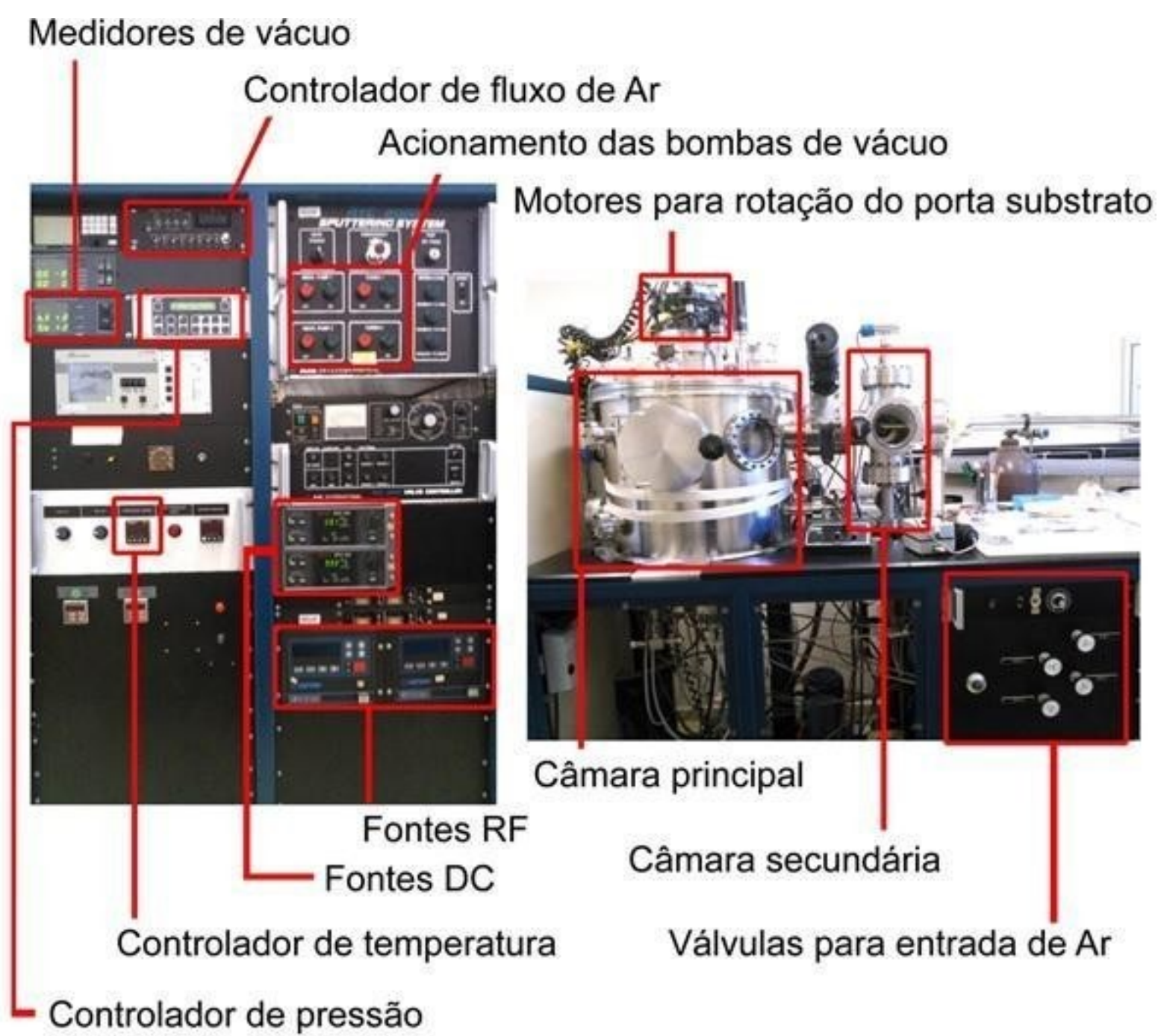

Figura 3.2: Imagem do equipamento com os principais componentes destacados. Extraído de [34].

O sistema possui um controlador adaptativo de pressão modelo VAT PM-5, o qual é associado a uma válvula gaveta que conecta a bomba turbo-molecular à câmara principal. Controladores de fluxo de massa, modelo 1179A - MKS, são utilizados juntamente a um controlador de quatro canais modelo 274C - MKS. Os gases utilizados possuem pureza de $99,999 \%$ (N50). Para este projeto, foi utilizado exclusivamente argônio como gás de trabalho.

No canhão de NPs, as taxas de deposição de cada material são influenciadas por fatores controláveis: fluxo e pressão do gás de trabalho, potência aplicada e temperatura da câmara. Esses fatores estão diretamente ligados ao livre caminho médio dos átomos dentro da câmara. Além disso, existe o sputter yield, característica de 
cada material, que depende da energia de ligação entre os átomos de que compõe o alvo. O sputter yield é definido como o número de átomos retirados do alvo por colisão por íon incidente [35]. Portanto, um material com maior sputter yield sofre o processo de sputtering mais facilmente.

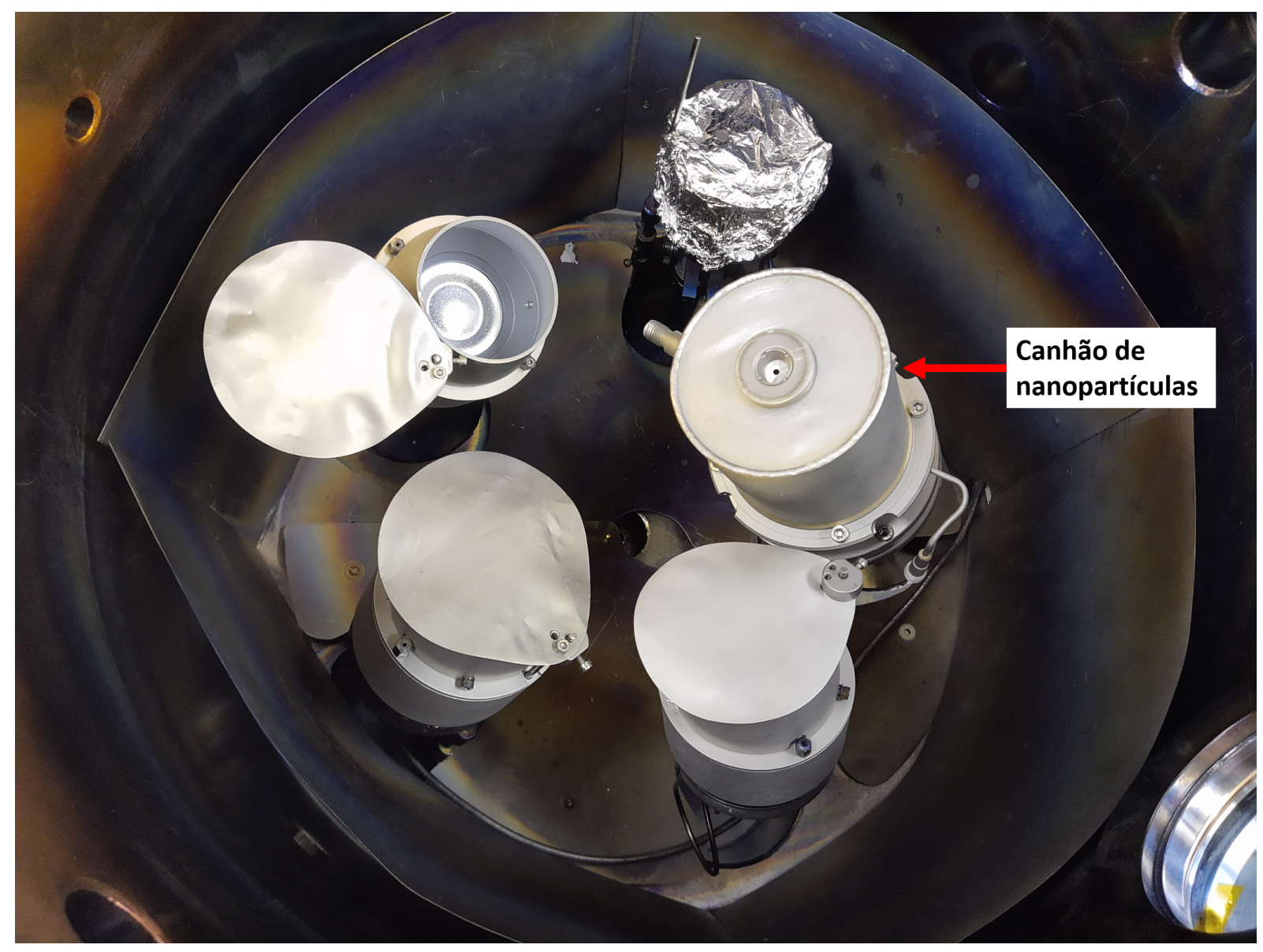

Figura 3.3: Visão interna da câmara principal do equipamento de sputtering. Canhão de NPs indicado e demais canhões de sputtering.

\subsection{Condensação de vapores e crescimento de NPs}

O processo de condensação de vapores atômicos envolve a probabilidade de haver a formação de ligações químicas entre átomos e aglomerados. Usualmente, essas probabilidades são descritas pela mecânica quântica [36], tendo complexidade suficiente para um estudo dedicado. Portanto, este trabalho não se dedica a descrição teórica dos processos atômicos envolvidos. Ainda assim, existem propriedades e grandezas, que precisam ser discutidas, referentes ao crescimento das nanopartículas.

Um sistema composto por um gás monoatômico pode ter seu livre caminho médio $(\lambda)$ estimado pela equação 


$$
\lambda=\frac{k_{B} T}{\sqrt{2} \pi P d^{2}},
$$

nos quais $\mathrm{T}$ é a temperatura do sistema, $\mathrm{P}$ a pressão, $\mathrm{d}$ o diâmetro atômico médio e $k_{b} \approx 1,4 \times 10^{-23} \mathrm{JK}^{-1}$ a constante de Boltzmann.

Considerando as condições usuais de operação, temos que $80 \mathrm{sccm}$ de fluxo de gás gera 780 mTorr de pressão dentro do tubo cilíndrico, que constitui o gerador de nanopartículas e age como câmara de agregação. Admitindo-se que o fluxo seja constante e lamelar de tal forma que o gás esteja aproximadamente em equilíbrio, usando o diâmetro covalente do Ar igual a $0,25 \mathrm{~nm}$, obtemos que, à temperatura ambiente ( $\sim 300 \mathrm{~K})$, o valor de livre caminho médio é aproximadamente igual a 0,1 mm.

Também é possível estimar a velocidade browniana média dos átomos de Ar, desconsiderando a componente do fluxo, através da equação

$$
<v_{p}>=\sqrt{\frac{2 k_{B} T}{m_{a}}},
$$

obtendo $<v_{p}>\approx 300 \mathrm{~m} / \mathrm{s}$. Já os átomos removidos do alvo possuem uma distribuição de energia muito larga, podendo chegar a dezenas de eV [37]. Porém, supondo energia cinética da ordem de $10 \mathrm{eV}$, os átomos removidos terão uma velocidade inicial da ordem de $\sim 6000 \mathrm{~m} / \mathrm{s}$. Se considerarmos átomos de Co, que possuem menos de 1,5 vezes a massa do átomo de Ar, é possível mostrar classicamente que um átomo removido perde energia rapidamente, tendo uma velocidade comparável com a velocidade do fluxo browniana após apenas 10 colisões. Somando essas informações ao livre caminho médio curto, é natural pensar que o vapor de cobalto tende a termalizar muito rapidamente, então seguindo o trajeto do fluxo do $\operatorname{Ar}(\sim 0,2 \mathrm{~mm} / \mathrm{s})$, quando a concentração de átomos de argônio é muito maior do que a de átomos removidos do alvo.

Sendo assim, o processo de crescimento das NPs depende de dois parâmetros: o fluxo de gás e a potência aplicada ao canhão. O fluxo de gás é responsável pela quantidade de átomos de Ar e, consequentemente, a pressão dentro do gerador, bem como é responsável pela remoção de NPs da câmara de agregação. Já a potência aplicada ao gerador define a quantidade de material removida do alvo, definindo a quantidade de átomos disponível para a formação de aglomerados.

\subsection{Gerador de nanopartículas planar}

A partir do nosso sistema magnetron sputtering foi desenvolvido, anteriormente a este projeto, um gerador de nanopartículas baseado em técnicas de agregação gasosa [5, 34, 38]. A adaptação para a criação do canhão de NPs utilizava um canhão 
planar. O canhão consistia em incluir uma região de alta pressão relativa ao longo da trajetória percorrida (entre o alvo e o substrato) pelo vapor atômico. Para isso, foi acoplado acima do alvo de interesse um tubo cilíndrico fechado de $10 \mathrm{~cm}$ de diâmetro e 15 cm de comprimento, mas com uma pequena abertura em sua extremidade (Figura 3.4). Dentro deste, era formada uma atmosfera de alta pressão relativa de Ar, responsável pelo resfriamento termodinâmico do vapor atômico através de sucessivas colisões com as moléculas do gás. O baixo livre caminho médio do vapor atômico permitia a sua condensação em NPs. No topo do tubo cilíndrico, foi feita uma abertura circular de 2,5 mm de diâmetro, gerando um gradiente de pressão entre esta câmara interna e a câmara principal do sistema de sputtering, permitindo a remoção do material para o substrato. Chamamos esse dispositivo de câmara de agregação.

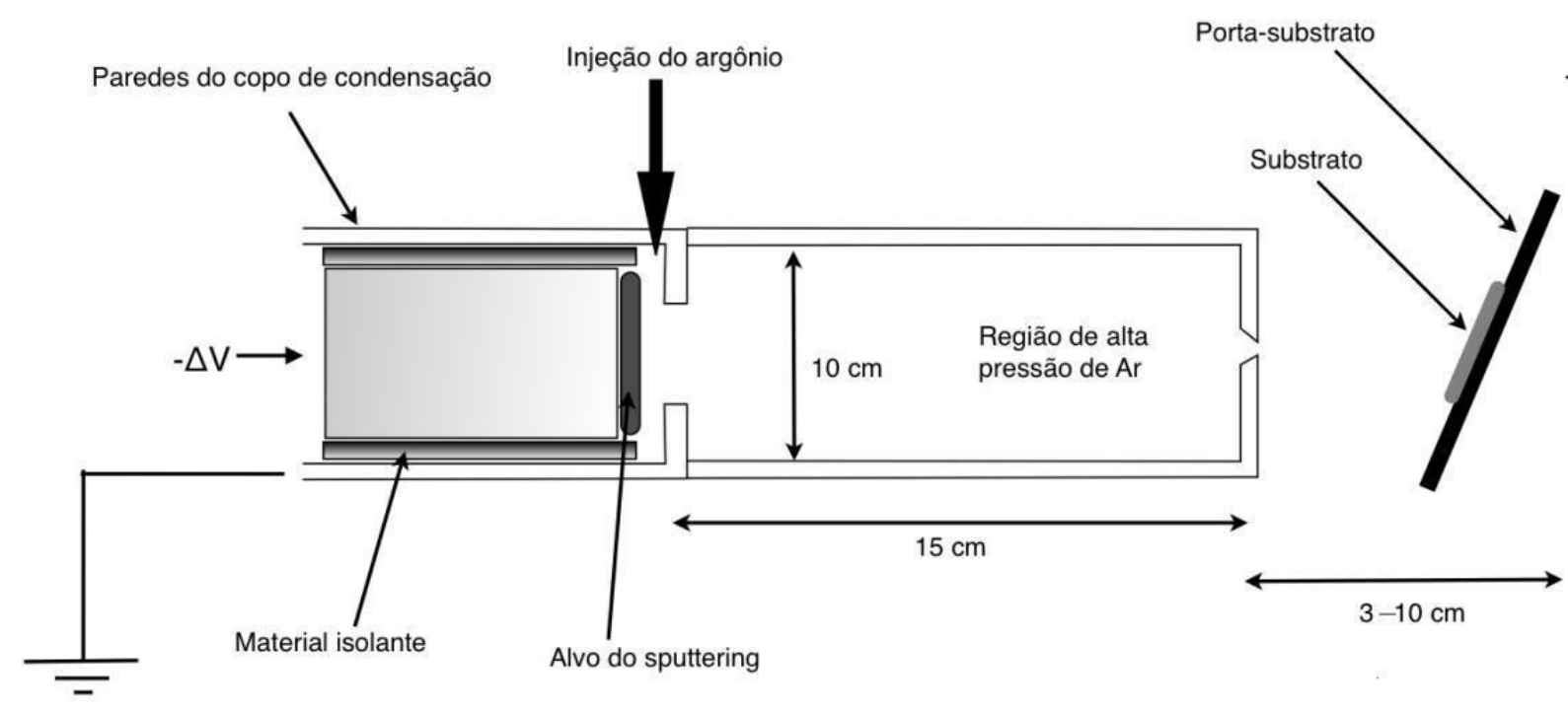

Figura 3.4: Diagrama esquemático do canhão de NPs planar. Extraído de [34].

A geometria do gerador leva à colimação de material, fazendo com que a deposição de NPs não seja homogênea como em um sistema de sputtering comum, resultando em uma mancha de material no substrato. As manchas possuem forma aproximadamente circular quando o substrato está parado e possuem perfil gaussiano, com maior concentração de material no seu centro, como veremos mais a frente, juntamente com as suas demais características.

Apesar dos resultados positivos do gerador de NPs planar [5, 34, 38, 39, 40], a instrumentação apresentou instabilidades. A câmara de agregação no topo do canhão planar permitiu a aglomeração dos átomos em NPs. Contudo, surgiu a necessidade de fluxos altos para carregar as NPs para fora da câmara de agregação [5], por conta de zonas de turbulência geradas nas bordas do alvo planar. Além disso, o sistema apresentava funcionamento intermitente, sem razões claras, em especial com alvos de caráter magnético, como o material de interesse, Co. Por fim, o gerador de NPs necessitava ser desmontado para a produção de filmes finos e demais uso do equi- 
pamento de sputtering. Todos esse fatores levaram ao desenvolvimento de um novo dispositivo, que se tornou o principal foco desse trabalho e será discutido em detalhes no próximo capítulo. 


\section{Capítulo 4}

\section{O novo gerador de nanopartículas}

Do ponto de vista instrumental, a trajetória do desenvolvimento do sistema é de extrema importância. Tendo em vista os problemas apresentados pelo canhão planar, decidiu-se repensar a instrumentação para a geração das NPs levando em consideração as informações obtidas durante o desenvolvimento do canhão de revestimento de NPs no trabalho de doutorado da Dra. Lima [38]. Foi decidida a reformulação do sistema de sputtering para um hollow cathode. Isso gerou a mudança de fluxo de gás, originando um magnetron sputtering radial (MSR). A estrutura do MSR se mostrou mais eficiente e mais estável em relação ao canhão planar original.

O projeto do gerador de NPs radial foi feito a partir de um canhão de sputtering não utilizado que estava armazenado. A ideia foi aproveitar peças que seriam de difícil construção própria, adaptando o sistema para ter um funcionamento similar ao canhão de revestimento projetado durante o já citado trabalho da Dra. Lima.

Para o desenvolvimento do novo canhão MSR, dois técnicos do DFMT-IFUSP auxiliaram o processo: o Sr. Sergio Romero, do LMM, responsável pela montagem, manutenção e operação do equipamento de sputtering e o Sr. Paulo Sergio Martins, da oficina mecânica do departamento, usinou e modificou as peças necessárias.

O desenvolvimento do projeto encontrou diversos empecilhos, que serão discutidos à frente, derivados das modificações em relação ao canhão planar padrão. Contudo, por conta das adaptações, foi possível manter a refrigeração e as conexões de alimentação de energia originais do sistema planar. O sistema também permite que o alvo cilíndrico seja trocado com facilidade, permitindo a troca entre os materiais de interesse. Além disso, pudemos utilizar um flange livre da câmara principal do sistema de sputtering, permitindo que o canhão gerador de NPs fique fixo no sistema, não sendo mais necessária sua desmontagem para os outros usos do sistema de sputtering. 


\subsection{Desenvolvimento do canhão de sputtering do tipo hollow cathode}

Em um hollow cathode [41] temos a passagem de um gás de trabalho, gerando íons e elétrons internos a um tubo. Segundo a literatura, essa geometria permite maior eficiência do que um sistema similar de flat cathode [42]. Por conta da sua eficiência no sistema de sputtering, geometrias de sputtering radial são uma opção utilizada para técnicas de agregação gasosa [43, 44]. O sistema pode possuir um fio central que funciona como cátodo e alvo de sputtering, sendo atingido radialmente por íons do gás de trabalho [45]. Em contra partida, o modelo de hollow cathode utiliza um cilindro como cátodo e alvo de sputtering. O modelo de hollow cathode foi escolhido como geometria para nosso canhão de sputtering, dando origem ao nosso sistema de sputtering com geometria radial.

No nosso sistema, o processo de sputtering, ao ocorrer dentro de um alvo cilíndrico, permite que haja uma maior concentração de íons de Ar. A hipótese foi de que essa maior concentração aumentaria a retirada de material do alvo e a produção de NPs, possivelmente melhorando a eficiência do sistema em relação à potência necessária. Contudo, ao final desse trabalho, nada se pode afirmar sobre a existência dessa correlação.

Os alvos dos materiais de interesse possuem $12,5 \mathrm{~mm}$ de diâmetro interno e uma parede de $2 \mathrm{~mm}$. Os primeiros testes mostraram que o sistema radial dependia do posicionamento do anel de plasma de forma muito cuidadosa. O tubo de injeção de gás fez com que arcos elétricos espúrios se abrissem em regiões entre este e o suporte do alvo, impossibilitando a formação de plasma na região interna do alvo. Por isso, a saída do gás de trabalho apresenta uma aba, que diminui o gap com o alvo, posicionando adequadamente o campo elétrico. Além disso, o tubo de gás foi revestido com Teflon, um material isolante elétrico que aguenta altas temperaturas (até $\sim 600 \mathrm{~K}$ ). Além disso, as paredes do porta alvo também foram revestidas com o mesmo material. Dessa forma, chegou-se a um desenvolvimento intermediário, mostrado na Figura 4.1, no qual foi possível realizar o processo de sputtering com o cobre. Contudo, o uso de alvos de materiais magnéticos continuou apresentando problemas mais graves, não havendo deposição visível.

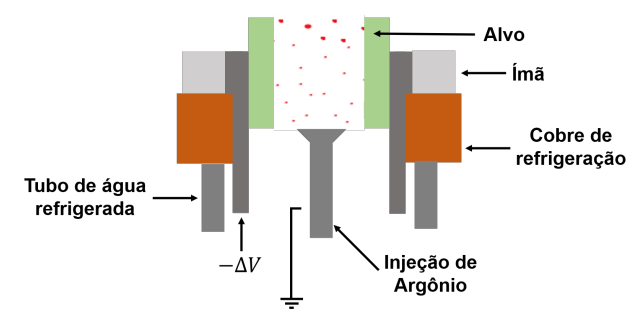

Figura 4.1: Diagrama esquemático do canhão de MSR inicial. 
Utilizando o Co como material de testes e uma sonda de efeito Hall, foi medido um campo de $\sim 200$ Oe na parede do alvo, que possui espessura de $2 \mathrm{~mm}$. Em comparação, era possível medir um campo da ordem de $2 \mathrm{kOe}$ com o alvo de cobre. Simulações foram realizadas com o programa FEMM (Finite Element Method Magnetics) [46]. Este é um conjunto de programas para resolver problemas eletromagnéticos de baixa frequência em sistemas bidimensionais com geometrias planares e radiais. Todas as simulações foram realizadas com simetria radial. O eixo de simetria é posicionado na lateral esquerda das imagens apresentadas. Somente as peças de materiais com caráter ferromagnético fizeram parte das simulações. Na Figura 4.2, é possível perceber que o fluxo magnético se mantém confinado no alvo magnético quando temos apenas o ímã e o alvo magnético. O fenômeno impossibilita o armadilhamento do plasma no local adequado e atrapalha o processo de sputtering.

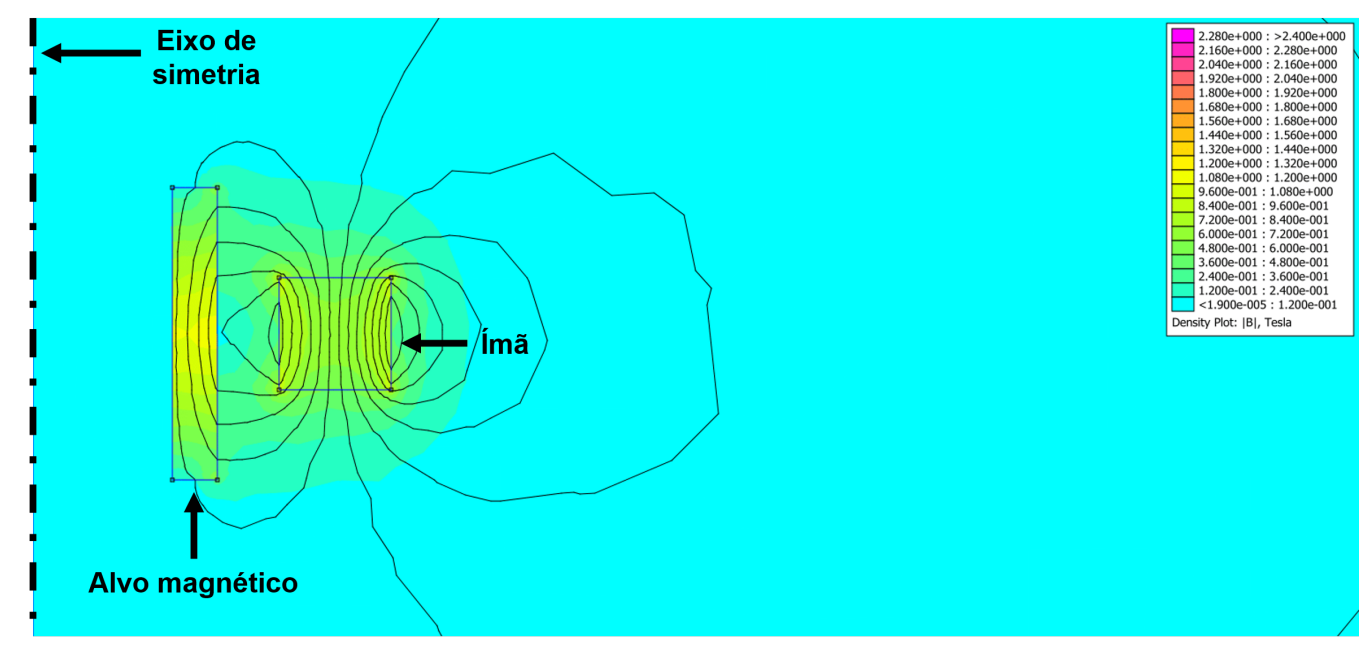

Figura 4.2: Simulação do fluxo magnético do sistema radial.

Foi necessário o uso de peças polares concentrando o campo magnético para o alvo. O pouco espaço disponível, foi frequentemente um limitador no desenvolvimento do projeto. Devido ao suporte do alvo, inicialmente, utilizou-se uma placa superior encostando no alvo e uma placa inferior que se mantinha a uma distância de $2 \mathrm{~mm}$ do alvo. Na Figura 4.3, vemos o canhão MSR montado com apenas a peça polar superior encostando no alvo.

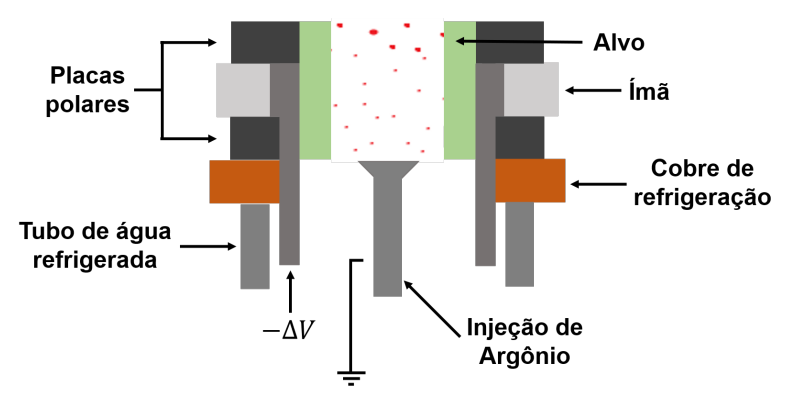

Figura 4.3: Diagrama esquemático do canhão de MSR com a peça polar inferior sem encostar no alvo. 
Na Figura 4.4, a simulação mostra uma maior concentração das linhas de campo concentradas ao centro do alvo. Contudo, existe linhas de campo concentradas na região inferior do alvo. Ainda assim, o campo medido passou a ser de $\sim 900 \mathrm{Oe}$, permitindo a operação do sistema. Com esse canhão, foi possível a produção das amostras que foram analisadas por microscopia eletrônica de transmissão e os resultados estão no Capítulo 5. Porém, tivemos instabilidades ocasionalmente, com o plasma sendo aberto abaixo do bico injetor de gás.

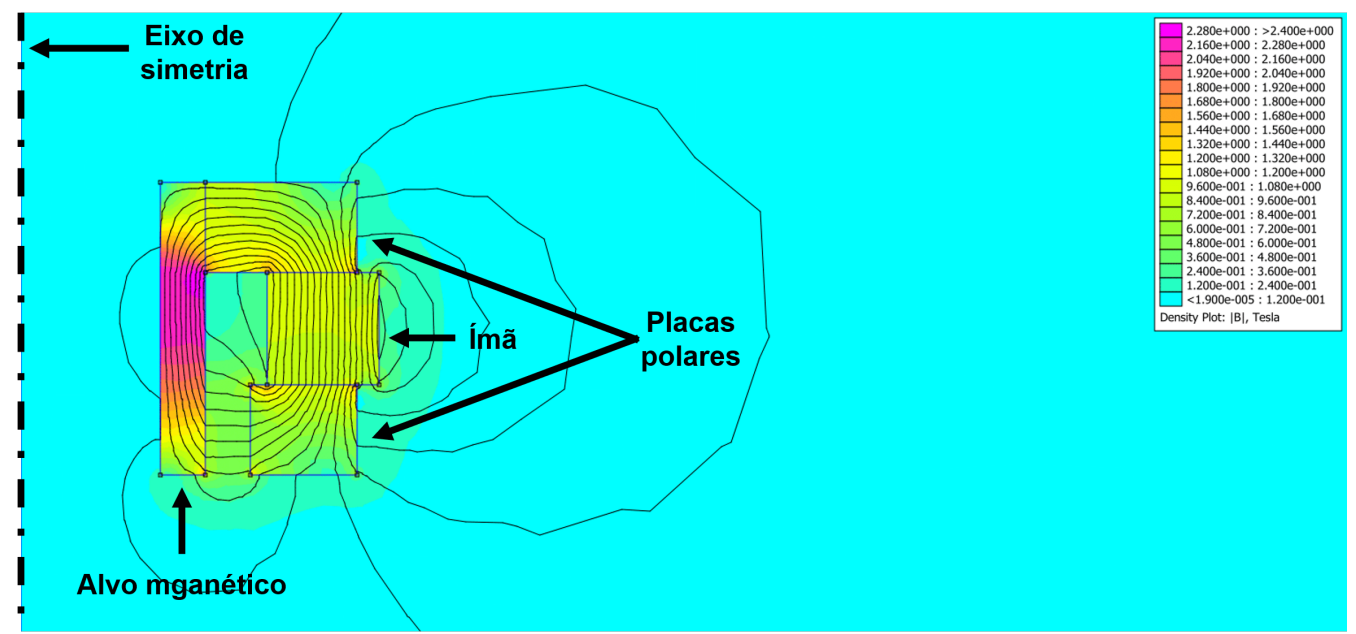

Figura 4.4: Simulação do fluxo magnético com apenas 1 peça polar tocando o alvo.

Isto nos levou a uma nova modificação, visando a supressão do gap magnético existente na montagem anterior. As simulações apresentadas na Figura 4.5 mostram que o contato entre ambas placas polares gera um confinamento ainda melhor das linhas de campo no centro do alvo. É importante ressaltar que as placas polares não cobrem toda a extensão do ímã para diminuir fuga do campo magnético para região externa do canhão de sputtering.

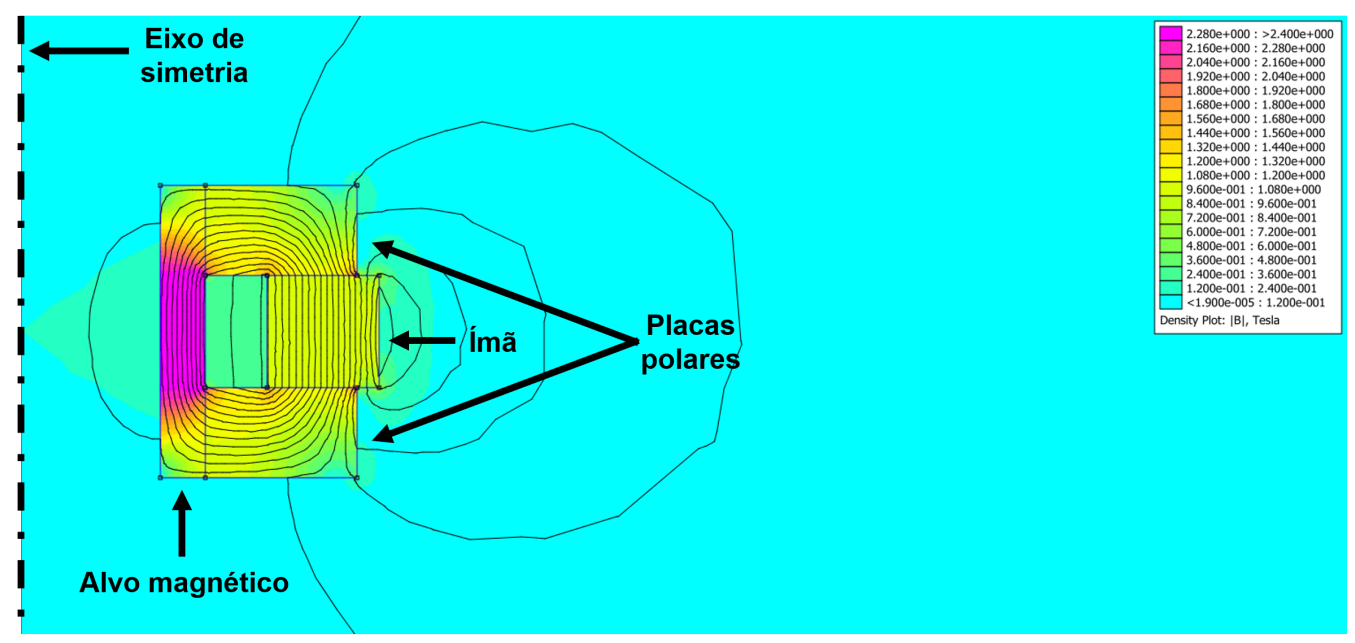

Figura 4.5: Simulação do fluxo magnético do sistema radial com ambas peças polares tocando 0 alvo. 
Outro ponto observado foi que o isolamento de Teflon degradava por conta das temperaturas, sendo necessária limpezas e trocas regulares. Passou-se a usar nitreto de boro (BN) em seu lugar, por ser um material cerâmico que aguenta temperaturas maiores (até $\sim 3000 \mathrm{~K}$ ), mas com a desvantagem de necessitar um manuseio delicado, o que não se mostrou um problema.

Levando em consideração essas informações, foi possível chegar a um canhão radial de magnetron sputtering como visto na Figura 4.6, no qual aproveitamos o sistema de refrigeração do canhão planar e mantivemos as mesmas conexões elétricas, de água e de gás.

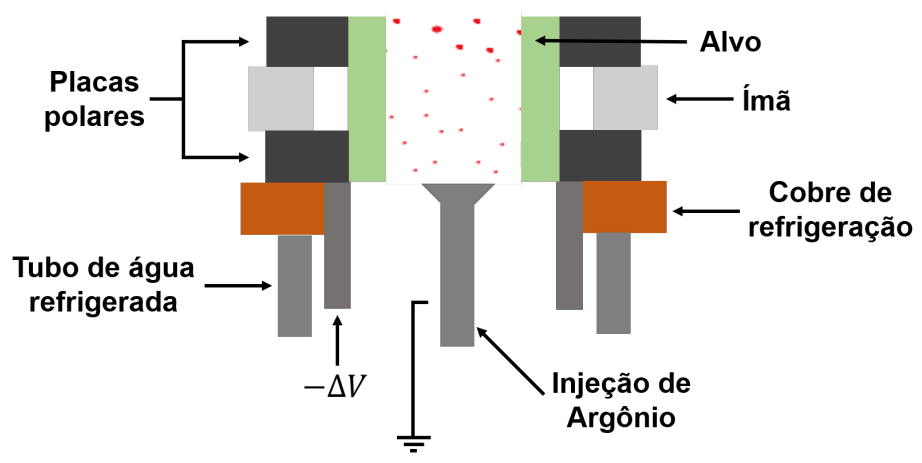

Figura 4.6: Diagrama esquemático do canhão de MSR em versão final.

A câmara do gerador de NPs foi posicionado no topo do canhão de sputtering radial, chegando ao sistema observado na Figura 4.7. Para evitar que plasmas indesejados ocorressem na região externa ao canhão de MSR, espaços vazios foram preenchidos com Teflon, para isolamento elétrico.

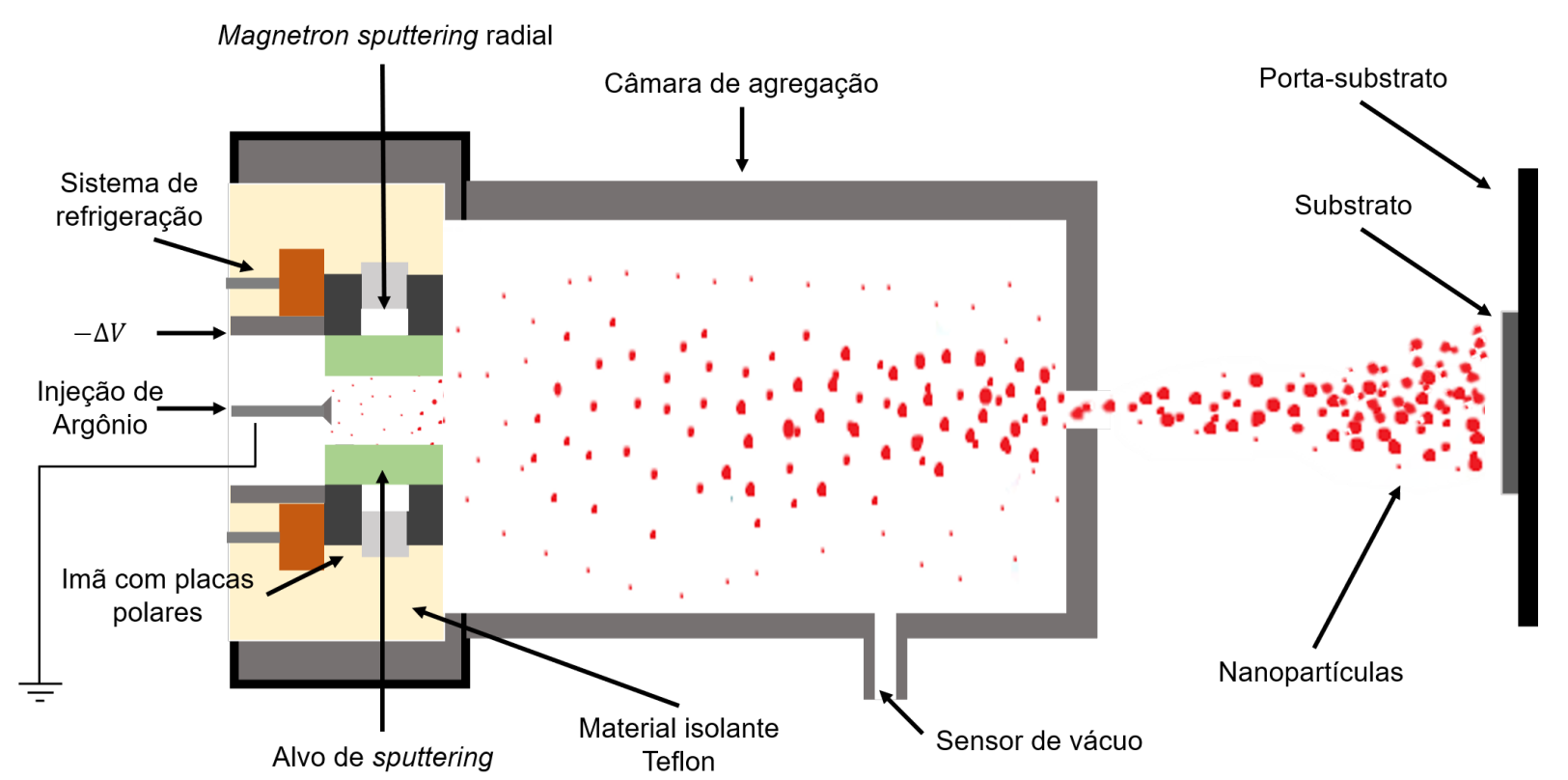

Figura 4.7: Desenho esquemático do gerador de NPs radial. 
Essa configuração se mostrou funcional. Ainda assim, com a intenção de melhorar a compreensão do sistema radial de produção de NPs, um estudo acerca do fluxo do gás de trabalho dentro do gerador foi realizado. Foram feitas uma série de simulações pelo Sr. Gioielli, cujo auxílio foi pedido dada sua experiência com simulações de fluxos de gases, adquirida durante o seu mestrado [40].

\subsection{Fluxo de gás do gerador de NPs}

A variação dos parâmetros potência e fluxo são determinantes no controle das taxas de deposição de NPs. Potências muito baixas inibem a deposição de material. Ao mesmo tempo, fluxos muito baixos resultam na não deposição de material, não conseguindo remover o mesmo da câmara de agregação. Fluxos muito altos também inibem a deposição, possivelmente devido a formação de turbulências em regiões dentro da câmara de agregação.

Primeiramente foi observada a relação do fluxo de Ar e a pressão dentro do gerador de NPs. Como pode ser visto na Figura 4.8, de acordo com o dados coletados, o aumento do fluxo de gás implica num aumento linear da pressão no dispositivo. $O$ comportamento mostrou-se sempre linear, independentemente da abertura de saída utilizada, a qual altera apenas a inclinação da reta. Este comportamento linear também foi observado experimentalmente em todas as montagens feitas.

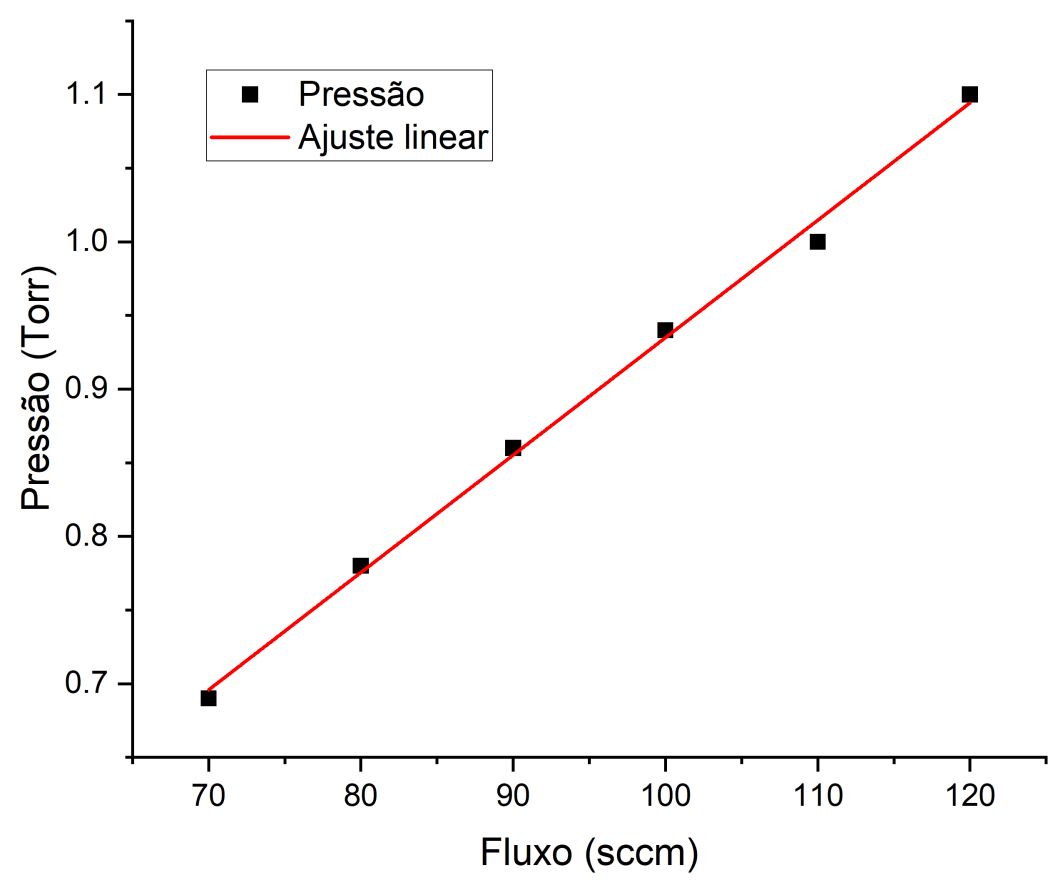

Figura 4.8: Relação entre pressão e fluxo dentro do gerador de NPs. 
Com os dados obtidos, o foco das simulações foi no fluxo de trabalho de 80 sccm, para manter parâmetros utilizados em estudos anteriores e que também proporcionaram bons resultados experimentais. As simulações foram realizadas com o software Elmer [47]. O Elmer é um software livre capaz de solucionar diversos tipos de equações diferenciais parciais (EDPs) a partir do Método de Elementos Finitos (FEM Finite Element Method). Este software possui implementado em seu código alguns modelos físicos para facilitar seu uso, dentre esses modelos estão: mecânica estrutural, eletromagnetismo, transferência de calor, acústica e fluidos dinâmicos. A representação das geometrias utilizadas no estudo do fluxo do gás de trabalho dentro do gerador de NPs, assim como a malha de pontos utilizada pelo Elmer para o cálculo, foi desenvolvida com a utilização do software Gmsh [48]. Um exemplo de malha pode ser visto na Figura 4.9. As simulações realizadas nesse trabalho tiveram caráter principalmente qualitativo, dada a complexidade do sistema e ausência de dados experimentais da distribuição de pressão na região interna ao canhão de NPs.

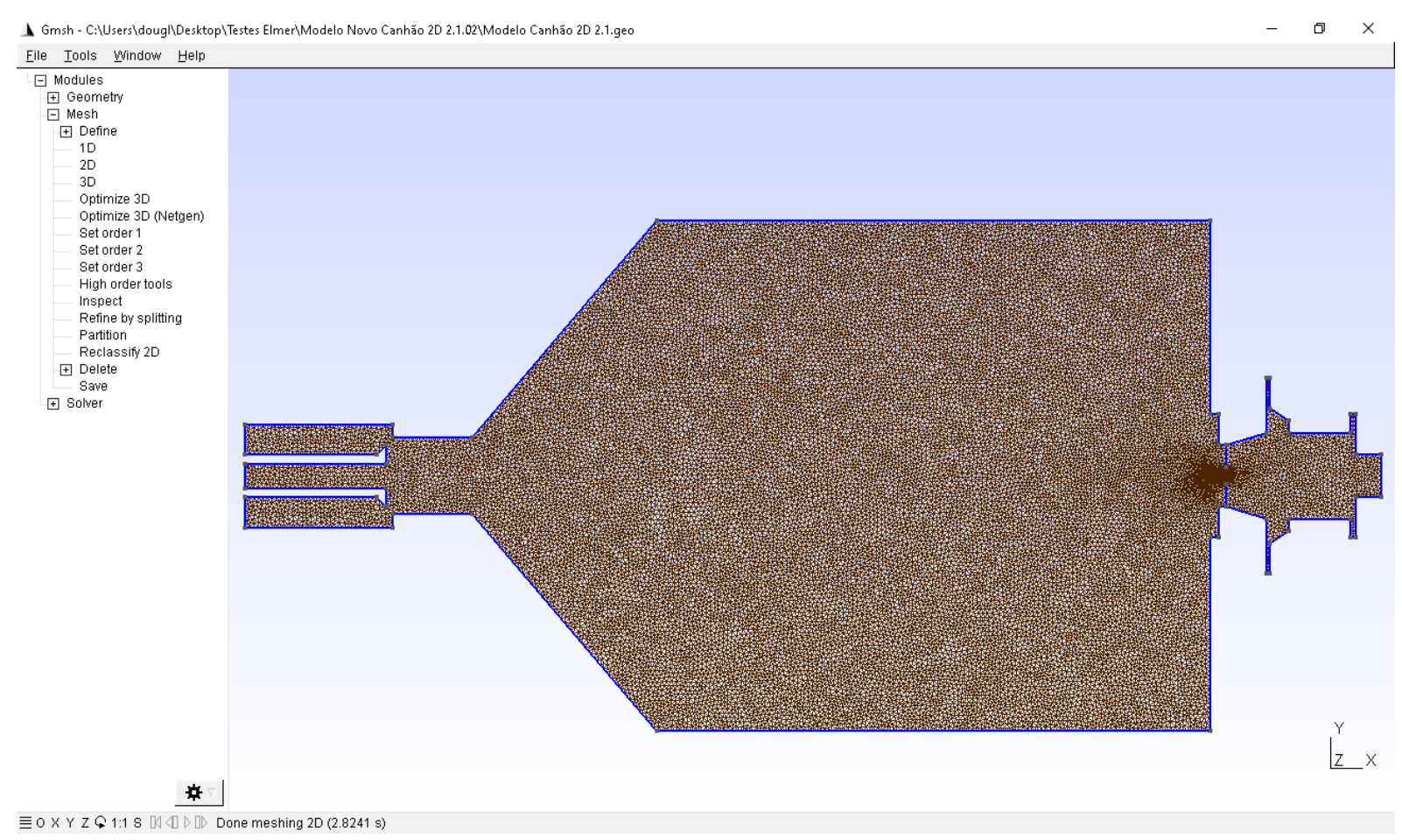

Figura 4.9: Exemplo de malha gerada no Gmsh.

O canhão radial permite a entrada do gás de trabalho no centro do alvo cilíndrico. Através das simulações, comparamos o fluxo gasoso entre o sistema planar e o sistema radial. A Figura 4.10 mostra os vetores da velocidade do gás em diferentes pontos. A simulação para o canhão planar foi realizada durante o projeto de mestrado do Sr. Gioielli [40]. As simulação do canhão radial (Figura 4.10b) levou em consideração um segundo canhão de MSR no topo do GNPR. O segundo canhão será discutido na Sessão 4.3. A escala de cores representa módulos das velocidades na horizontal 
em [m/s]. Portanto, podemos identificar a intensidade do fluxo de gás para que haja comparação dos dois modelos de gerador de NPs. Pode-se ver como o fluxo entrando pelo centro de um alvo cilíndrico favorece o escoamento de gás para fora do tubo cilíndrico, pois as NPs seguem o fluxo de gás e são carregadas por este fluxo. Também na Figura 4.10a, é possível perceber que o fluxo de gás é praticamente ausente na região de sputtering do canhão planar. Isso é uma vantagem clara do sistema com simetria radial.

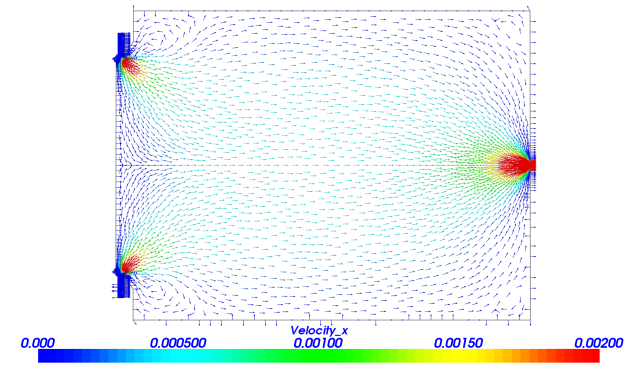

(a)

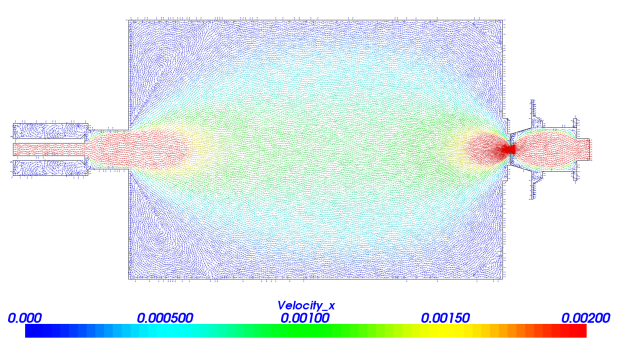

(b)

Figura 4.10: Comparação entre a simulação do fluxo de gás do GNP com canhão planar (a) e com canhão radial (b). A escala de cores é relativa à velocidade na horizontal em [m/s].

Com as simulações, não conseguimos identificar um fator específico para as quedas repentinas de deposição do sistema planar. Contudo, temos como hipótese que a queda de deposição deve ser causada pela passagem para um regime turbulento ao longo da operação do canhão planar. Isso explicaria por que a realização de um novo vácuo traz a volta de deposição. A volta à condição de vácuo pode permitir a recuperação da condição de fluxo lamelar, necessário para o funcionamento adequado do sistema.

As informações obtidas pelas simulações e a hipótese referente ao fluxo lamelar, foram indicativos de que o GNPR seria operacional. Assim, realizamos as primeiras tentativas de produção de NPs. Inicialmente optou-se pelo uso dos alvos de $\mathrm{Cu}$. $\mathrm{O}$ cobre é um material de baixo custo relativo e possui um sputtering yield de valor 2.0. Este valor é considerado elevado, facilitando, em princípio, o processo de sputtering e, portanto, a formação das NPs.

O que se observou foi uma alta quantidade de material depositada nas laterais da câmara de agregação. Isso se deve à variação abrupta de diâmetros ao longo da câmara, que gera uma variação brusca no fluxo. O diâmetro do alvo é de $12,5 \mathrm{~mm}$ enquanto o diâmetro da câmara de agregação é de $100 \mathrm{~mm}$. A simulação mostrada na Figura 4.11 indica que essa variação direciona o fluxo de gás e as NPs para as paredes da câmara de agregação e gera pequenas turbulências na saída do alvo cilíndrico. Isso foi resolvido com a adição de uma peça em formato cônico para minimizar o gradiente de velocidade na transição, como mostrado na Figura 4.11b. Uma grande quantidade 
de material acaba por ser depositado nesse cone, mas há um aumento significativo na quantidade de material retirado da câmara de agregação.

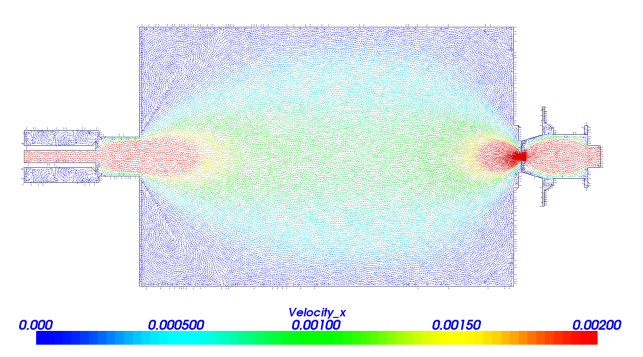

(a)

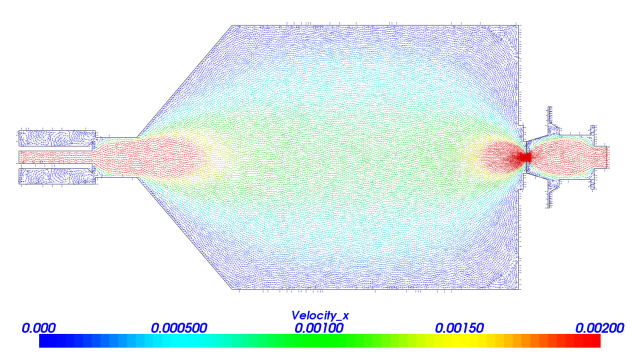

(b)

Figura 4.11: Comparação entre as simulações do fluxo de gás no GNPR sem parede angulada (a) e com parede angulada (b) sobre o canhão de MSR. A escala de cores é relativa à velocidade na horizontal em $[\mathrm{m} / \mathrm{s}]$.

Dessa forma, chegamos ao modelo final apresentado na Figura 4.12. O gerador de nanopartículas radial (GNPR) opera com potências entre 20 e $40 \mathrm{~W}$ para metais, resultando em correntes que variam entre 90 e $280 \mathrm{~mA}$ a depender do material e das condições de operação do equipamento. $O$ cobre apresenta uma corrente típica de $160 \mathrm{~mA}$ com uma potência de $40 \mathrm{~W}$. O cobalto, por sua vez, apresenta uma corrente típica de $115 \mathrm{~mA}$ na mesma potência.

O canhão de nanopartículas radial desenvolvido permitiu vantagens cruciais: além de possibilitar o uso simultâneo de 4 canhões de sputtering e o gerador de NPs. O sistema passou a se comportar de forma mais estável, inclusive para materiais magnéticos. Com isso, a manutenção foi facilitada, se resumindo, em geral, a limpeza do acumulo de material depositado nas peças e troca de alvos. 


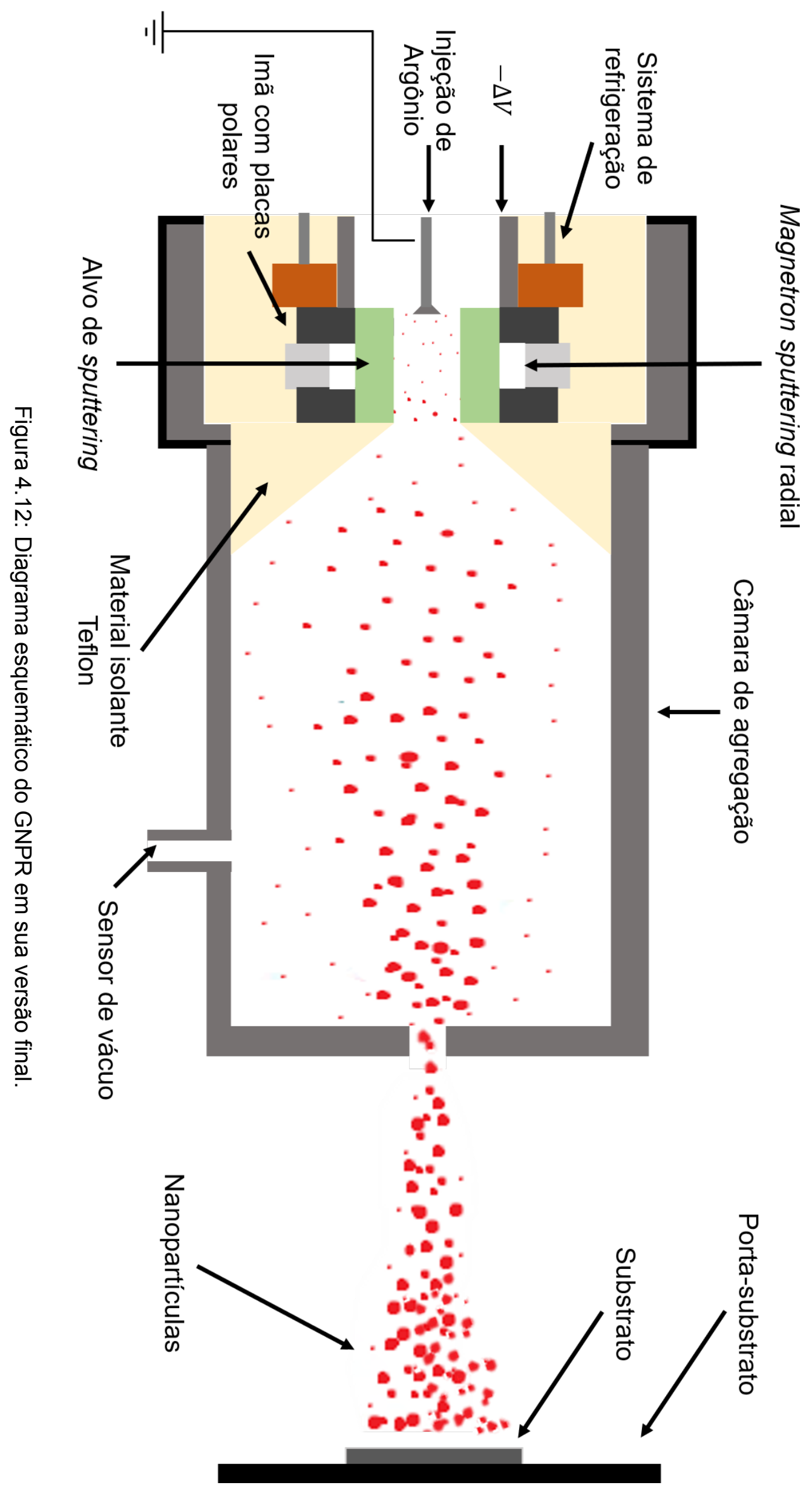




\subsection{Outras possibilidades de uso do canhão radial}

O canhão de sputtering radial foi projetado com o intuito de ser utilizado no gerador de nanopartículas. Contudo, o canhão foi construído de modo a poder operar como um quinto canhão para o sistema de sputtering. Para isso, basta remover a câmara de agregação e possuir um alvo cilíndrico do material de interesse. Em princípio, é possível produzir filmes finos a partir de alvos metálicos, utilizando a fonte DC.

É importante ressaltar que grande parte das dificuldades apresentadas no desenvolvimento do canhão se deve a condição de operação na câmara de agregação. Como vimos na Seção 4.2, as pressões dentro do gerador de NPs são muito maiores do que as pressões típicas de uma câmara de sputtering. Isso facilita a abertura de plasma em lugares indesejados, por exemplo. Contudo, esses problemas não ocorrem sem a presença da câmara de agregação. Quando em período de testes iniciais, o canhão foi capaz de produzir filmes de cobre e cobalto, utilizando potências de 20 a 40 W, sem apresentar problemas de operação. No entanto, para que o canhão radial seja utilizado na produção de filmes finos, o principal uso do nosso sistema de sputtering, é necessário um estudo dedicado quanto as suas condições e taxas de deposição de material. Esse estudo não foi realizado nesse projeto com o intuito de manter o foco na produção de NPs.

Outro aspecto a se considerar em relação às possibilidades do canhão radial, é a sua inspiração. No projeto de doutorado da Dra. Lima [38], um canhão de MSR foi desenvolvido para ser colocado no topo da câmara de agregação e revestir de cobre as NPs extraídas, ainda em voo. Sendo assim, existiu o interesse de se construir outro canhão de MSR para revestir as NPs magnéticas produzidas nesse projeto. $O$ revestimento tem o intuito de proteger as NPs de oxidação e isolar as NPs, evitando aglomerações de 2 ou mais NPs.

A construção de um novo canhão se mostrou necessário pois o interesse era no uso da prata como material de revestimento. Optou-se por um diâmetro do alvo semelhante ao do canhão do GNP, que permitisse o uso dos mesmos alvos em ambos canhões. Portanto, foi necessário o desenvolvimento de um canhão de revestimento compatível com as novas dimensões. A prata foi escolhida para que se pudesse estudar os plasmons de superfície de tal material. O novo canhão de revestimento foi construído e o seu esquema pode ser visto na Figura 4.13. O suporte do alvo é polarizado negativamente em relação ao bico ejetor da câmara de agregação, possibilitando o processo de sputtering. A peça de PVC é originada do canhão de revestimento da Dra. Lima e foi modificada de modo a permitir que o canhão, por ela construído com alvo de cobre, continue podendo ser usado. 
O canhão de revestimento foi capaz de produzir filmes de prata utilizando um fluxo de 80 sccm e uma potência de $3 \mathrm{~W}$. Contudo, não foi possível co-depositar NPs de cobalto quando o canhão de revestimento esteve em operação. A simulação de fluxos de gás foi realizada levando em consideração a presença do canhão de revestimento de prata, como vimos anteriormente. Contudo, observando a simulação e a operação do dispositivo, não foi possível obter uma hipótese do motivo que leva a esse comportamento. As condições de operação do GNPR juntamente ao canhão de revestimento ainda está sendo estudado e faz parte de futuros projetos do LMM-IFUSP. Portanto, as NPs produzidas nesse projeto não possuem o revestimento de prata, sendo compostas ou de cobre ou de cobalto apenas.

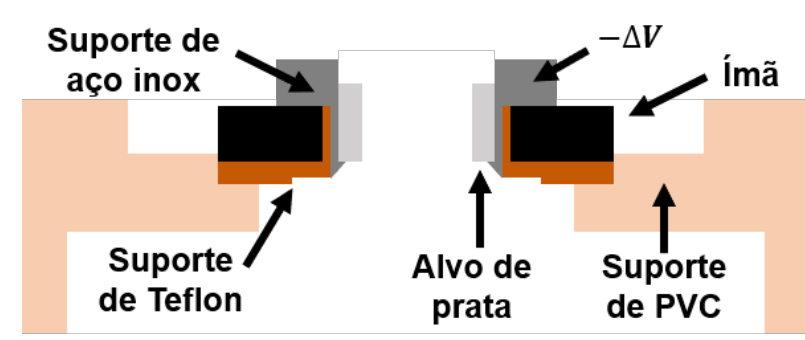

Figura 4.13: Diagrama esquemático do canhão de MSR desenvolvido para revestimento de NPs em voo. 


\section{Capítulo 5}

\section{Resultados experimentais}

As mudanças na geometria do sistema permitiram um aumento de estabilidade na produção de NPs. Com isso, foram produzidas amostras para diferentes análises. Em seguida, apresentamos os resultados obtidos.

\subsection{Parâmetros e aspectos visuais da deposição}

Testes foram realizados depositando NPs de cobalto sobre papel sulfite branco. A deposição em papel permite uma resposta rápida sobre o funcionamento do canhão de NPs, por possuir deposições na forma de manchas muito visíveis através da janela lateral da câmara do sistema de sputtering. O papel sulfite é usado pois as manchas geradas contrastam com o branco do papel, possibilitando análises qualitativa.

Foram testados bicos com saídas circulares de 2,0, 2,5, 3,0, 3,5 e 4,0 mm de diâmetro. Na Figura 5.1, são apresentadas exemplos de deposição de NPs realizadas no papel sulfite branco com as saídas de $2,5 \mathrm{~mm}$ e $3,0 \mathrm{~mm}$. As manchas foram escaneadas utilizando um scanner comercial de escritório Samsung modelo C4062FX. Ao variar fluxos de 70 a $120 \mathrm{sccm}$, na potência de 40W, pudemos notar consistência na variação da deposição com o fluxo. Bicos com saídas maiores do que $3,0 \mathrm{~mm}$ não permitem diferenciação visual das deposições de acordo com os fluxos. A potência foi escolhida levando em consideração que deposições com potências mais baixas não são visíveis. Cada deposição foi feita durante 1 minuto. Logo após a remoção do papel da câmara, a imagem é registada, para se antecipar à oxidação do metal, que ocorre rapidamente. Com a oxidação, a mancha se torna mais transparente, adquire coloração amarelada e a região mais externa da mancha se torna difícil de ser visualizada. O diâmetro de uma mancha é de $1 \mathrm{a} 2 \mathrm{~cm}$ e pode ser controlado com a intensidade do fluxo ou com o tamanho do furo de saída do gerador. A mancha não possui aspecto metálico como o de um filme, sendo escura. O caráter nanoparticulado do material é o responsável pelo confinamento da luz. 


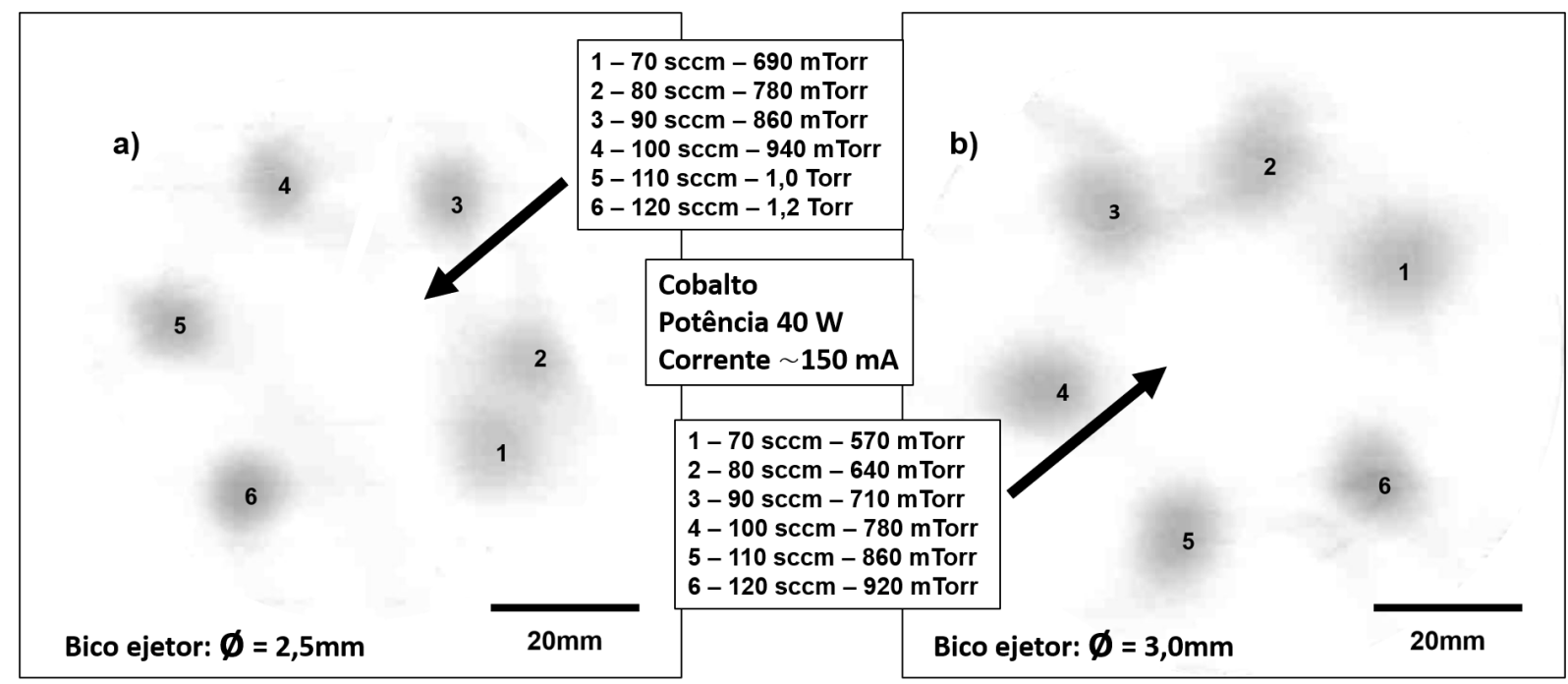

Figura 5.1: Imagens em folha de papel de NPs de cobalto depositado usando bico de saída circular de diâmetro (a) 2,5 mm e (b) 3,0 mm.

A Figura 5.1 também mostra que um bico de saída com maior diâmetro gera manchas com diâmetros maiores, o que pode indicar maior quantidade de material depositado. Contudo, nenhum dado confirma essa informação. Além disso, bicos de saída com maiores diâmetros necessitam, naturalmente, de maiores fluxos de Ar para alcançar as mesmas pressões de operação que saídas com diâmetro menores. Fluxos muito altos de operação, aumentam a possibilidade da existência de turbulências na câmara de agregação.

Na Figura 5.2 é possível ver a influência dos fluxos na quantidade de material depositada, com um gráfico em 3D e cores falsas para deposições com saída de 2,0 $\mathrm{mm}$. Percebe-se que o aumento de fluxo até $110 \mathrm{sccm}$ gera um aumento de deposição. Após esse valor crítico, pode-se ver uma queda de deposição. Isso ocorre pois fluxos mais intensos permitem o surgimento de um regime turbulento dentro do GNPR. É importante ressaltar que essa análise não apresenta uma quantificação do material depositado, mas apenas um indicativo da operação do sistema.

As imagens das manchas apresentam um perfil de intensidade gaussiano. É possível ajustar uma curva gaussiana bidimensional à imagem de cada mancha numa escala de cinza de 8 bits, como visto na Figura 5.3. A mancha corresponde à mancha 5 da Figura 5.2. O ajuste foi feito utilizando o software Image [ [49], um pacote de processamento de imagem que reúne vários plug-ins que facilitam a análise científica de imagens. Essa análise serviu de indicativo de que gerador de NPs com canhão radial gerava deposições de forma semelhante ao gerador de NPs planar, tendo padrões semelhantes aos vistos em análise por RBS [5]. 


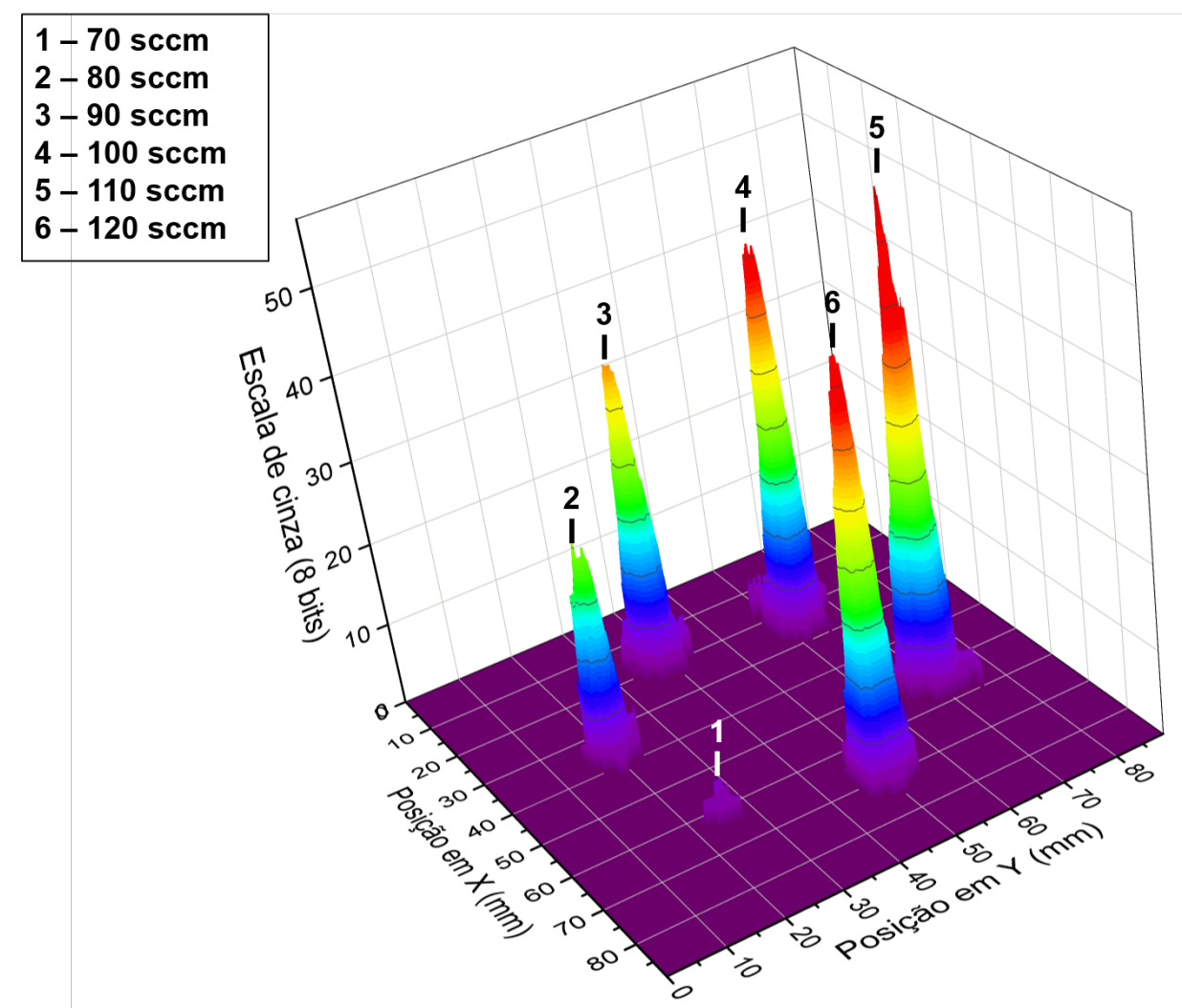

Figura 5.2: Intensidade das manchas de NPs de cobalto em diferentes fluxos na saída de 2.0 $\mathrm{mm}$. A escala de cores visa apenas facilidade de visualização.

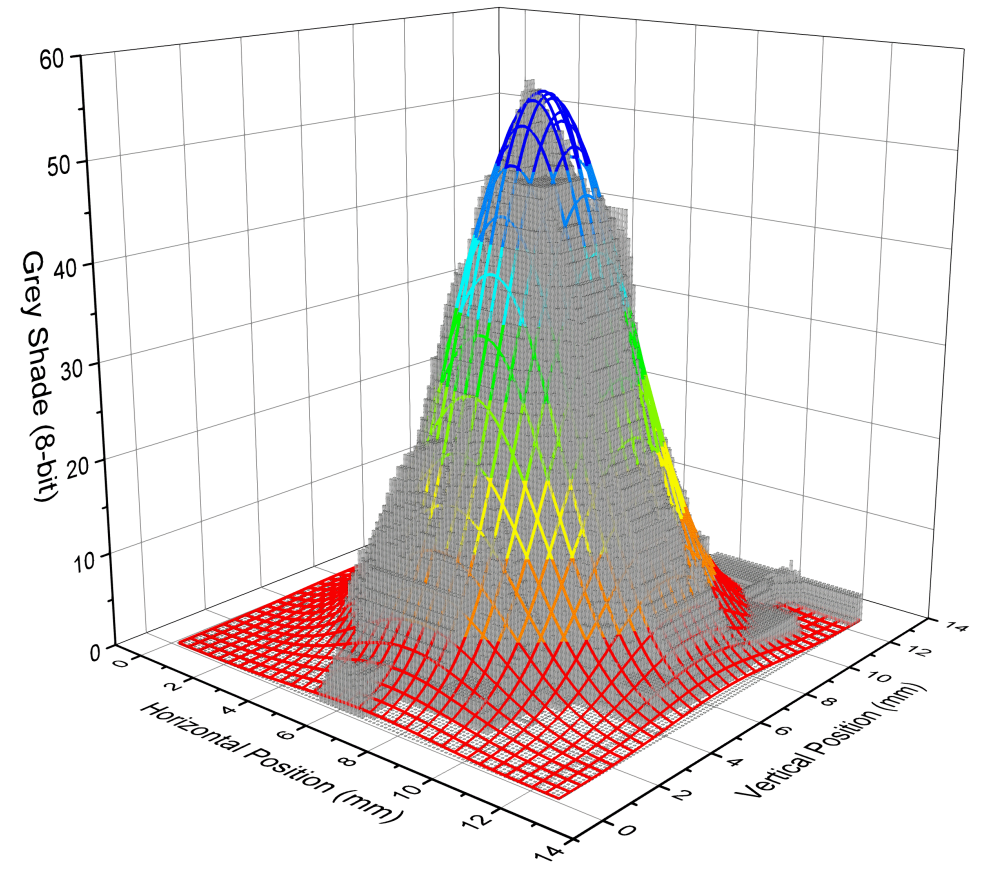

Figura 5.3: Gráfico do ajuste gaussiano à uma mancha de NPs de cobalto, correspondente à mancha 5 da Figura 5.2 . 


\subsection{Microscopia eletrônica de transmissão}

Tendo em vista o êxito na deposição de material, foram produzidas amostras de cobre e de cobalto para uma análise morfológica inicial no microscópio eletrônico de transmissão. As amostras foram produzidas com fluxo de Ar de $80 \mathrm{sccm}$, potência de $40 \mathrm{~W}$, em 1 min e com o substrato girando. As manchas das NPs depositadas possuem bordas com menor quantidade de material do que em seu centro. A deposição com o substrato girando é importante para que haja melhor distribuição das NPs.

\subsubsection{Nanopartículas de Cobre}

Na Figura 5.4 vemos a disposição das nanopartículas de cobre na grade. É perceptível que as NPs tendem a se aglomerar, formando pequenas estruturas. Até agora, não foi possível se determinar se esta aglomeração ocorre no substrato ou durante o processo de crescimento das NPs. Ainda assim é possível diferenciar as NPs entre si para medir seus respectivos tamanhos.

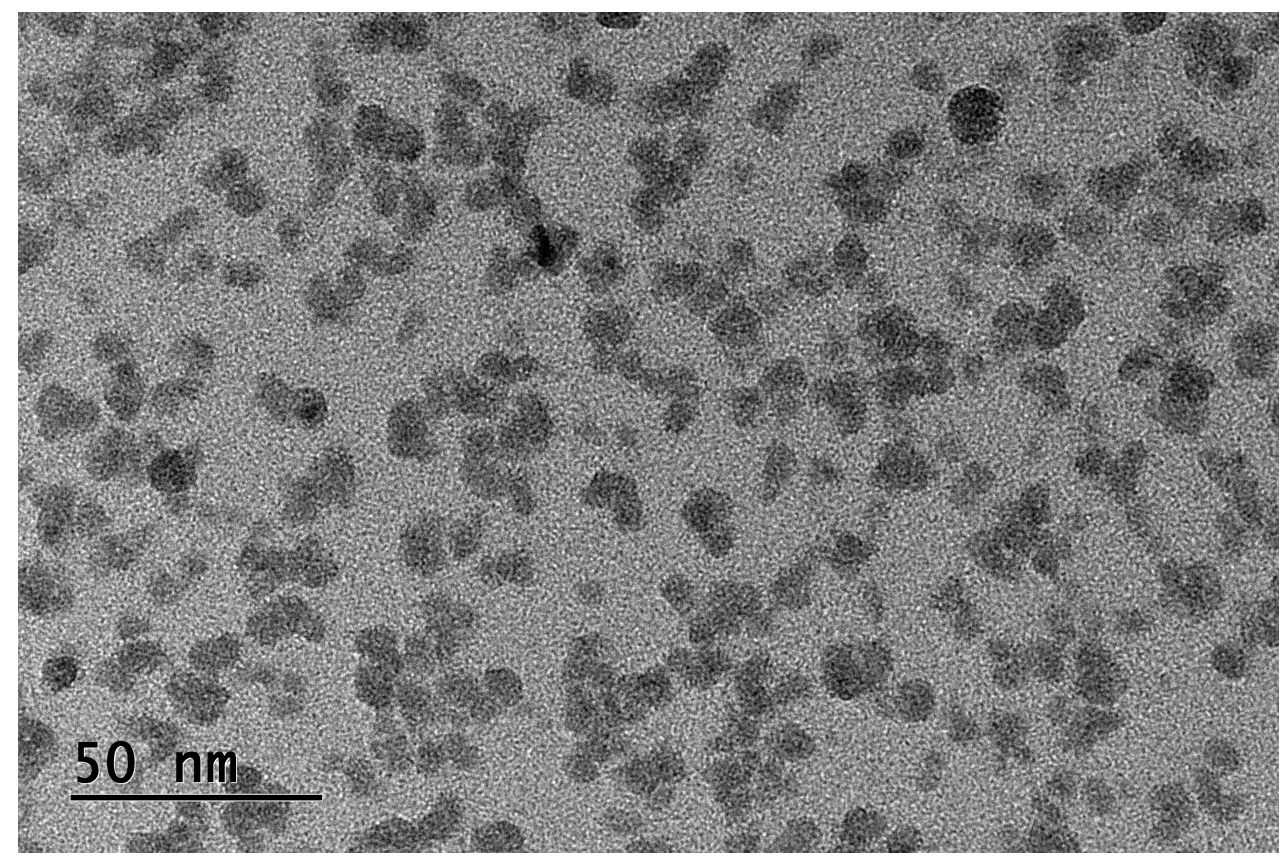

Figura 5.4: Imagem obtida por MET das NPs de cobre.

Utilizando as ferramentas do Image J, foi realizado o tratamento das imagens e seleções automatizadas, sendo possível separar zonas que representam uma NP. As imagens de microscopias possuem 10.7 megapixels. Para melhorar o contrate, subtraímos o fundo em cada imagem. Para a construção do fundo, foi realizada uma média de raio 500 pixels em torno de cada pixel. Em seguida, a imagem resultante da média é subtraída da imagem original. A diferença a olho nu é sutil, contudo isso facilita 
a diferenciação entre as NPs e o nível de fundo da imagem por parte do software. A Figura 5.5 ilustra a realização e o resultado da operação.
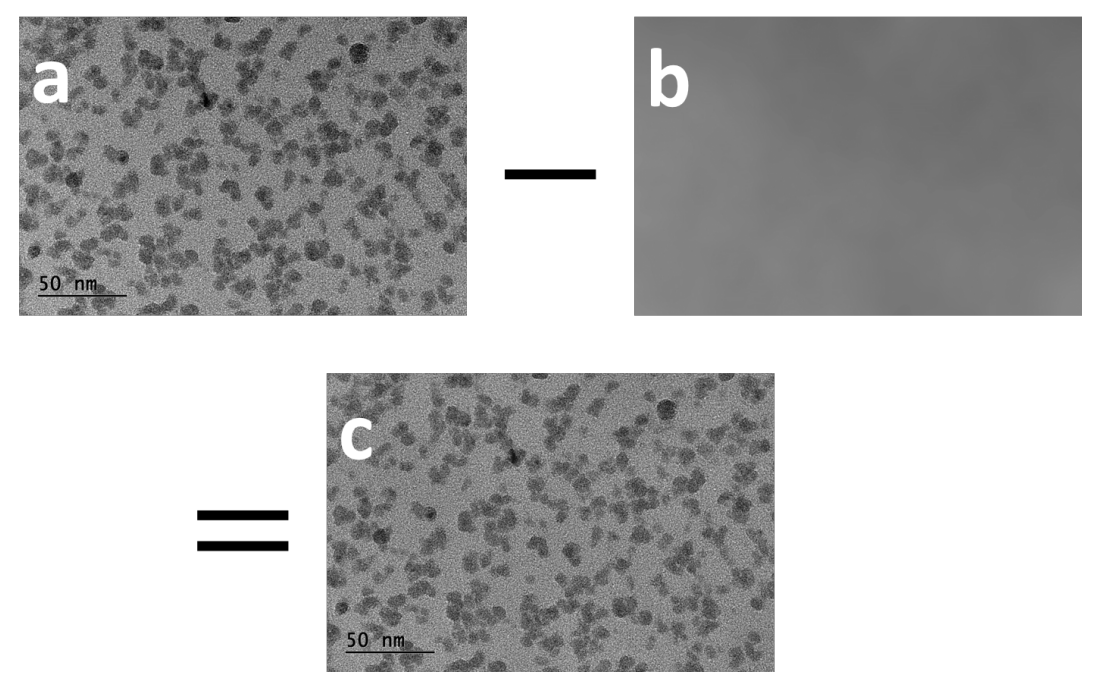

Figura 5.5: Método de subtração de fundo em imagem obtida por MET das NPs de cobre (a). Subtrai-se a média (b) resultando na imagem de microscopia com aumento de contraste (c).

Em seguida, foi aplicada uma média gaussiana ao longo de cada imagem resultante da operação ilustrada na Figura 5.5. Podemos ver um exemplo disso na Figura 5.6a. O objetivo foi uniformizar as zonas correspondentes a cada NP e melhor diferenciá-las do fundo. O raio aplicado variou de acordo com a imagem, indo de 10 a 25 pixels, de acordo com a escala. Utilizamos para a análise de tamanhos imagens com $50 \mathrm{~nm}$ e $20 \mathrm{~nm}$ de escala. Isso implica que a faixa de 10 a 25 pixels se traduz diâmetros de até $1,25 \mathrm{~nm}$ em todas as imagens. Partículas com diâmetros menores do que esse valor não tinham como serem diferenciadas do ruído de fundo antes ou depois do tratamento. Portanto, a média gaussiana permitiu que sempre fosse possível diferenciar partículas muito próximas entre si com uma incerteza de até $1 \%$ em partículas de diâmetro próximo a 1,25 nm. Em partículas maiores, o erro é ainda menor. Após isso, podemos aplicar nas imagens um limite na escala de cinza e torná-las binárias, representando as NPs em branco e o fundo em preto. A escala escrita na imagem também é removida.

A imagem obtida na Figura 5.6b mostra aglomerações de NPs. É possível utilizar a ferramenta Watershed do ImageJ, que realiza segmentação em imagens em preto e branco usando métodos de erosão e dilatação ao tratar os pixels da imagem como a topologia local de uma bacia hidrográfica [50]. Desse modo, a ferramenta separa os aglomerados de NPs, selecionando automaticamente cada região representando uma NP. Devido a limitações do algoritmo, algumas combinações de duas ou mais NPs são interpretadas como apenas uma. Além disso, resíduos do ruído de fundo são passíveis de serem interpretados como NPs. Portanto, ajustes finos também foram realizados manualmente. Partículas posicionadas nas bordas da microscopia não 
foram consideradas para evitar o uso de partículas exibidas parcialmente. Pode ser visto, na Figura 5.7, um exemplos de NPs selecionadas e a sua circunscrição sobreposta à imagem da MET. O ImageJ numera cada objeto encontrado e fornece uma tabela com sua posição, área e outras informações geométricas.

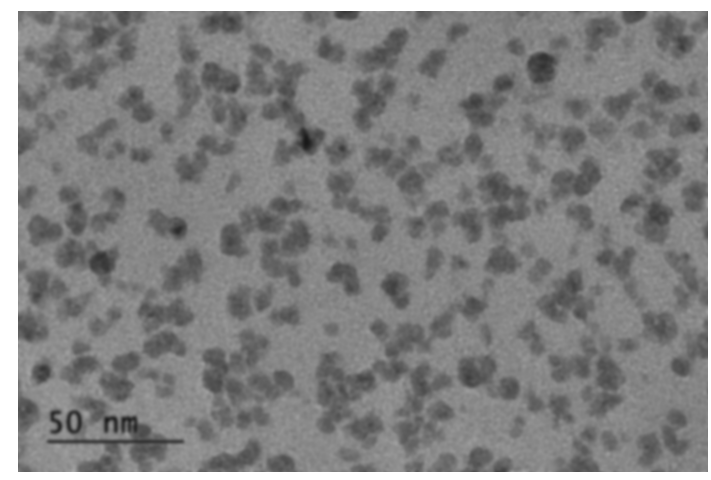

(a)

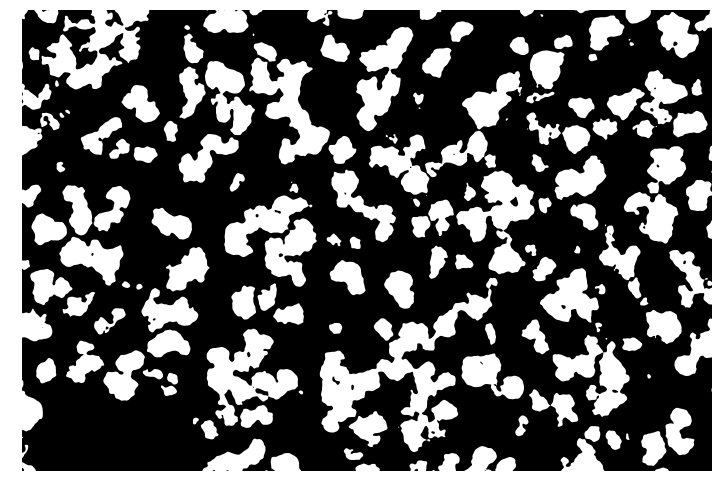

(b)

Figura 5.6: Média gaussiana aplicada à imagem obtida por MET com contraste melhorado (a) e limitação da escala de cinza aplicada às imagens com média gaussiana (b).

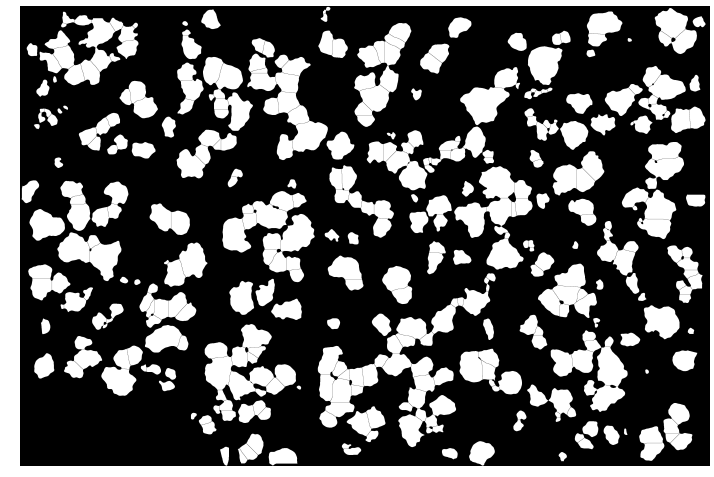

(a)

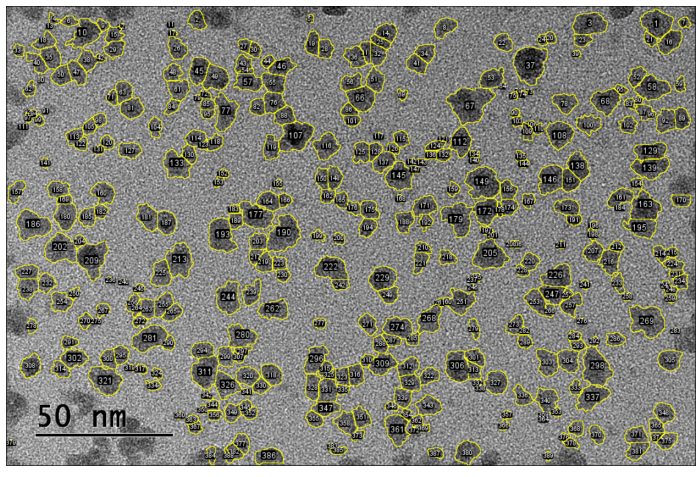

(b)

Figura 5.7: Exemplos de NPs de cobre selecionadas através do tratamento da imagem obtida por MET (a) e circunscrição das NPs de cobre selecionadas na imagem obtida por MET (b).

Dessa forma, é possível medir as áreas na figura e, assumindo que as NPs são esféricas, calcular os respectivos diâmetros efetivos. Ajustamos uma distribuição log-normal em função dos diâmetros obtidos $D$, seguindo a função densidade de probabilidade

$$
\operatorname{PDF}(D)=\frac{1}{D w \sqrt{2 \pi}} \exp \left[-\frac{(\ln D-\mu)^{2}}{2 w^{2}}\right],
$$

na qual $\mu$ é a média e $w$ é o desvio padrão, ambos em escala logarítmica. Assim, em escala natural, o diâmetro médio é $D_{m}=\exp \left(\mu+\frac{w^{2}}{2}\right)$ e o desvio padrão é $\sigma=$ $D_{m} \sqrt{e^{w^{2}}-1}$. 
Na Figura 5.8, comparamos a distribuição de tamanhos dos aglomerados de NPs e das NPs separadas após o tratamento apresentado na Figura 5.7. Os aglomerados possuem diâmetro médio $D_{m}^{A}=9,1(2) \mathrm{nm}$ com um desvio padrão $\sigma^{A}=7,6(1)$ $\mathrm{nm}$. O ajuste da distribuição log-normal aos diâmetros de NPs segmentadas resultou num valor médio $D_{m}=5,79(8) \mathrm{nm}$ com um desvio padrão $\sigma=2,97(5) \mathrm{nm}$. Isso indica que, de fato, existe uma aglomeração de NPs durante a produção e deposição no substrato.

Na Figura 5.9, temos a comparação entre as curvas das log-normais ajustadas, porém em uma mesma escala. As curvas foram normalizadas com área 1 para facilitar a comparação. É perceptível que os aglomerados de NPs possuem uma distribuição tamanhos mais larga do que a distribuição de NPs.

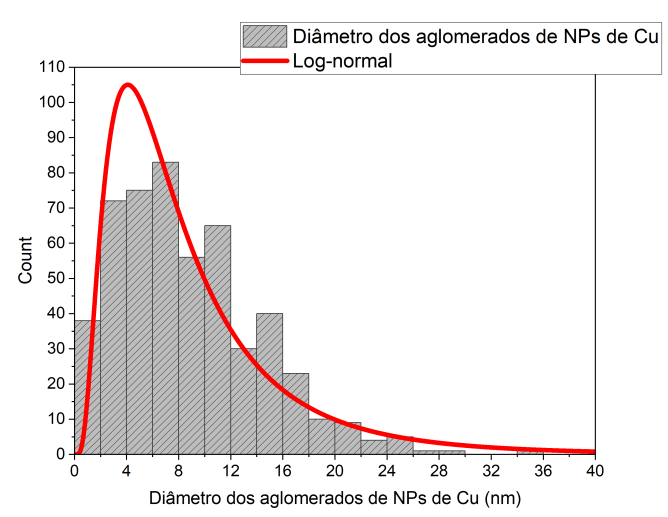

(a)

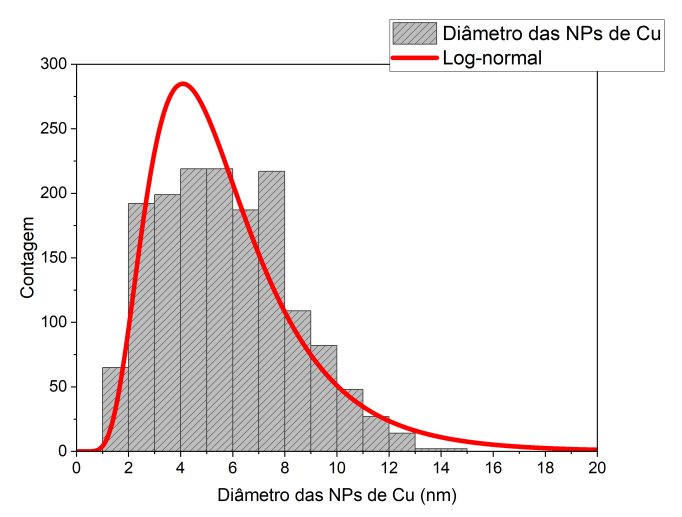

(b)

Figura 5.8: Distribuição de diâmetros de aglomerados e NPs de Cu (a) e distribuição de diâmetros de NPs de $\mathrm{Cu}(\mathrm{b})$.

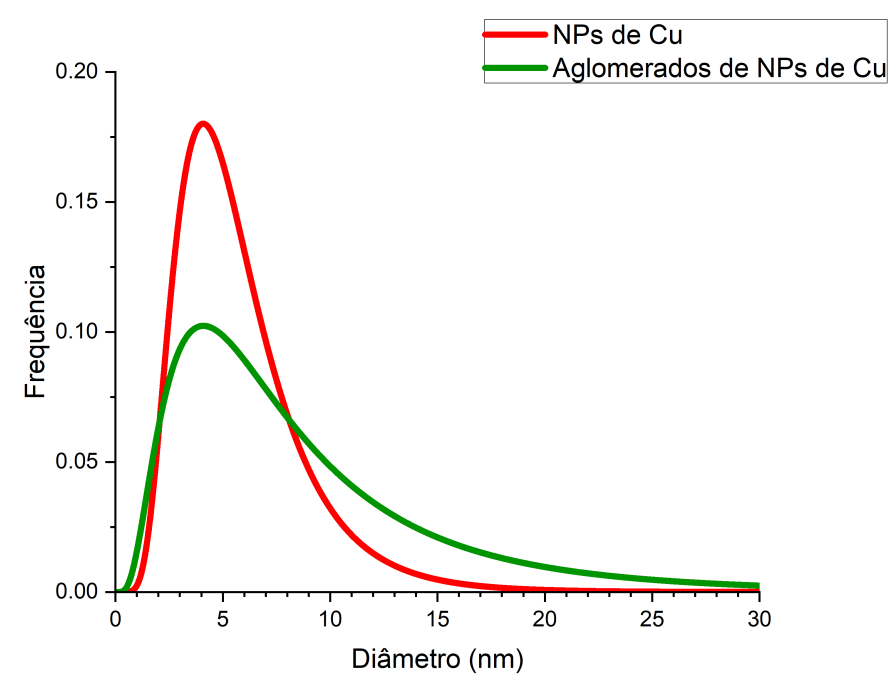

Figura 5.9: Comparação entre as PDFs de diâmetros para NPs de Cu aglomeradas e segmentadas. 
Considerando a resolução das micrografias, é possível encontrar partículas isoladas. Nestas, é possível perceber a presença de planos cristalinos. Na Figura 5.10, temos partículas em específico, onde os planos cristalinos podem ser visualizados. Podemos identificar a distância interplanar aplicando a transformada rápida de Fourier (FFT) em uma pequena região, marcada pelo quadro em vermelho, para observar a frequência de aparição dos planos, como visto na Figura 5.10. No quadro expandido, temos o resultado da FFT, onde podemos determinar a distância interplanar. Sendo assim, foi obtido um valor $d=0,25(1) \mathrm{nm}$, compatível com valor esperado para os planos (110) da estrutura FCC do cobre que é $0,2556 \mathrm{~nm}$, calculado pela equação

$$
d_{h k l}=\frac{a}{\sqrt{h^{2}+k^{2}+l^{2}}}
$$

nos quais $d_{h k l}$ é a distância entre os planos cristalinos, $a=0,3615$ nm é o parâmetro de rede e $(h k l)$ são o índices de Miller.

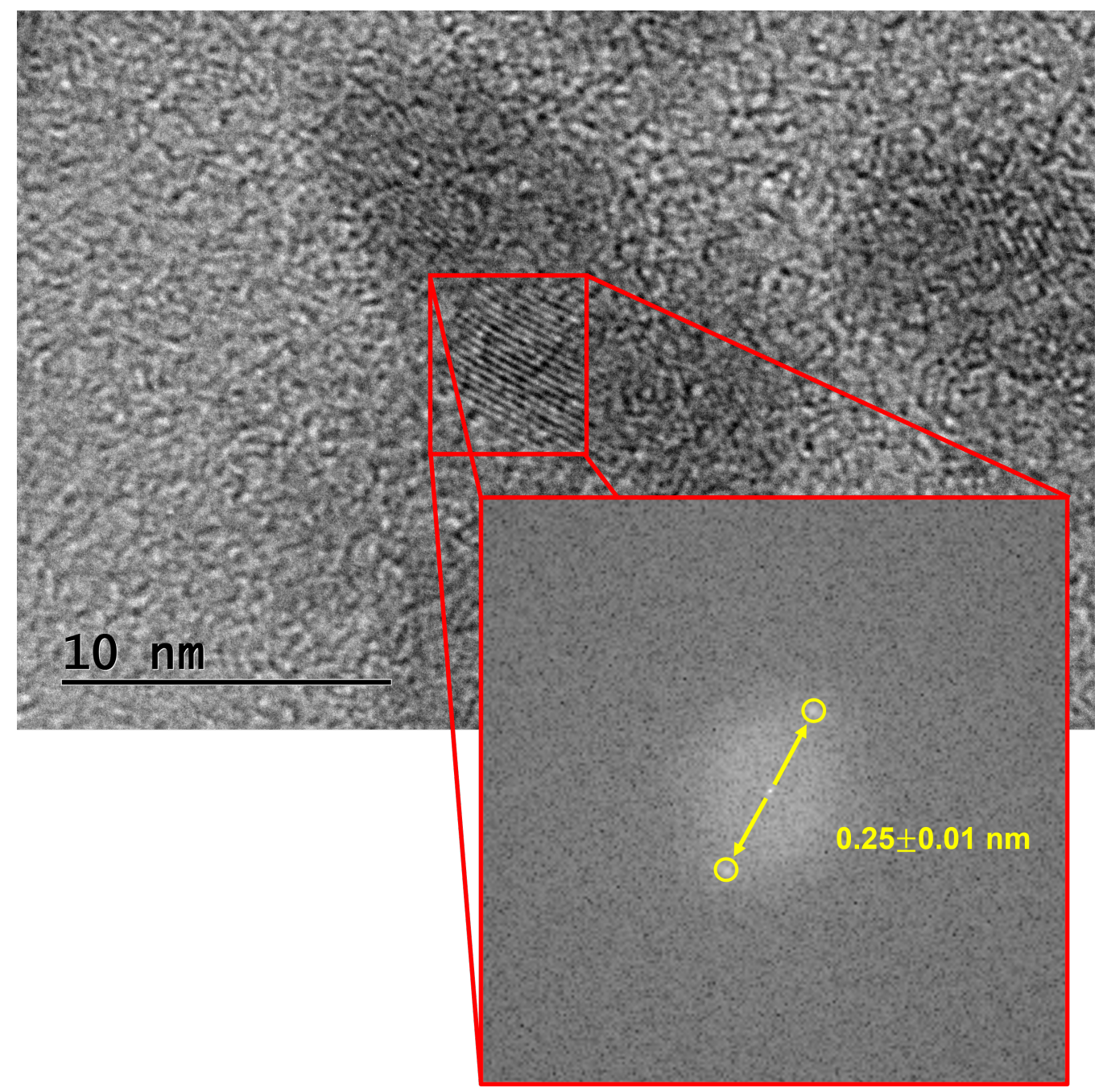

Figura 5.10: Imagem obtida por MET mostrando a presença de planos cristalinos nas NPs de cobre. O quadro vermelho indica a região onde é aplicada a FFT para obtenção das distâncias interplanares e o resultado obtido. 


\subsubsection{Nanopartículas de Cobalto}

Em seguida, passamos à produção de NPs de Co. Para isto foi usinado um alvo cilíndrico usando-se o material. $O$ alvo de cobalto tem $13 \mathrm{~mm}$ de comprimento, diâmetro interno de $12.5 \mathrm{~mm}$ e parede com $2 \mathrm{~mm}$ de espessura. Com este alvo usamos a potência de $40 \mathrm{~W}$ e o fluxo de $\mathrm{Ar}$ de $80 \mathrm{sccm}$. Mais uma vez, a amostra foi produzida com o substrato girando. Vimos que o desbaste do alvo devido ao processo de sputtering ficou localizado na região central do alvo.

$\mathrm{Na}$ Figura 5.11, vemos uma imagem MET para uma amostra com NPs de cobalto, onde podemos ver a disposição das nanopartículas de cobalto na grade para microscopia. É perceptível a mesma tendência de aglomeração observada nas NPs de cobre.

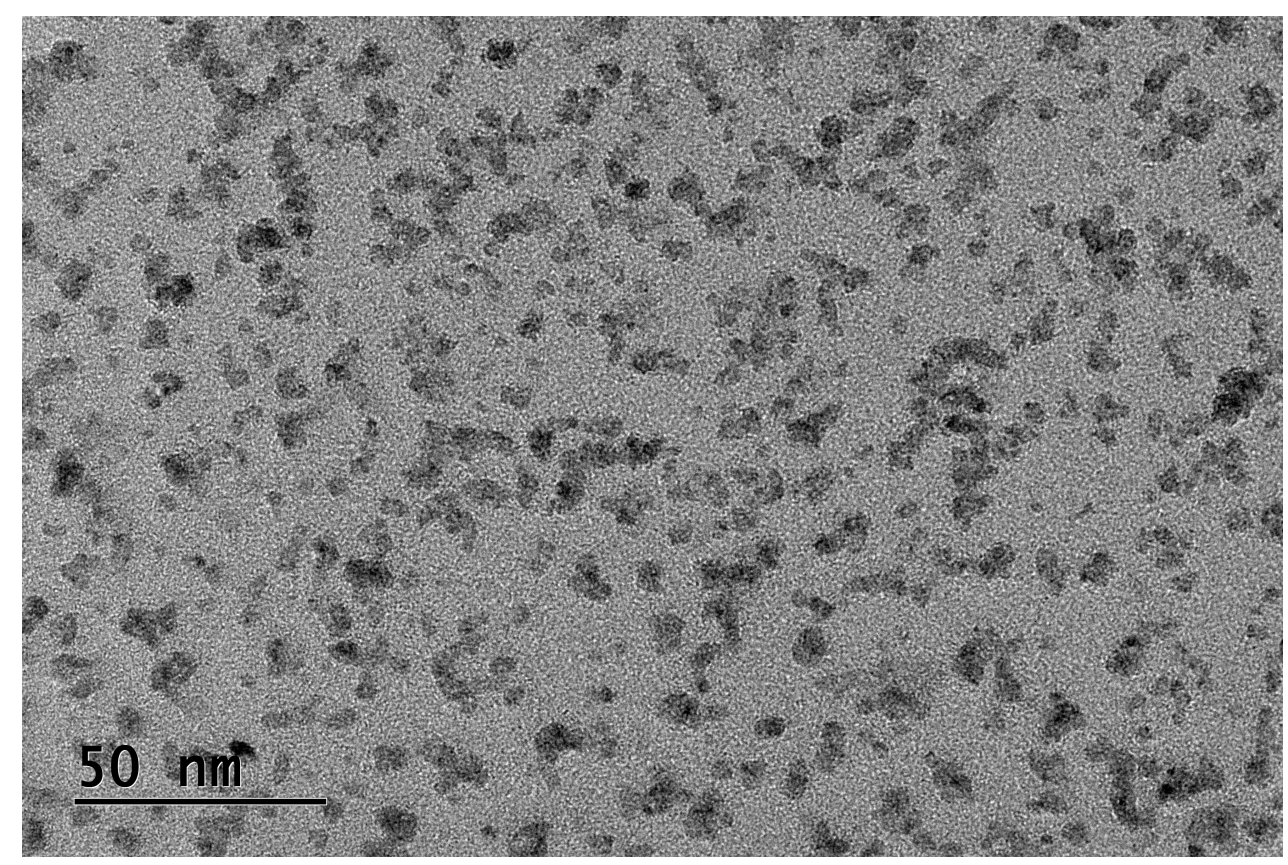

Figura 5.11: Imagem obtida por MET das NPs de cobalto.

Mantendo a metodologia de processamento de imagens usada com a amostra de cobre, determinamos a distribuição de tamanhos das NPs. A Figura 5.12 mostra as distribuições de tamanho para aglomerados e NPs segmentadas e a Tabela 5.1 mostra todas os resultados de tamanhos obtidos. $\mathrm{O}$ ajuste da distribuição log-normal resulta num diâmetro médio $D_{m}^{A}=5,17(7)$ com um desvio padrão $\sigma^{A}=3,64(5) \mathrm{nm}$ para os aglomerados de NPs. Por outro lado, o ajuste da distribuição log-normal aos diâmetros de NPs resultou num valor médio $D_{m}=3,88(3) \mathrm{nm}$ com um desvio padrão $\sigma=1,74(2)$ $\mathrm{nm}$. Novamente, existe aglomeração de NPs durante a produção e deposição das NPs. Na Figura 5.13, vemos as curvas das log-normais ajustadas em cada caso e normalizadas. Novamente, como era de se esperar, percebemos que os aglomerados de NPs possuem uma distribuição tamanhos mais larga do que a distribuição de NPs. 
Como o cobre tem um alto sputter yield, é esperado que as NPs de cobalto sejam tipicamente menores que as de cobre. Podemos observar a comparação das curvas ajustadas para os diâmetros das NPs de Cu e das NPs de Co na Figura 5.14. É visível a diferença dos diâmetros médios e que a distribuição de NPs de Cu é a mais larga. O cobre é capaz de sofrer o processo de sputtering pela ação de seus próprios íons removidos do alvo, chamado self-sputtering [51]. É possível que esse processo secundário contribua para que haja uma maior variedade de tamanhos nas NPs de Cu.

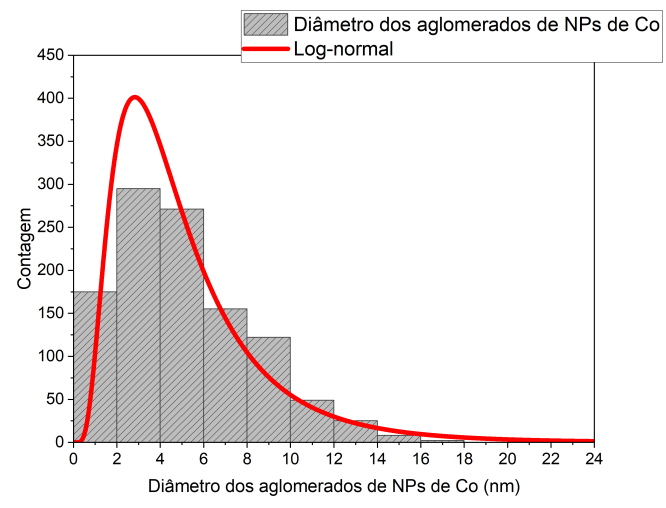

(a)

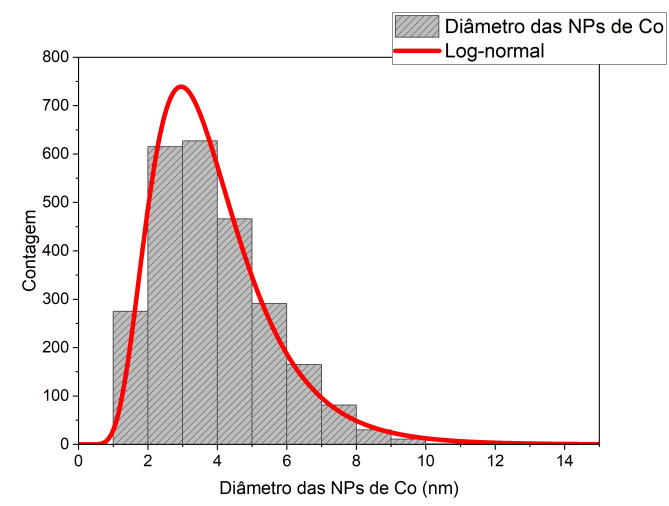

(b)

Figura 5.12: Distribuição de diâmetros de aglomerados de NPs de Co (a) e distribuição de diâmetros de NPs de Co (b).

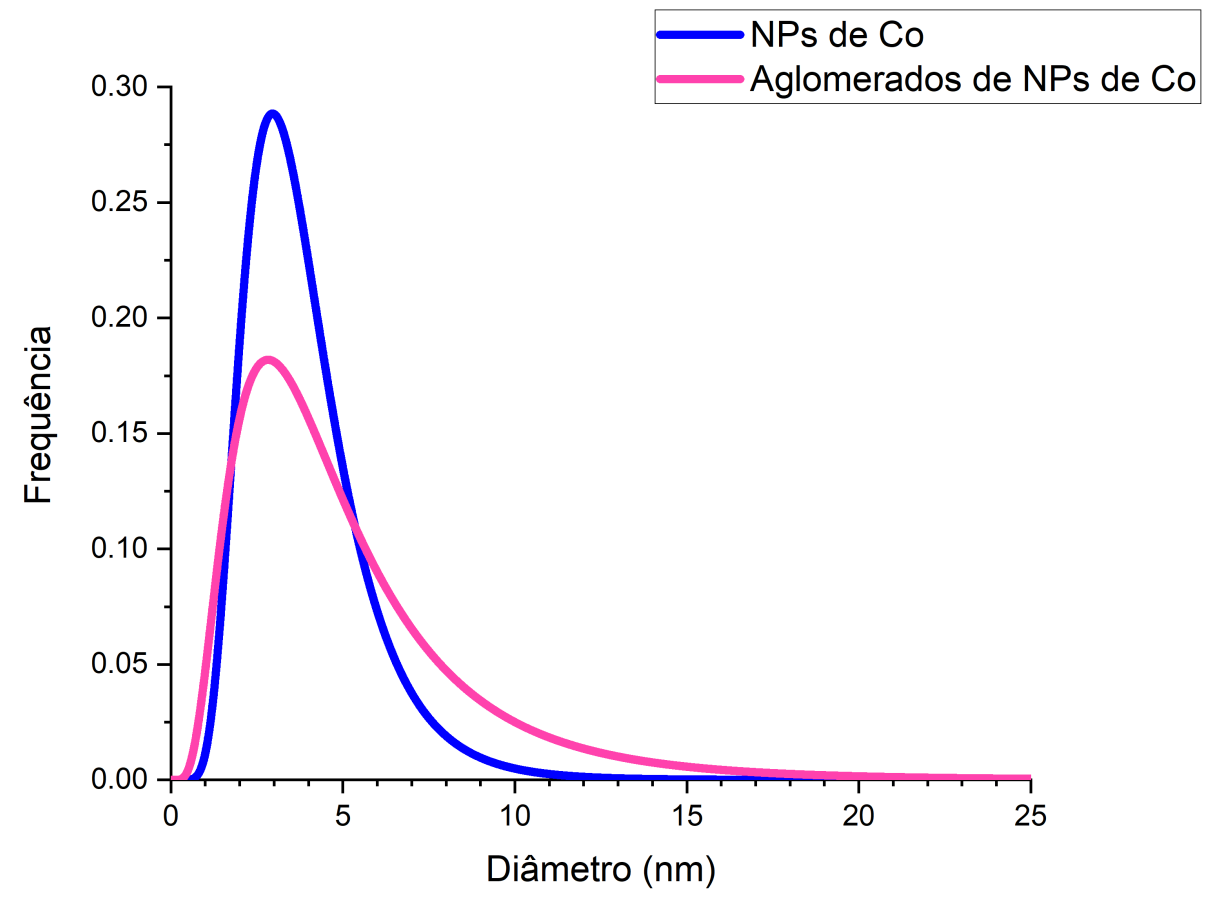

Figura 5.13: Comparação entre as PDFs de diâmetros para NPs de Co aglomeradas e segmentadas. 


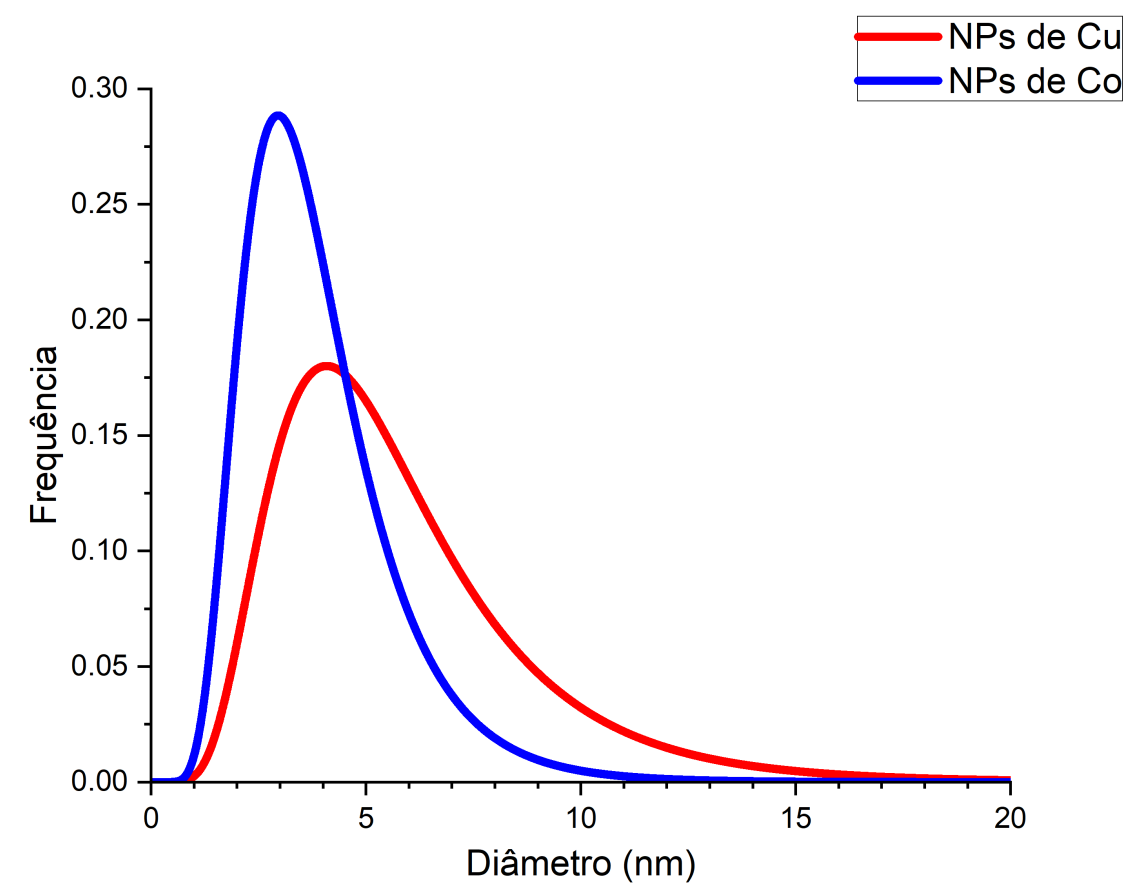

Figura 5.14: Comparação entre as PDFs de diâmetros para NPs de Cu e NPs de Co.

\begin{tabular}{|c|c|c|}
\hline Amostra & Diâmetro médio (nm) & Desvio-padrão $(\mathrm{nm})$ \\
\hline Aglomerado de NPs de Cu & $9,1(2)$ & $7,6(1)$ \\
NPs de Cu & $5,79(8)$ & $2,97(5$ \\
Aglomerado de NPs de Co & $5,17(7)$ & $3,64(5)$ \\
NPs de Co & $3,88(3)$ & $1,74(2)$ \\
\hline
\end{tabular}

Tabela 5.1: Tamanhos de partículas obtidos por análise de imagens obtidas por MET.

Com o cobalto, percebe-se, mais uma vez, a presença de planos cristalinos, como mostrado na Figura 5.15. Novamente, podemos usar a FFT numa pequena região de interesse. Obtemos uma distância interplanar $d=0,21(1) \mathrm{nm}$, compatível com o valor esperado de $0,2042 \mathrm{~nm}$ para os planos (111) da estrutura FCC calculado pela Equação 5.2 ou com o valor esperado de $0,2045 \mathrm{~nm}$ para a distância dos planos (002) da estrutura HCP, calculado pela equação

$$
\frac{1}{d_{h k l}^{2}}=\frac{4}{3}\left(\frac{h^{2}+h k+k^{2}}{a^{2}}\right)+\frac{l^{2}}{c^{2}}
$$

nos quais $d_{h k l}$ é a distância entre os planos cristalinos, $a=0,2505 \mathrm{~nm}$ e $c=0,4089$ $\mathrm{nm}$ são os parâmetros de rede e $(h k l)$ são o índices de Miller. É natural que essa compatibilidade, tendo em vista a equivalência das distâncias planos (111) da FCC com os planos (002) da HCP.

A estrutura cristalina do Co permite, também, a identificação de padrões hexagonais nas imagens. A Figura 5.16 mostra os padrões hexagonais, bem como a 
FFT aplicada à região de interesse destacada pelo quadrado em vermelho. Aplicando a FFT, obtemos um valor de $0,26(1) \mathrm{nm}$ na periodicidade, sendo compatível com o parâmetro de rede de $0,2505 \mathrm{~nm}$ da estrutura HCP do Co.

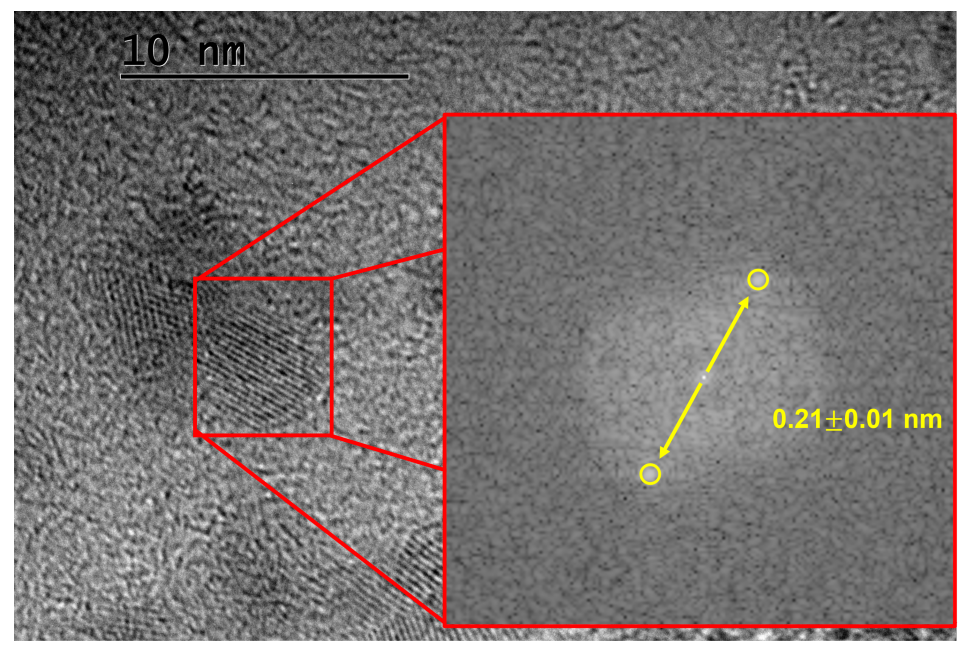

Figura 5.15: Imagem obtida por MET mostrando a presença de planos cristalinos nas NPs de cobalto. O quadro vermelho indica a região onde é aplicada a FFT para obtenção das distâncias interplanares e o resultado obtido.

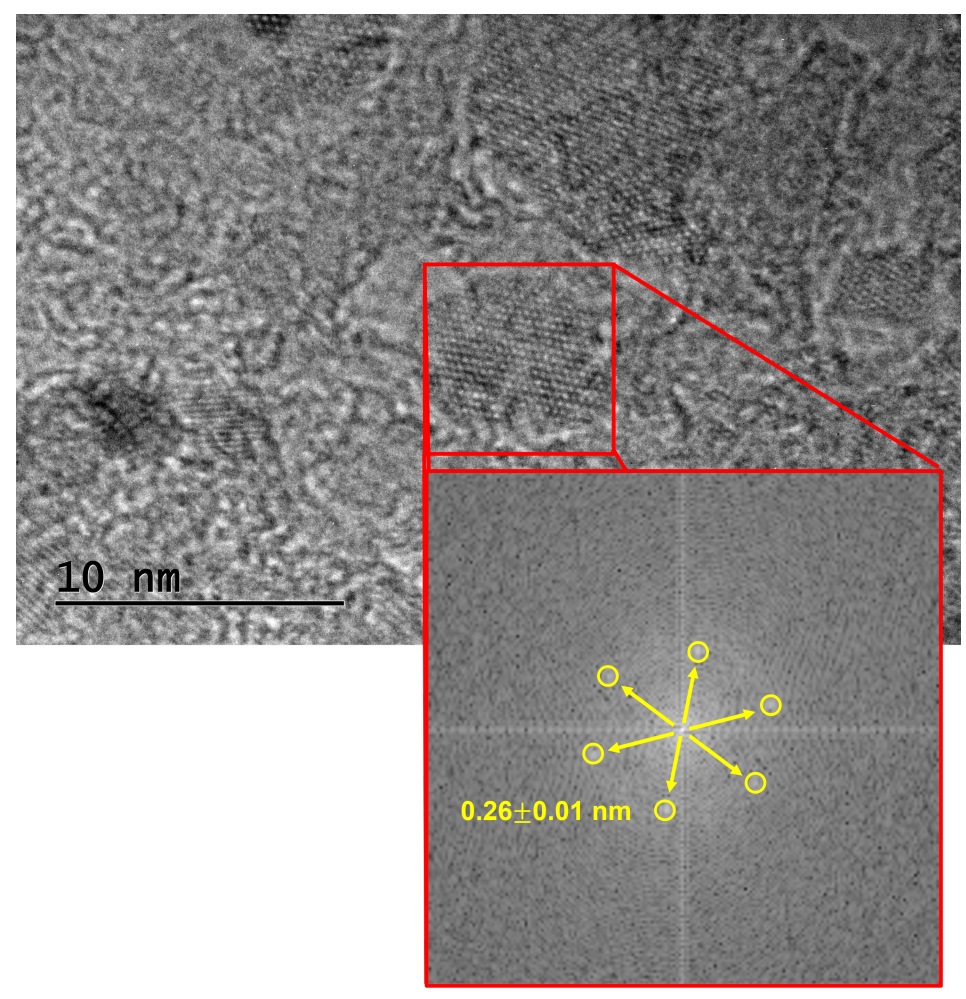

Figura 5.16: Imagem obtida por MET mostrando a presença do padrão haxagonal da estrutura cristalina das NPs de cobalto. O quadro vermelho indica a região onde é aplicada a FFT para obtenção do parâmetro de rede e o resultado obtido. 


\subsection{Magnetômetro de amostra vibrante}

Tendo em vista o objetivo desse trabalho, a caracterização magnética das NPs de cobalto é essencial. A Figura 5.17 mostra uma curva de histerese de NPs de Co depositadas num substrato de Kapton. Pelo tamanho das NPs de cobalto é de se esperar que as mesmas possuam comportamento superparamagnético. Contudo, é visível que a curva possui um comportamento ferromagnético, com a presença de campo coercivo da ordem de $100 \mathrm{Oe}$. A amostra utilizada para medida foi produzida com um fluxo de $\operatorname{Ar}$ de 80 sccm, com potência de $40 \mathrm{~W}$ e num intervalo de 5 minutos e 30 segundos. $O$ tempo foi escolhido para que houvesse uma maior quantidade de material. A medida foi realizada com com um campo máximo de $2 \mathrm{kOe}$. No gráfico, vemos o intervalo de -300 Oe a 300 Oe e linhas tracejadas vermelhas lingando os pontos para melhor visualização da histerese da amostra. A presença de histerese se explica pela aglomeração das NPs, formando estruturas de maior dimensão, como visto na Subseção 5.2 .2 .

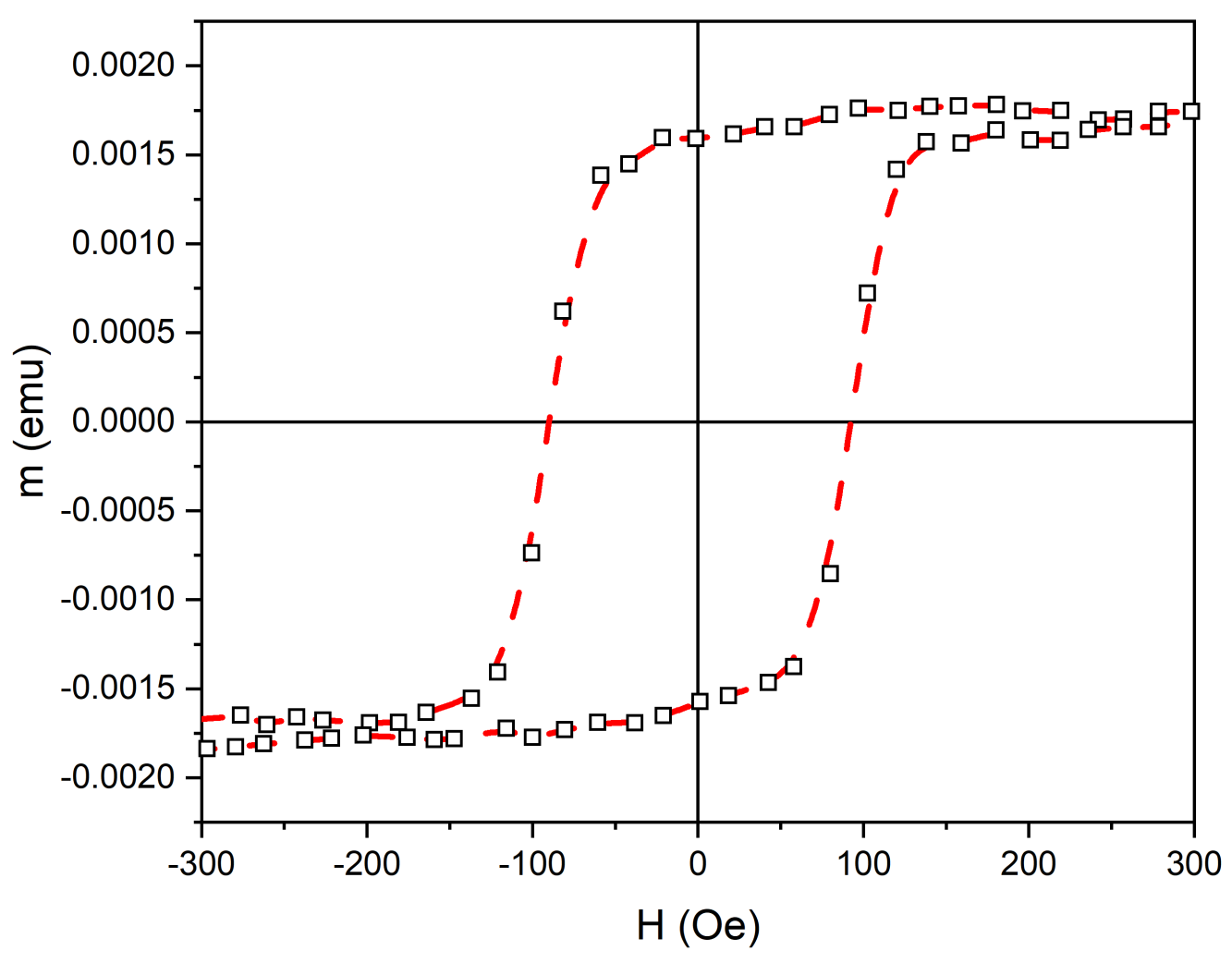

Figura 5.17: Curva de histerese de uma amostra de NPs de Co depositadas por 5 minutos e 30 segundos em substrato de Kapton. As linhas tracejadas vermelhas ligam os pontos para melhor visualização da histerese da amostra. 


\subsubsection{Nanopartículas de cobalto co-depositadas com material die- létrico}

Para que o comportamento superparamagnético esperado apareça, é necessário isolar as NPs. Essa necessidade já havia sido prevista e foi uma da motivações para o canhão de revestimento, já discutido na Sessão 4.3. Contudo, o canhão de revestimento não pôde ser concluído nesse projeto, pois não foram achados parâmetros adequados que permitissem o funcionamento simultâneo do GNPR e do canhão de revestimento. Assim, optou-se pela co-deposição de um material dielétrico com as NPs de Co, utilizando um dos canhões de sputtering do equipamento e a fonte RF. O material escolhido foi o nitreto de silício $\left(\mathrm{Si}_{3} \mathrm{~N}_{4}\right)$, por ser um material com alvo disponível no LMM-IFUSP e de parâmetros de deposição conhecidos.

O $\mathrm{Si}_{3} \mathrm{~N}_{4}$ é um material com baixa taxa de deposição. É esperado que filmes com menos de $5 \mathrm{~nm}$ sejam produzidos num período de 2 minutos. Por outro lado, era esperado que filmes nessa escala fossem capazes de isolar, ao menos, camadas sobrepostas de NPs. Assim, decidimos produzir amostras em substrato de Kapton novamente e de duas formas diferentes, mas que permitem comparações.

A primeira amostra foi produzida mantendo-se uma deposição constante de $\mathrm{Si}_{3} \mathrm{~N}_{4}$ com um fluxo de $80 \mathrm{sccm}$ e $200 \mathrm{~W}$ de potência na fonte RF e NPs de Co foram co-depositadas. Chamaremos essa amostra de NP-intercalado, por haver, em princípio, um intercalação de $\mathrm{Si}_{3} \mathrm{~N}_{4}$ envolvendo as NPs de Co. Primeiramente, foi depositada uma camada de apenas $\mathrm{Si}_{3} \mathrm{~N}_{4}$ durante 3 minutos. Em seguida, começou a co-deposição de NPs de Co de forma intervalada a uma potência de $60 \mathrm{~W}$. A potência foi maior do que nas amostra anteriores para que houvesse uma maior quantidade de material e resultasse num sinal de maior intensidade no VSM. As NPs eram depositadas durante 30 segundos a cada 2 minutos. Esse processo foi realizado 10 vezes, equivalendo à deposição de 5 minutos de NPs. Após a última deposição de NPs, o canhão de $\mathrm{Si}_{3} \mathrm{~N}_{4}$ foi mantido ligado por 5 minutos para o revestimento final da amostra. Esse processo foi realizado esperando-se que as NPs de Co ficassem envolvidas numa matriz dielétrica semelhante ao esquema apresentado na Figura 5.18a. Era esperado que essa amostra apresentasse o comportamento superparamagnético e que a matriz dielétrica evitasse a oxidação das NPs.

Por outro lado, a segunda amostra foi produzida em três camadas, semelhante ao esquema apresentado na Figura 5.18b. Chamaremos essa amostra de NP-revestido, por haver uma camada inferior e uma camada superior revestindo o conjuntos das NPs. A primeira camada é composta de $\mathrm{Si}_{3} \mathrm{~N}_{4}$ depositado durante 3 minutos. A camada de NPs de Co foi depositada da mesma forma intervalada que a amostra NP-intercalado, porém sem o $\mathrm{Si}_{3} \mathrm{~N}_{4}$. Existe um intervalo de tempo não determinado entre ligar a fonte que fornece o potencial elétrico e o início da deposição de NPs. Portanto, manter a 
deposição intervalada de NPs é importante para garantir que a mesma quantidade de material fosse depositada em ambas amostras, permitindo uma melhor comparação dos resultados. Por fim, foi produzida uma camada de $\mathrm{Si}_{3} \mathrm{~N}_{4}$ depositado durante 5 minutos, com o intuito de evitar a oxidação das NPs.

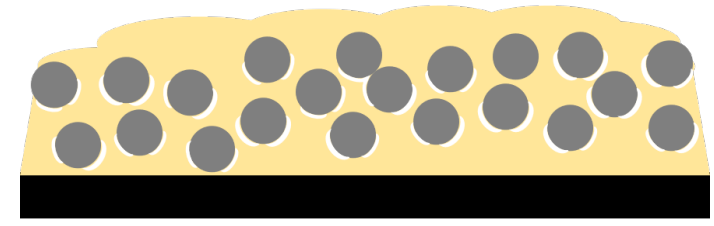

(a)

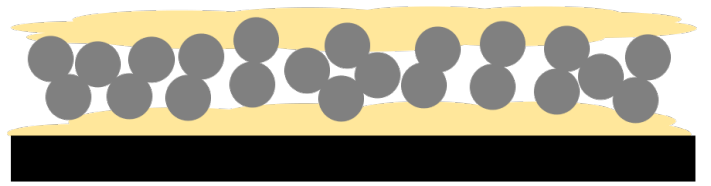

(b)

Figura 5.18: Diagramas esquemáticos das amostras produzidas através da co-deposição de $\mathrm{Si}_{3} \mathrm{~N}_{4}$ e NPs de Co. Vemos (a) NPs co-depositadas com $\mathrm{Si}_{3} \mathrm{~N}_{4}$ sobre uma camada de $\mathrm{Si}_{3} \mathrm{~N}_{4} \mathrm{e}$ recobertas por uma segunda camada de $\mathrm{Si}_{3} \mathrm{~N}_{4}$ em um substrato de Kapton e (b) NPs depositadas sobre uma camada de $\mathrm{Si}_{3} \mathrm{~N}_{4}$ e recobertas com uma segunda camada de $\mathrm{Si}_{3} \mathrm{~N}_{4}$ em um substrato de Kapton.

Com essas amostras, obtivemos curvas de histerese no VSM à temperatura ambiente, realizando-se medidas com um campo máximo de 5 kOe. Na Figura 5.19, vemos as curvas obtidas para as amostras NP-intercalado em azul e NP-revestido em vermelho. Ambas amostras apresentam comportamento superparamagnético associado a um comportamento diamagnético do substrato. A amostra NP-intercalado apresenta, ainda, campo coercivo da ordem de 140 Oe. Não foi possível encontrar uma hipótese que explique adequadamente esse comportamento aparecer apenas na amostra NP-intercalado. Contudo, isso indica que a quantidade de $\mathrm{Si}_{3} \mathrm{~N}_{4}$ depositada não foi suficiente para isolar totalmente as NPs na amostra NP-intercalado. A amostra NP-revestido não apresenta campo coercivo e possui um sinal de intensidade 5 vezes maior do que NP-intercalado.

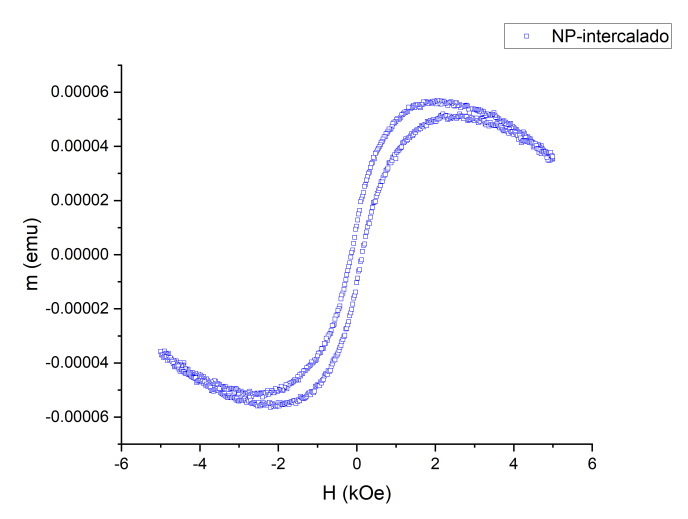

(a)

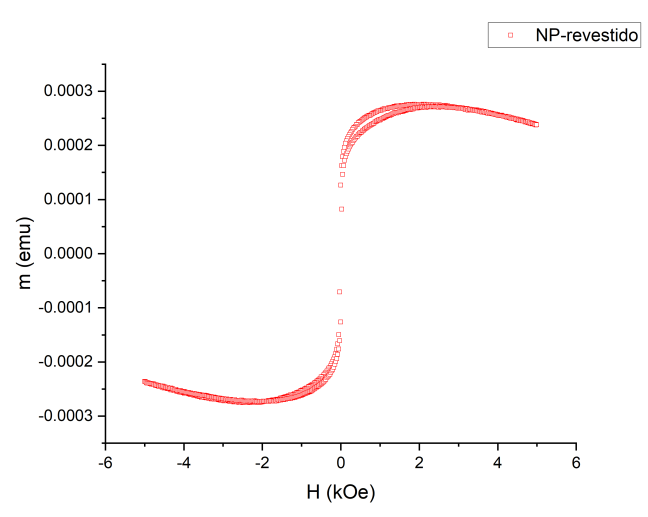

(b)

Figura 5.19: Curvas de histerese para NPs de Co co-depositadas com $\mathrm{Si}_{3} \mathrm{~N}_{4}$. Vemos as curvas para as amostras (a) NP-intercalado e (b) NP-revestido. 
As curvas de histerese com comportamento superparamagnético nos permitem estudar os diâmetros das NPs produzidas. A magnetização de um sistema de NPs em regime superparamagnético pode ser descrita pela combinação da função Langevin e dos parâmetros da PDF da distribuição de tamanhos [52]. Pudemos, dessa forma, ajustar os parâmetros: número de aglomerados magneticamente ativos $N$, diâmetro médio $D_{m}$, desvio-padrão $\sigma$, momento magnético total da amostra $m_{T}$ e um parâmetro $x=\mu_{0} M_{S} \pi D^{3} H /\left(6 k_{B} T\right)$. Para isso, utiliza-se a equação

$$
m_{T}(H, T)=N \int_{0}^{\infty} \frac{x k_{B} T}{\mu_{0} H}\left[\operatorname{coth}(x)-\frac{1}{x}\right] \operatorname{PDF}(D) d D,
$$

na qual $\operatorname{PDF}(D)$ se refere à Equação 5.1. $O$ ajuste dos parâmetros de interesse foi realizado utilizando uma metodologia de algorítimo genético [53]. Esse método permite o ajuste de múltiplos parâmetros simultaneamente, levando a função erro a um mínimo global com relativa velocidade. $O$ ajuste também leva em consideração o diamagnetismo do substrato através do acréscimo de uma equação de reta na Equação 5.4.

Em ambas amostras, foi realizada um média os momentos magnéticos de campos correspondentes. É levado em consideração uma superposição de de superparamagnetismo e ferromagnetismo. Deste modo, as médias aplicadas em cada curva nos fornecem curvas sem a presença de histereses. Dada a superposição, isso representa apenas o comportamento superparamagnético das amostras, facilitando a aplicação do modelo. Além disso, as medidas foram passadas para o S.I. para aplicação do modelo. Na Figura 5.20a, podemos ver os pontos obtidos para NP-intercalado em azul e a curva de magnetização ajustada em preto. A média é apresentada em laranja. Desse ajuste, obtemos uma distribuição de diâmetros com média $D_{m}=3,1(1) \mathrm{nm}$ e desvio-padrão $\sigma=1,2(1) \mathrm{nm}$, com $N=7,3 \times 10^{12}$ partículas.

A amostra NP-revestido também pode ser ajustada, chegando no resultados apresentado na Figura $5.20 \mathrm{~b}$, onde temos os pontos em vermelho e a curva ajustada em preto. A média é apresentada em ciano. Nessa amostra, obtivemos uma distribuição de diâmetros com valor médio $D_{m}=3,8(2) \mathrm{nm}$ e desvio-padrão $\sigma=2,2(2) \mathrm{nm}$, com $N=5,9 \times 10^{12}$ partículas. O modelo utilizado não é capaz de diferenciar NPs de aglomerados de NPs. Portanto, um aglomerado de NPs é interpretado como uma NP de maior tamanho. Dessa forma, como as distribuições de tamanhos se aproximam mais a distribuição de tamanhos de NPs segmentadas obtidas na Subsessão 5.2.2, ambos resultados indicam que a presença de $\mathrm{Si}_{3} \mathrm{~N}_{4}$ permite uma separação entre as NPs maior do que sem a presença do filme dielétrico.

Na Figura 5.21, podemos ver a comparação entre as PDFs dos diâmetros, obtidas através das imagens de MET e do ajuste das curvas de magnetização. As curvas estão normalizadas para possuir área com valor 1. A curva vermelha (NP-revestido) 
apresenta uma distribuição mais próxima da curva preta (MET), possuindo partículas maiores do que a curva azul (NP-intercalado). Esse resultado é de acordo com o esperado, visto que o processo de produção da amostra NP-intercalado visava um maior isolamento das NPs, com uma menor quantidade de possíveis aglomerados, do que as obtidas na produção de NP-revestido ou nas amostras para MET.

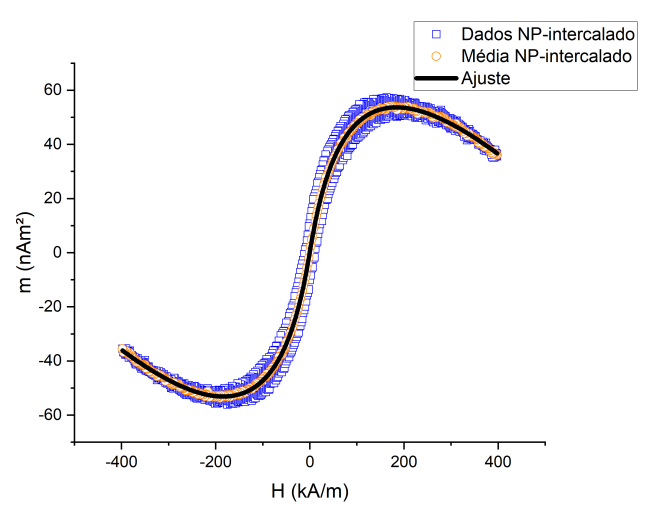

(a)

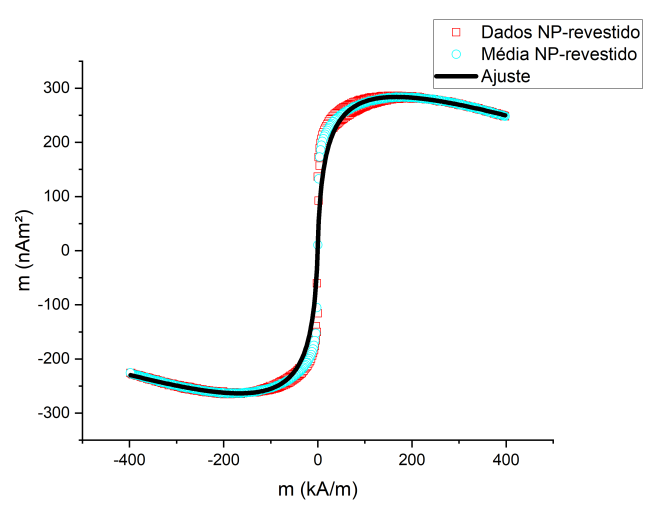

(b)

Figura 5.20: Curvas de magnetização ajustadas para NPs de Co co-depositadas com $\mathrm{Si}_{3} \mathrm{~N}_{4}$. Vemos os resultados para as amostras (a) NP-intercalado e (b) NP-revestido.

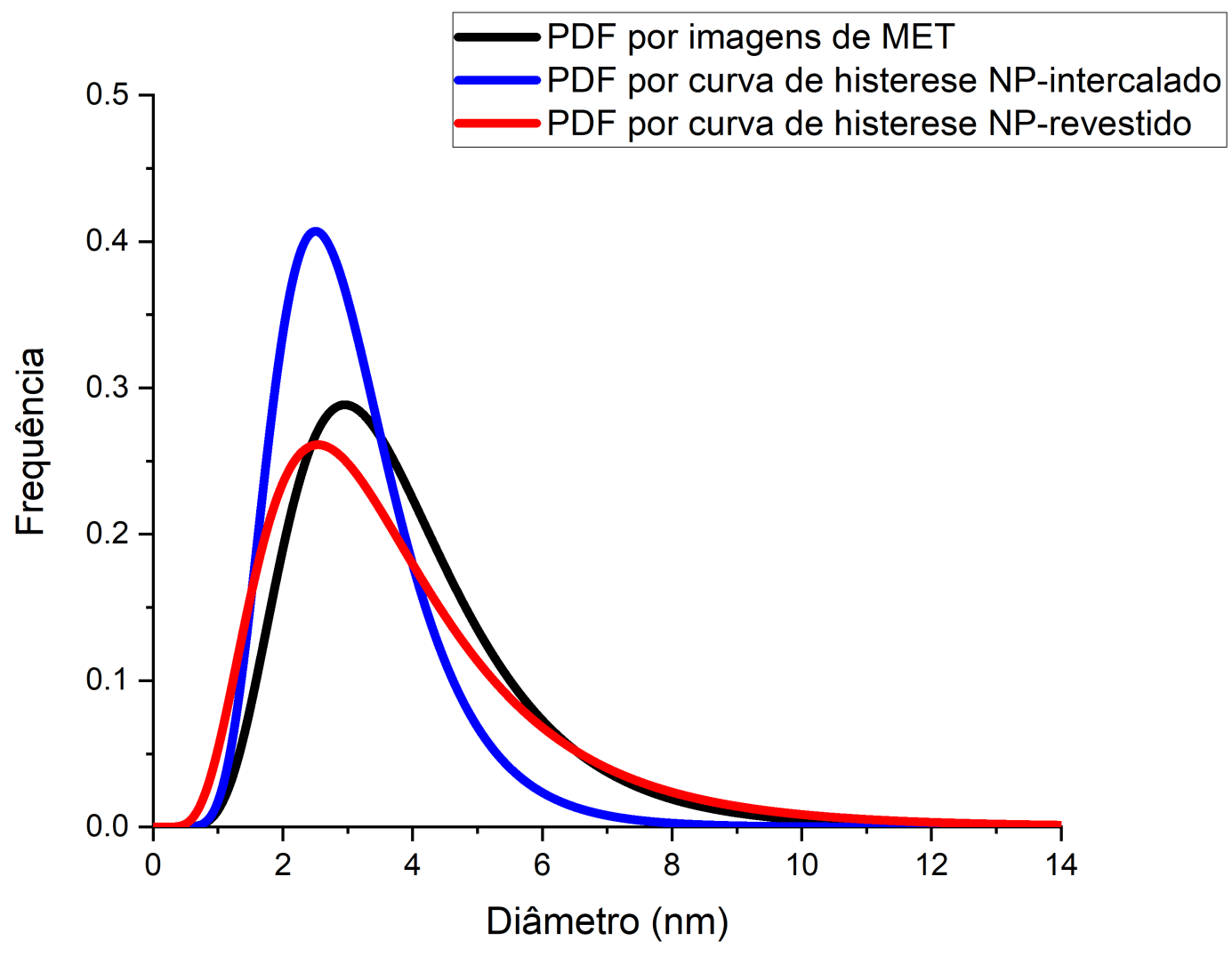

Figura 5.21: Comparação entre as PDFs de diâmetros para amostras analisadas por MET e por curva de histerese. 


\subsubsection{Processo de envelhecimento (aging) das nanopartículas de cobalto}

Um dos aspectos desejados na produção de NPs magnéticas em vácuo é evitar a formação de óxidos, que possuem comportamento magnético menos intenso ou são paramagnéticos. Contudo, a oxidação das amostras pode ocorrer logo após a remoção das amostras da câmara de vácuo. Dessa forma, houve o interesse de identificar a presença ou não-presença desse processo de envelhecimento nas NPs de cobalto codepositadas com $\mathrm{Si}_{3} \mathrm{~N}_{4}$. Era esperado que o $\mathrm{Si}_{3} \mathrm{~N}_{4}$ protegesse as NP de Co, evitando a oxidação. Isso era esperado, em especial, na amostra NP-intercalado, que possui uma maior deposição de $\mathrm{Si}_{3} \mathrm{~N}_{4}$ e possui o material dielétrico permeando os espaços entre NPs, em princípio.

Para a análise do processo de degradação das NPs de Co, foram realizadas novas medidas no VSM para as mesmas amostras, com o intuito de identificar a intensidade do sinal de magnetização e realizar ajustes para a PDF de diâmetros. Repetimos a metodologia aplicada originalmente nas amostras NP-intercalado e NPrevestido após 1 semana da produção de cada uma. Na Figura 5.22 vemos os resultados obtidos e os ajustes realizados. A amostra NP-intercalado apresentou uma queda de $46 \%$ na intensidade máxima do sinal e a amostra NP-revestido apresentou uma queda de $41 \%$, indicando um envelhecimento semelhante em ambas amostras após 1 semana. O ajuste resulta em $N=2,5 \times 10^{12} \mathrm{NPs}$ para a amostra NP-intercalado, resultando numa queda de $66 \%$ no número de NPs magnéticas. Simultaneamente, obtemos $N=2,0 \times 10^{12}$ NPs para a amostra NP-revestido, resultando, mais uma vez, numa queda de $66 \%$ no número de NPs magnéticas. Essa consistência nos resultados dos ajustes indica que não há mudança nos índices de oxidação de NPs de Co entre os diferentes modos de co-deposição de NPs de Co com $\mathrm{Si}_{3} \mathrm{~N}_{4}$.

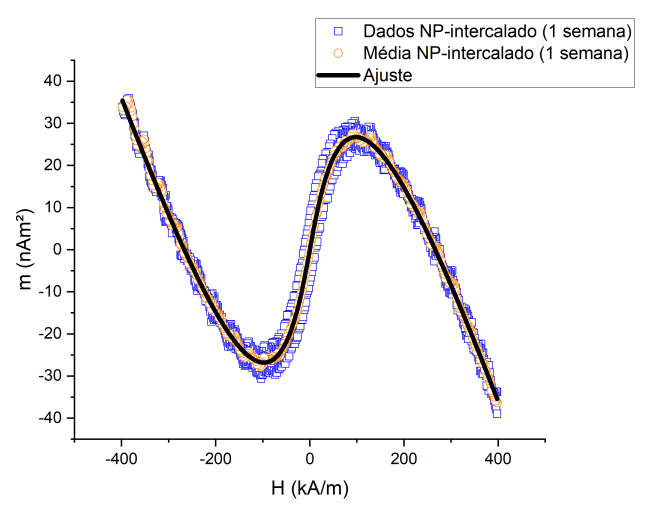

(a)

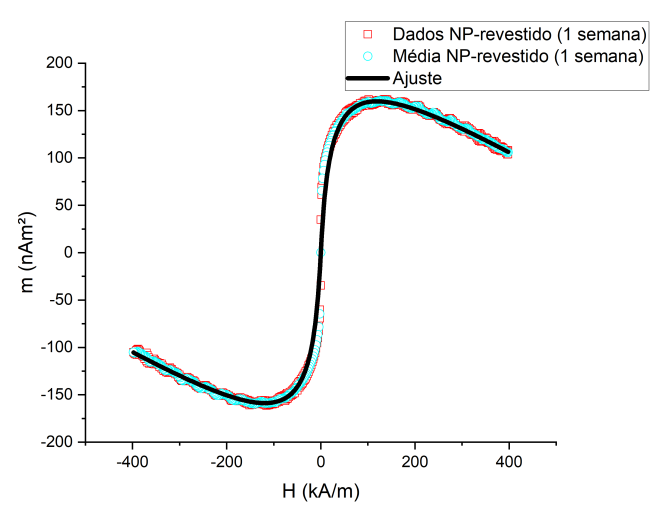

(b)

Figura 5.22: Curvas de magnetização ajustadas para NPs de Co co-depositadas com $\mathrm{Si}_{3} \mathrm{~N}_{4}$, após 1 semana da produção. Vemos os resultados para as amostras (a) NP-intercalado e (b) NP-revestido. 
É importante notar a diferença da inclinação devido ao comportamento diamagnéticos do Kapton, ao compararmos antes e depois. Isso se deve a pequenas diferenças no posicionamento da amostra durante as medições. Essas diferenças ocorrem devido à dificuldade de ajuste do posicionamento para amostras com sinais de baixa intensidade.

Na Figura 5.23 vemos a comparação entre as PDFs das amostras logo após a produção, discutidas anteriormente, e após 1 semana. Já na Tabela 5.2, comparamos os parâmetros obtidos pela análise de imagens de MET e ajuste das curvas de magnetização. As curvas foram normalizadas em relação à quantidade de NP de cada amostra logo após a produção. Logo, as distribuições após 1 semana possuem $66 \%$ da área das distribuições logo após a produção, com área 0,66. A PDF ciano representa a amostra NP-intercalado após 1 semana, possuindo diâmetro médio $D_{m}=4,2(1) \mathrm{nm}$ e desvio-padrão $\sigma=1,04(9) \mathrm{nm}$. A PDF magenta representa a amostra NP-revestido após 1 semana, possuindo diâmetro médio $D_{m}=5,3(2)$ nm e desvio-padrão $\sigma=2,2(2)$ $\mathrm{nm}$. Analisando esses valores e as curvas no gráfico, é perceptível a diminuição da quantidade de NPs com tamanhos reduzidos após 1 semana.

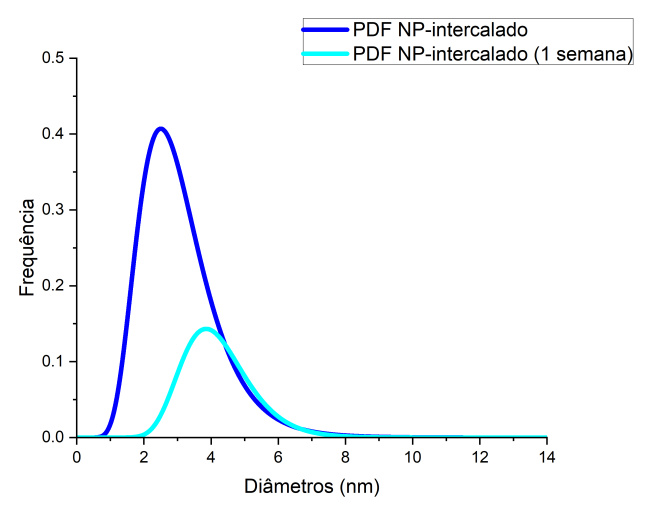

(a)

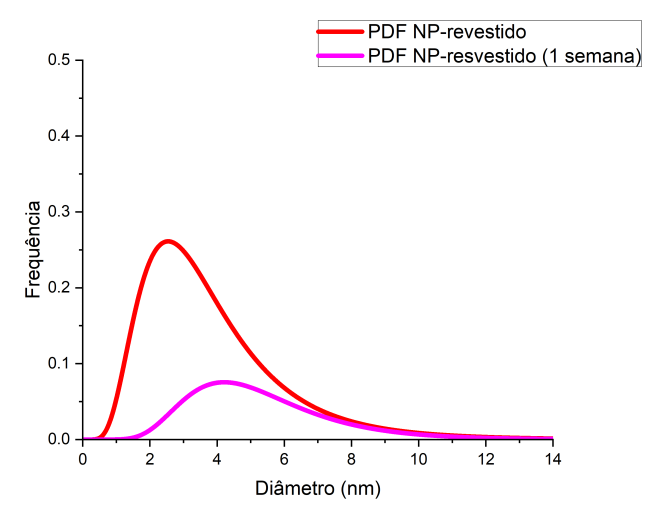

(b)

Figura 5.23: Comparação entre as PDFs de diâmetros no dia da produção e após 1 semana para as amostras (a) NP-intercalado e (b) NP-revestido.

\begin{tabular}{|c|c|c|}
\hline Amostra & Diâmetro médio $(\mathrm{nm})$ & Desvio-padrão $(\mathrm{nm})$ \\
\hline NPs de Co por MET & $3,88(3)$ & $1,74(2)$ \\
NP-intercalado & $3,1(1)$ & $1,2(5)$ \\
NP-intercalado (1 semana) & $4,2(1)$ & $1,04(9)$ \\
NP-revestido & $3,8(3)$ & $2,2(2)$ \\
NP-revestido (1 semana) & $5,3(2)$ & $2,2(2)$ \\
\hline
\end{tabular}

Tabela 5.2: Tamanhos de partículas obtidos por análise de imagens obtidas por MET. 
É natural imaginar que a oxidação das NPs tenha um maior reflexo, do ponto de vista magnético, nas NPs de menor tamanho. A oxidação de uma NP leva à mudança do comportamento magnético da amostra. Também sabemos que a relação entre área superficial e volume de uma esfera é inversamente proporcional ao diâmetro da mesma. Isso nos diz que, levando em consideração a oxidação na superfície das NPs, um tamanho reduzido leva a uma oxidação proporcionalmente maior. Portanto, os resultados no levam a crer na oxidação de NPs menores, apresentando comportamento paramagnético. Os resultados também vão de encontro com um efeito de proteção esperado do filmes de $\mathrm{Si}_{3} \mathrm{~N}_{4}$. Acreditamos que as baixas taxas de deposição do $\mathrm{Si}_{3} \mathrm{~N}_{4}$ não geraram filmes com espessura necessária para proteção. Sendo assim, é necessário o uso de outro material para essa função. Uma das possibilidades é o uso do tântalo (Ta), metal inerte em temperatura ambiente e que possui um sputter yield próximo ao do cobalto, permitido maiores taxas de deposição do que o $\mathrm{Si}_{3} \mathrm{~N}_{4}$. Outra possibilidade é o uso da prata, planejado com a conclusão do canhão de revestimento. 


\section{Capítulo 6}

\section{Conclusões}

Este trabalho teve como foco o aperfeiçoamento do gerador de nanopartículas que utiliza as técnicas de magnetron sputtering e agregação gasosa. Para isso, foi desenvolvido um canhão de magnetron sputtering com alvo cilíndrico. A maior vantagem apresentada é a capacidade de produzir NPs de diferentes metais, incluindo metais ferromagnéticos. $O$ dispositivo foi concebido como um acréscimo a um sistema de magnetron sputtering comercial, sendo possível a co-deposição das NPs com outros materiais. O canhão de sputtering utilizado foi desenvolvido utilizando o princípio do hollow cathode, que possui geometria cilíndrica. Isso o diferencia do canhão padrão de sputtering, que utiliza alvos planos. O dispositivo foi chamado de canhão de magnetron sputtering radial.

Para que o canhão de magnetron sputtering radial fosse construído, foi necessário o estudo dos aspectos elétricos, magnéticos e aerodinâmicos do dispositivo desejado. O estudo e construção do dispositivo consistiu na maior parte do trabalho apresentado. Diversos problemas técnicos surgiram ao longo do desenvolvimento do projeto e exigiram soluções originais. Por exemplo, o tubo de injeção de gás, que necessita de uma aba em sua saída para auxiliar no confinamento do campo elétrico utilizado. Além disso, foi necessário revestir o tubo de injeção de gás e o suporte de posicionamento do alvo com nitreto de boro, material isolante elétrico que aguenta altas temperaturas. Por fim, houve a necessidade de placas polares para intensificar o campo magnético na superfície interna de alvos de materiais magnéticos. A presença de placas polares permitiu a produção de NPs de cobalto pelo canhão radial. Do ponto de vista aerodinâmico, foi constatado que o fluxo gasoso no canhão radial favorece a extração das NPs da câmara de agregação.

Produzindo manchas de NPs sobre papel sufite, foi possível obter os parâmetros ideais de trabalho com uma potência de $40 \mathrm{~W}$ e $80 \mathrm{sccm}$. Foram produzidas NPs de cobre e de cobalto. Ao assumirmos que as NPs são esféricas, pudemos medir os tamanhos das NPs através do tratamento das imagens obtidas por MET. Curvas do tipo log-normal foram ajustadas às respectivas distribuições de tamanho. 
Aglomerados de NPs de Cu apresentaram diâmetro médio $D_{m}^{A}=9,1(2)$ com um desvio padrão $\sigma^{A}=7,6(1) \mathrm{nm}$, enquanto NPs segmentadas apresentaram diâmetro médio $D_{m}=5,79(8) \mathrm{nm}$ com um desvio padrão $\sigma=2,97(5) \mathrm{nm}$. Com a análise da imagens obtidas por MET também foi possível perceber a presença de planos cristalinos nas NPs de cobre. Utilizando a FFT, foi possível medir as distâncias interplanares. Obteve-se um valor $d=2,5(1) \AA$, compatível com valor esperado para os planos (110) da estrutura FCC do cobre.

Por outro lado, aglomerados de NPs de cobalto apresentaram diâmetro médio $D_{m}^{A}=5,17(7)$ com um desvio padrão $\sigma^{A}=3,64(5) \mathrm{nm}$, enquanto NPs de Co segmentadas apresentaram diâmetro médio $D_{m}=3,88(3) \mathrm{nm}$ com um desvio padrão $\sigma=1,74(2)$ $\mathrm{nm}$. Como o cobre tem um alto sputter yield, era esperado que as NPs de cobalto fossem tipicamente menores que as de cobre. Também percebeu-se, mais uma vez, a presença de planos cristalinos. Obteve-se uma distância interplanar $d=2,1(1) \AA$, compatível com o valor esperado para o cobalto nos planos (111) da estrutura FCC ou nos planos (001) da estrutura HCP. Além disso, foi possível identificar um parâmetro de rede de 2,6(1) $\AA$, compatível com o parâmetro de rede da estrutura HCP do Co. Dessa forma, é possível afirmar que o GNPR é capaz de produzir NPs metálicas com estruturas cristalinas e com diferentes tamanhos, representados por uma PDF log-normal.

Ainda para o cobalto, foram realizadas medidas no VSM. Produziu-se uma amostra sobre folha de Kapton para minimizar a sua contribuição nas medidas magnéticas. Numa amostra produzida num intervalo de 5 minutos e 30 segundos, foi verificada a presença de histerese da ordem de $100 \mathrm{Oe}$, apresentando comportamento ferromagnético. Era esperado comportamento superparamagnético das NPs de cobalto, devido a seu tamanho. A presença de histerese se explica pela aglomeração das NPs, formando estruturas de maior dimensão.

Com o intuito de isolar as NPs cobalto e estudar seu comportamento superparamagnético, foram realizadas co-deposições de NPs de Co com $\mathrm{Si}_{3} \mathrm{~N}_{4}$. Isso também visou proteger as amostras do aging causado pela oxidação das NPs. Estudamos uma amostra intercalando NPs e $\mathrm{Si}_{3} \mathrm{~N}_{4}$ (NP-intercalado) e uma amostra revestindo o conjunto de NPs (NP-revestido), ambas com 5 minutos de deposição de NPs. Ambas apresentaram comportamento superparamgnético em medidas no VSM, com a amostra NP-intercalado ainda apresentando histerese de $140 \mathrm{Oe.}$

Em ambas amostras foram ajustadas curvas de magnetização que nos fornecem PDFs dos diâmetros das NPs e quantidade de NPs. Dessa forma, obtivemos um diâmetro médio $D_{m}=3,1(1) \mathrm{nm}$ com um desvio padrão $\sigma=1,2(1) \mathrm{nm}$ para a amostra NP-intercalado, enquanto a amostra NP-revestido apresentou diâmetro médio $D_{m}=3,8(2) \mathrm{nm}$ com um desvio padrão $\sigma=2,2(2) \mathrm{nm}$. A amostra NP-revestido mostrou uma PDF mais próxima da distribuição da amostra produzida por MET. 
Por fim, foram realizadas novas medidas no VSM após 1 semana para analisar a efetividade dos filmes de $\mathrm{Si}_{3} \mathrm{~N}_{4}$ em proteger as NPs de Co do processo de oxidação. A amostra NP-intercalado apresentou uma queda de $46 \%$ de intensidade de sinal, com uma queda de $66 \%$ no número de NPs, apresentando diâmetro médio $D_{m}=4,2(1)$ $\mathrm{nm}$ com um desvio padrão $\sigma=1,04(9) \mathrm{nm}$. A amostra NP-revestido apresentou uma queda de $41 \%$ de intensidade de sinal, com uma queda de também $66 \%$ no número de NPs, apresentando diâmetro médio $D_{m}=5,3(2) \mathrm{nm}$ com um desvio padrão $\sigma=2,2(2)$ $\mathrm{nm}$. Esses valores e os gráficos das respectivas PDFs indicam que existe uma degradação majoritária das NPs de tamanho reduzido e que o filme de $\mathrm{Si}_{3} \mathrm{~N}_{4}$ não foi capaz de proteger adequadamente as NPs de Co da oxidação. Isso aponta, como previsto, a necessidade do estudo do revestimento das NPs utilizando a estrutura core@shell ou o uso de filmes metálicos.

Atualmente, o gerador de nanopartículas radial é considerado estável e reprodutível. É possível produzir nanopartículas puramente metálicas com facilidade e rapidez. O sistema de sputtering manteve todas as suas funcionalidades, podendo haver co-deposição de NPs metálicas com filmes dielétricos ou metálicos.

\section{Perspectivas futuras}

O GNPR abre possibilidades diversas. Desejamos estudar as condições de revestimento das NPs, utilizando a co-deposição com filmes metálicos. Atualmente o tântalo é o principal candidato de material para o filme de revestimento, por ser não reativo em temperatura ambiente e, em princípio, não afetar o comportamento magnético das NPs. Outro material de interesse é a prata, não só como filme, mas na formação de NPs com estrutura núcleo@casca (core@shell) com a conclusão do desenvolvimento do canhão de revestimento. Visamos formar NPs de Co@Ag, formando NPs que classificamos com magnetoplasmônicas. A prata (Ag) tem um comportamento eletrônico do tipo Drude, em toda a faixa do visível e por isso se apresenta como o melhor material plasmônico disponível para a luz visível, se dando, assim, o motivo de nossa escoIha. Acreditamos que a produção de NPs em simultâneo com filmes de outros metais propiciarão um amplo leque de condições de estudo fundamentais magnéticos, óticos (ressonâncias plasmônicas), estruturais e morfológicos, além de permitir novos estudos sobre a metodologia de crescimento das nanopartículas do tipo núcleo@casca. 


\section{Bibliografia}

[1] A. M. Ealia and M. P. Saravanakumar. A review on the classification, characterisation, synthesis of nanoparticles and their application. IOP Conference Series: Materials Science and Engineering, 263:032019, nov 2017.

[2] S. Bhatia. Nanoparticles Types, Classification, Characterization, Fabrication Methods and Drug Delivery Applications, pages 33-93. Springer International Publishing, Cham, 2016.

[3] A. S. Edelstein and R. C. Cammarata, editors. Nanomaterials: Synthesis, Properties and Applications. Taylor \& Francis Group, 1996.

[4] D. Depla and S. Mahieu, editors. Reactive Sputter Deposition. Springer Berlin Heidelberg, 2008.

[5] G.T. Landi. Dissertação de Mestrado, CNPq, Desenvolvimento de um gerador de nanopartículas e caracterização de nanopartículas de cobalto. IFUSP, 2009.

[6] A.-H. Lu et al. Nanoengineering of a magnetically separable hydrogenation catalyst. Angewandte Chemie International Edition, 43(33):4303-4306, 2004.

[7] A. K. Gupta and M. Gupta. Synthesis and surface engineering of iron oxide nanoparticles for biomedical applications. Biomaterials, 26(18):3995 - 4021, 2005.

[8] I. Kavre et al. Fabrication of magneto-responsive microgears based on magnetic nanoparticle embedded pdms. RSC Adv., 4:38316-38322, 2014.

[9] S. Mornet et al. Magnetic nanoparticle design for medical applications. Progress in Solid State Chemistry, 34(2):237 - 247, 2006.

[10] C. Altavilla and E. Ciliberto. Inorganic Nanoparticles. CRC Press, April 2016.

[11] J. Philip, P. D. Shima, and B. Raj. Nanofluid with tunable thermal properties. Applied Physics Letters, 92(4):043108, January 2008.

[12] J. Philip et al. A tunable optical filter. Measurement Science and Technology, 14(8):1289-1294, jul 2003. 
[13] J. Curiale et al. Magnetic dead layer in ferromagnetic manganite nanoparticles. Applied Physics Letters, 95(4):043106, July 2009.

[14] T. Sato et al. Magnetic properties of ultrafine ferrite particles. Journal of Magnetism and Magnetic Materials, 65(2-3):252-256, March 1987.

[15] X. Batlle and A. Labarta. Finite-size effects in fine particles: magnetic and transport properties. Journal of Physics D: Applied Physics, 35(6):R15-R42, March 2002.

[16] D. Fiorani, editor. Surface Effects in Magnetic Nanoparticles. Springer US, 2005.

[17] A. P. Guimarães. Principles of Nanomagnetism - Second Edition. Springer, 2017.

[18] Hari Singh Nalwa, editor. Handbook of Nanostructured Materials and Nanotechnology. Academic Press, 2000.

[19] S. Kulkarni. Synthesis of Nanomaterials—I (Physical Methods), pages 55-76. 01 2015.

[20] C. Minelli. Doctoral Thesis, Bottom-up approaches for organizing nanoparticles with polymers. Lausanne, EPFL, 2005.

[21] A. L. Glover et al. Magnetic heating of iron oxide nanoparticles and magnetic micelles for cancer therapy. IEEE Transactions on Magnetics, 49(1):231-235, January 2013.

[22] N. Yukawa et al. Structure of chromium-rich cr-ni, cr-fe, cr-co, and cr-ni-fe alloy particles made by evaporation in argon. Metallurgical and Materials Transactions B, 3(4):887-895, April 1972.

[23] A. H. Pfund. Bismuth black and its applications. Review of Scientific Instruments, 1(7):397-399, 1930.

[24] Y. Xu et al. Preparation and magnetic properties of CoPt and CoPt:Ag nanocluster films. Journal of Magnetism and Magnetic Materials, 266(1-2):164-170, October 2003.

[25] S. Tanemura et al. Fabrication and structural characterization of TiO nanoparticle soft-landed on substrate by the magnetron sputtering-gas aggregation method. The European Physical Journal D, 34(1-3):79-82, July 2005.

[26] J.-M. Qiu and J.-P. Wang. Monodispersed and highly ordered 110 FePt nanoparticles prepared in the gas phase. Applied Physics Letters, 88(19):192505, May 2006. 
[27] S. Nonose et al. Structure and reactivity of bimetallic cobalt-vanadium (ConVm) clusters. The Journal of Physical Chemistry, 94(7):2744-2746, April 1990.

[28] A.I. Korchagin et al. Production of silver nano-powders by electron beam evaporation. Vacuum, 77(4):485-491, March 2005.

[29] R.-P. Methling et al. Magnetic studies on mass-selected iron particles. The European Physical Journal D, 16(1):173-176, October 2001.

[30] S. H. Baker et al. The construction of a gas aggregation source for the preparation of size-selected nanoscale transition metal clusters. Review of Scientific Instruments, 71(8):3178-3183, August 2000.

[31] D. L. Smith. Thin-Film Deposition: Principles and Practice. McGraw-Hill, 1995.

[32] C. G. Granqvist and R. A. Buhrman. Ultrafine metal particles. Journal of Applied Physics, 47(5):2200-2219, May 1976.

[33] B. Briehl and H. M. Urbassek. Monte carlo simulation of growth and decay processes in a cluster aggregation source. Journal of Vacuum Science \& Technology A: Vacuum, Surfaces, and Films, 17(1):256-265, January 1999.

[34] V.F.G. Lima. Dissertação de Mestrado, CAPES, Preparação e caracterização de nanopartículas magnéticas de Sm-Co, Nd-Fe-B, Fe-Pt e Co-Pt pelo método de agregação gasosa. IFUSP, 2013.

[35] J. Sarkar. Sputtering Materials for VLSI and Thin Film Devices. Elsevier, 2014.

[36] J. Bansmann et al. Magnetic and structural properties of isolated and assembled clusters. Surface Science Reports, 56(6):189-275, 2005.

[37] Milton Ohring, editor. Materials Science of Thin Films. Elsevier, second edition edition, 2002.

[38] V.F.G. Lima. Tese de Doutorado, CAPES, Desenvolvimento da metodologia física de produção de nanopartículas do tipo núcleo@casca. IFUSP, 2019.

[39] G. T. Landi and A. D. Santos. High-density gas aggregation nanoparticle gun applied to the production of smco clusters. Journal of Materials Science, 45(18):4906-4911, 2010.

[40] D.A.S.G. Santos. Dissertação de Mestrado, CNPq, CAPES, Preparação e caracterização de nanopartículas de metais nobres pelo método de agregação gasosa. IFUSP, 2018.

[41] F. Paschen. Bohrs heliumlinien. Annalen der Physik, 355(16):901-940, 1916. 
[42] H. Eichhorn, K. H. Schoenbach, and T. Tessnow. Paschen's law for a hollow cathode discharge. Applied Physics Letters, 63(18):2481-2483, 1993.

[43] R. B. Bartlow, S. T. Griffin, and J. C. Williams. Axial evolution of the negative glow in a hollow cathode discharge. Analytical Chemistry, 64(22):2751-2757, Nov 1992.

[44] R. Mavrodineanu. Hollow cathode discharges: analytical applications. Journal of research of the National Bureau of Standards, 89:143-185, 1984.

[45] A. D. T. d. Sá. Dissertação de Mestrado, CNPq, CAPES, Desenvolvimento de uma fonte de nano-agregados metálicos. IFGW - Unicamp, 2009.

[46] "FEEM - Finite Element Method Magnetics." Versão 4.2, David Meeker, URL: https://www.femm.info/wiki/HomePage. Acessado 22/01/2021.

[47] "Elmer." 2008-2020, CSC - IT Center for Science, URL: https://www.csc.fi/fi/web/elmer. Acessado 22/01/2021.

[48] C. Geuzaine and J.-F. Remacle. Gmsh: A 3-D finite element mesh generator with built-in pre and post-processing facilities. International Journal for Numerical Methods in Engineering, 79(11):1309-1331, 2009.

[49] "Fiji Is Just ImageJ." Versão 1.53c, Laboratory for Optical and Computational Instrumentation, URL: https://imagej.net/Fiji. Acessado 22/01/2021.

[50] P. Soille and L. M. Vincent. Determining watersheds in digital pictures via flooding simulations. In Murat Kunt, editor, Visual Communications and Image Processing '90: Fifth in a Series. SPIE, September 1990.

[51] A. Anders, J. Andersson, and A. Ehiasarian. High power impulse magnetron sputtering: Current-voltage-time characteristics indicate the onset of sustained selfsputtering. Journal of Applied Physics, 102:113303, 122007.

[52] A. Tamion et al. Accurate determination of the magnetic anisotropy in clusterassembled nanostructures. Applied Physics Letters, 95(6):062503, August 2009.

[53] M. Wormington et al. Characterization of structures from x-ray scattering data using genetic algorithms. Philosophical Transactions of the Royal Society of London. Series A: Mathematical, Physical and Engineering Sciences, 357(1761):2827-2848, October 1999. 